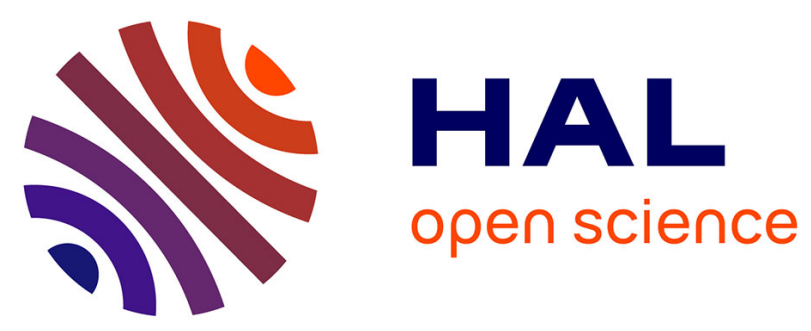

\title{
Chronostratigraphy of a 270-ka sediment record from Lake Selina, Tasmania: Combining radiometric, geomagnetic and climatic dating
}

Agathe Lisé-Pronovost, Michael-Shawn Fletcher, Quentin Simon, Zenobia Jacobs, Patricia Gadd, David Heslop, Andy I.R. Herries, Yusuke Yokoyama, Team Aster

\section{To cite this version:}

Agathe Lisé-Pronovost, Michael-Shawn Fletcher, Quentin Simon, Zenobia Jacobs, Patricia Gadd, et al.. Chronostratigraphy of a 270-ka sediment record from Lake Selina, Tasmania: Combining radiometric, geomagnetic and climatic dating. Quaternary Geochronology, 2021, pp.101152. 10.1016/j.quageo.2021.101152 . hal-03126888

\section{HAL Id: hal-03126888 https://hal.science/hal-03126888}

Submitted on 2 Mar 2021

HAL is a multi-disciplinary open access archive for the deposit and dissemination of scientific research documents, whether they are published or not. The documents may come from teaching and research institutions in France or abroad, or from public or private research centers.
L'archive ouverte pluridisciplinaire HAL, est destinée au dépôt et à la diffusion de documents scientifiques de niveau recherche, publiés ou non, émanant des établissements d'enseignement et de recherche français ou étrangers, des laboratoires publics ou privés.

\section{(ㅇ)(1) $\$$}

Distributed under a Creative Commons Attribution - NonCommercial - NoDerivatives $\mid 4.0$ 


\section{Journal Pre-proof}

Chronostratigraphy of a 270-ka sediment record from Lake Selina, Tasmania:

Combining radiometric, geomagnetic and climatic dating

Agathe Lisé-Pronovost, Michael-Shawn Fletcher, Quentin Simon, Zenobia Jacobs, Patricia S. Gadd, David Heslop, Andy I.R. Herries, Yusuke Yokoyama, Aster team

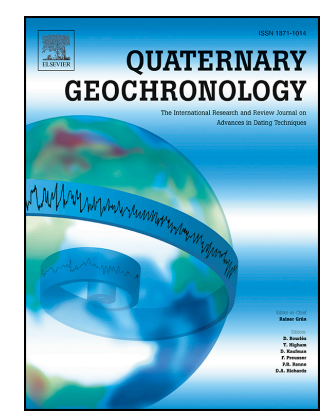

PII: S1871-1014(21)00003-0

DOI: https://doi.org/10.1016/j.quageo.2021.101152

Reference: QUAGEO 101152

To appear in: Quaternary Geochronology

Received Date: 19 February 2020

Revised Date: 11 January 2021

Accepted Date: 12 January 2021

Please cite this article as: Lisé-Pronovost, A., Fletcher, M.-S., Simon, Q., Jacobs, Z., Gadd, P.S., Heslop, D., Herries, A.I.R., Yokoyama, Y., team, A., Chronostratigraphy of a 270-ka sediment record from Lake Selina, Tasmania: Combining radiometric, geomagnetic and climatic dating, Quaternary Geochronology (2021), doi: https://doi.org/10.1016/j.quageo.2021.101152.

This is a PDF file of an article that has undergone enhancements after acceptance, such as the addition of a cover page and metadata, and formatting for readability, but it is not yet the definitive version of record. This version will undergo additional copyediting, typesetting and review before it is published in its final form, but we are providing this version to give early visibility of the article. Please note that, during the production process, errors may be discovered which could affect the content, and all legal disclaimers that apply to the journal pertain.

(c) 2021 Published by Elsevier B.V. 


\section{Chronostratigraphy of a 270-ka sediment record from Lake Selina,}

2 Tasmania: combining radiometric, geomagnetic and climatic dating

Agathe Lisé-Pronovost 1,2, Michael-Shawn Fletcher 3, Quentin Simon 4, Zenobia Jacobs 5, Patricia S

1 School of Earth Sciences, University of Melbourne, Carlton, 3053, VIC, Australia

2 The Australian Archaeomagnetism Laboratory, Palaeoscience Labs, Department of Archaeology and History, La Trobe University, Melbourne Campus, Bundoora, 3086, VIC, Australia

3 School of Geography, University of Melbourne, Carlton, 3053, VIC, Australia

4 CEREGE UM34, Aix Marseille Univ, CNRS, IRD, INRAE, Coll France, 13545 Aix en Provence, France

5 Australian Research Council Centre of Excellence for Australian Biodiversity and Heritage and School of Earth, Atmospheric and Life Sciences, University of Wollongong, Wollongong, NSW 2522, Australia

6 Australian Nuclear Science and Technology Organisation (ANSTO), New Illawarra Road, Lucas Heights 2234, Australia

7 Research School of Earth Sciences, Australian National University, Acton 2601, ACT, Australia

8 Department of Earth and Planetary Sciences, Graduate School of Science, University of Tokyo, Chiba 277-8564, Japan

*Georges Aumaître, Didier L. Bourlès, Karim Keddadouche.

Declarations of interests: none.

Keywords

paleomagnetism, optically stimulated luminescence, radiocarbon, authigenic 10Be/9Be ratio,

Pleistocene, lake sediment, Australia

Highlights

- Chronostratigraphy of a $266 \pm 8$ ka continuous lake sediment archive from Australia

- We combine radiometric $\left({ }^{14} \mathrm{C}, \mathrm{OSL}\right)$ and relative dating (geomagnetic and climatic)

- Bayesian modeling and dynamic programing integrate dating constraints

- $\quad$ First identification of the Laschamp geomagnetic excursion in Australia 
Abstract

Lake sediment archives covering several glacial cycles are scarce in the Southern Hemisphere and they are challenging to date. Here we present the chronostratigraphy of the oldest continuous lake sediment archive in Tasmania, Australia; a $5.5 \mathrm{~m}$ and $270 \mathrm{ka}$ (Marine Isotope Stage 8) sediment core from Lake Selina. We employ radiometric dating (radiocarbon and optically stimulated luminescence) and relative dating (geomagnetic and climate comparisons). Bayesian modeling of the radiometric ages reaches back to $80 \mathrm{ka}(1.7 \mathrm{~m})$ and relative dating using a dynamic programing algorithm allows dating of the full sequence. Elemental data, magnetic properties and beryllium isotopes from Lake Selina reveal a close fit to Antarctic ice core climate proxies. Weaker correlation during the Last Glacial Period (MIS 2-4) is attributed to additional local factors impacting Lake Selina proxies at a time of climate changes and human arrival into Tasmania. Over that period, full vector paleomagnetic records and authigenic ${ }^{10} \mathrm{Be} /{ }^{9} \mathrm{Be}$ ratios are combined to identify the Laschamp geomagnetic excursion for the first time in Australia and constrain the chronology. The multimethod approach provides two preferred age models, indiscernible within their uncertainties, which allows the use of a geomagnetic dipole-independent (full archive) or a climate-independent (111 ka to present) age model.

\section{Introduction}

Lake sediments preserve some of the best continuous records of rapid environmental changes, but those covering multiple glacial-interglacial cycles are notoriously difficult to date. At present, only one such long continental record is found on the island of Tasmania, south of mainland Australia (Darwin Crater, Howard and Haines, 2007; Lisé-Pronovost et al., 2019a). Long archives of environmental change from Tasmania have the potential to elucidate how terrestrial environments respond to large-scale and rapid climatic change in an under-documented region of the Southern Hemisphere. Further, developing a precise chronostratigraphy for lake sediments covering the Last Glacial Period in Australia offers the possibility of investigating the timeline and linkages of environmental changes across the local and broader region, shedding light on Earth system dynamics and contributing to debated issues such as megafauna extinction (Roberts et al., 2001; Wroe and Field, 2006; Rule et al., 2012; Van der Kaars et al., 2017; Saltré et al., 2019) and the impact and timing of human arrival on the Australian continent (Cosgrove, 1999; Clarkson et al., 2017; O'Connell et al., 2018). The lacustrine sediments from Lake Selina, a Tasmanian record argued to span the Last Glacial Cycle (Colhoun et al., 1999), provide an opportunity to explore these questions, but their tractability depends on the ability to obtain a reliable chronology.

Dating lacustrine sediments beyond the range of radiocarbon (>40-50 ka) is challenging. An ability to combine different dating methods is therefore key to obtaining a reliable chronology (e.g. Colman et al., 2006; Shanahan et al., 2013; Simon et al., 2020a). Commonly used numerical dating methods for lacustrine sediments include radiocarbon dating of organic material, optically-stimulated luminescence dating of quartz and feldspar, U-series dating of carbonates, varve counting, and ash dating. Other chronological methods include correlation of climate signals (wiggle-matching), tephrochronology, and paleomagnetic dating. An important consideration in the application of multiple methods for developing chronologies is to avoid circular reasoning; i.e., ensuring the use of dating methods that are independent of the variable you are attempting to reconstruct or infer from analysis of the lake sediments (Blaauw et al., 2012). For example, avoid climate comparison if you discuss past climate, and avoid magnetostratigraphy if you discuss the Earth's magnetic field. 
Paleomagnetic dating is useful at the multi-millennial timescale using paleosecular variations of the geomagnetic field and major instabilities such as polarity reversals and excursions (Channell et al., 2020). Regional (sub-millennial) paleomagnetic dating is currently infeasible in Australia because there is a critical lack of empirical data required to build paleomagnetic reference curves, a limitation that also biases geomagnetic field models (e.g. Panovska et al., 2015; Constable et al., 2016). The available Pleistocene sedimentary paleomagnetic data from Australia span the past $16 \mathrm{ka}$ and includes only two full vector lacustrine records from northeast Australia (Lake Eacham and Barrine, Constable, 1985; Constable and McElhinny, 1985), four directions-only lacustrine records from southeast Australia (Lake Bullenmerri, Lake Keilambete, Lake Gnotuk, 10 ka, Barton and McElhinny 1981; Lake Johnston, 9.5 ka, Ankers et al., 2001) and two directions-only lagoon records from southeast Australia (Big Jibbon Lagoon 5 ka, and Tocal Homestead Lagoon 2 ka, Gale et al., 2013).

Importantly, none of these previous Australian studies meet the modern standards of laboratory experiments and analytical methods (e.g. Korte et al., 2019), such as magnetic mineral characterisation to identify the magnetic remanence carriers and assess the reliability of the paleomagnetic record. Moreover, while it is now routine to perform stepwise demagnetisation to identify a stable and reliable characteristic remanent magnetisation (ChRM) and calculate the paleomagnetic directions from the best least-squares line fit by principal component analysis (Kirschvink, 1980), available Australian studies employ either single step alternating field (AF) 'blanket' demagnetisation or no demagnetisation at all. New state-of-the-art high-quality sedimentary paleomagnetic and archaeomagnetic data are necessary to confidently isolate the geomagnetic signal from environmental biases and start building Australian regional reference curves (sub-millennial behavior). In the meantime, global geomagnetic dipole moment variation can be used for millennial-timescale paleomagnetic dating by correlating individual records to relative paleointensity (RPI) stacks (e.g. GLOPIS, Laj et al., 2004) or models (e.g. GGF100k, Panovska et al., 2018).

An alternative means for reconstructing millennial-scale geomagnetic dipole moment variations is through reconstructing the concentration of cosmogenic radionuclide beryllium-10 $\left({ }^{10} \mathrm{Be}\right)$ deposited in natural archives (Lal and Peters, 1967). Atmospheric ${ }^{10} \mathrm{Be}$ is produced by spallation reactions when highly energetic galactic cosmic ray (GCR) particles interact with nitrogen and oxygen atoms. The incoming rate of these charged GCRs, which directly controls ${ }^{10} \mathrm{Be}$ production rate, depends on the strength of geo- and heliomagnetic fields, with a nonlinear inverse relationship: i.e. lower ${ }^{10} \mathrm{Be}$ production rate at high fields (Beer et al., 2012). In a similar manner to RPI representing paleomagnetic field intensity by removing depositional and environmental influences (King et al., 1983; Roberts et al., 2013), normalised ${ }^{10} \mathrm{Be}$ concentrations from sediment and ice records trace production variations that are mainly modulated by geomagnetic field strength at the millennial timescale (e.g. Frank et al., 1997; Muscheler et al., 2005; Horiuchi et al., 2016; Simon et al., 2016a, 2018). Normalised ${ }^{10} \mathrm{Be}$ can therefore be employed along with RPI proxies to evaluate their respective limitations (Suganuma et al., 2010, 2011; Valet et al., 2014, 2019; Simon et al., 2019, $2020 \mathrm{~b}$ ) and help recovering reliable records of paleomagnetic dipole moment variations from lacustrine sedimentary sequences (Nilsson et al., 2011; Du et al., 2018; Tang et al., 2019).

In this study, we present the chronostratigraphy of Lake Selina in Tasmania, Australia, combining radiocarbon, optically stimulated luminescence (OSL) dating, full-vector sedimentary paleomagnetism, authigenic ${ }^{10} \mathrm{Be} /{ }^{9} \mathrm{Be}$ ratio, and climate comparison. 


\section{Regional setting}

Lake Selina $\left(41^{\circ} 52^{\prime} 41^{\prime \prime} \mathrm{S}, 145^{\circ} 36^{\prime} 34^{\prime \prime} \mathrm{E}\right)$ is a shallow basin located in the West Coast Range of Tasmania, southeast Australia, 516 meters above sea level ( $\mathrm{m}$ asl) and $40 \mathrm{~km}$ east of the Southern Ocean (Fig. 1). The modern lake has a surface area of $190 \mathrm{~m}^{2}$ and maximum water depth of approximately $5 \mathrm{~m}$. It has no permanent inflow or outflow; but an ephemeral creek connects Lake Selina to the larger and higher altitude Lake Westwood $\left(380 \mathrm{~m}^{2}, 605 \mathrm{~m}\right.$ asl) $\sim 1 \mathrm{~km}$ to the west. The local geology is dominated by the Ordovician Owen Conglomerate and Cambrian Mount Read Volcanics. The Owen Conglomerate is a coarse siliciclastic molasse with hematite-stained quartz and rounded to sub-rounded quartzite pebbles and cobbles in an argillite matrix (Bradley, 1954). While Mount Selina ( $1 \mathrm{~km}$ to the east) was prospected for lead and zinc mining, the local mining activities are associated with the Mount Read Volcanics and include the Rosebery mine for galena at $\sim 12 \mathrm{~km}$ distance and the Henty gold mine $\sim 5 \mathrm{~km}$ distance from Lake Selina (Fig. 1C).

The climate in western Tasmania is temperate maritime with average temperature ranging from 6 to $16^{\circ} \mathrm{C}$ and average annual rainfall of $2400 \mathrm{~mm}$ (Queenstown; Australian Bureau of Meteorology). Pleistocene glacial activity has been documented in Tasmania for the Last Glacial Period (MIS 2-3; Colhoun 1985; Mackintosh et al., 2006) and before, however, with poor age constraints (possibly MIS 4, 6, 8, and/or 10, 12; Barrows et al., 2002; Augustinus et al., 2017). The West Coast Range has many cirques and moraines, which provide evidence of paleo-glaciers at Mount Murchison $(1279 \mathrm{~m}$ asl) to the north of Lake Selina, Mount Tyndall (1179 m asl) to the south, and Eldon Range (1440 m asl) to the east. Previous coring of the uppermost $4 \mathrm{~m}$ sediments at Lake Selina revealed that the lake was not ice covered during the Last Glacial Period (Colhoun et al., 1999).

\section{Material and methods}

\subsection{Coring and sampling}

Coring of Lake Selina was completed in November 2014 from a floating platform rigged on two inflatable rafts. Two sites were cored from the approximate lake center (Fig. 1C). Three cores were recovered including a short gravity core LA $(84 \mathrm{~cm})$ and two Nesje (Nesje, 1992) cores N1 (sections A, B, C; $394 \mathrm{~cm}$ ) and N2 (sections A, B, C, D; $497 \mathrm{~cm}$ ) (Fig. 2A). The cores were transported to the University of Melbourne, stored in a cold room, and split using a GEOTEK core splitter. For each core section, one half was reserved for micro-XRF (ITRAX) core scanning and archiving, and the other half for multi-proxy sampling. The sampling strategy includes biogenic proxies (results reported elsewhere), radiocarbon dating, OSL dating, paleo- and rock-magnetism, and beryllium isotopes.

\subsection{Micro-XRF core scanning}

The cores were scanned using a micro X-ray fluorescence ITRAX core scanner at the Australian Nuclear Science and Technology Organisation (ANSTO). Optical and X-ray radiograph images of the split cores were acquired, and elemental composition was measured at $0.02 \mathrm{~cm}$ intervals. All measurements were conducted using a molybdenum (Mo) target tube set at $30 \mathrm{kV}$ and $55 \mathrm{~mA}$ with a dwell time of $10 \mathrm{~s}$. The pass-through radiation (RAD) is a proxy for density (Francus et al., 2015) and the ratio inc/coh is a proxy for sediment organic content (Woodward and Gadd, 2018). Principal component analysis (PCA) of the XRF core scanning data was performed to extract the main components of variance. The selected variables include elements with significant counts ( $>30 \mathrm{kcps})$, 
RAD, inc/coh, and color RGB. Prior to PCA, each variable was scaled by subtracting the mean and normalising by the standard deviation.

\subsection{Radiocarbon dating}

Samples for radiocarbon dating were taken from core sections LA, N2-A and N2-B (Fig. 2A). Supplementary Material 1 includes core photographs and radiocarbon samples position. A total of 29 bulk sediment samples of $0.5 \mathrm{~cm}$ thickness were analysed at DirectAMS Radiocarbon Dating Service laboratory. The radiocarbon ages are calibrated using the Southern Hemisphere calibration curve ShCal20 (Hogg et al., 2020).

\subsection{Optically stimulated luminescence (OSL) dating}

Twenty-three samples for OSL dating (OSL samples) and an additional 21 from above, between and below each OSL sample for field moisture content and environmental dose rate measurements (DOS samples), were collected from core sections N1-A, N1-B, N1-C, and N2-D (Fig. 2 and Sup. Mat. 1). Samples were 3-7 cm thick and collected from clastic sediment facies. Quartz grains $(90-125 \mu \mathrm{m}$ diameter) were isolated for OSL dating, purified using standard procedures (e.g. Wintle, 1997) and measured on an automated Ris $\varnothing$ TL-DA-20 luminescence reader (Bøtter-Jensen et al., 2003).

Equivalent dose (De) values were estimated from 6-10 multi-grain aliquots ( $\sim 300$ grains per aliquot) for each sample using the single aliquot regenerative-dose (SAR) procedure (Wintle and Murray, 2000). Aliquots were preheated at $240^{\circ} \mathrm{C}$ for $10 \mathrm{~s}$ prior to optical stimulation with blue LEDs for $40 \mathrm{~s}$ at $125^{\circ} \mathrm{C}$ prior to measurement of the natural (Ln) and regenerative doses (Lx). A fixed test dose ( $\sim 5.4 \mathrm{~Gy}$, also preheated at $240^{\circ} \mathrm{C}$ for $5 \mathrm{~s}$ ) was applied after each $\mathrm{Ln}$ and $\mathrm{Lx}$ and the induced OSL signals ( $\mathrm{Tn}$ and $\mathrm{Tx}$ ) measured. Also included were duplicate and zero regenerative dose cycles and an OSL-IR depletion ratio test. Sensitivity-corrected ( $L x / T x)$ dose response curves (DRCs) were then constructed from the Lx and TX OSL signals, using a saturating exponential function, and the sensitivity-corrected natural OSL signal ( $\mathrm{Ln} / \mathrm{Tn}$ ) projected onto the fitted DRC to estimate De by interpolation.

Choice of measurement parameters were tested using a series of dose recovery tests (Galbraith et al., 1999). Aliquots of sample OSL5 $(\mathrm{N}=21)$ were measured using seven different preheat combinations (180/180, 260/160, 180/160, 200/200, 220/220, 240/220 and 240/240) and given dose of $\sim 80 \mathrm{~Gy}$. Accurate measured/given dose ratios were only obtained for two combinations: $240^{\circ} \mathrm{C}$ for $10 \mathrm{~s}(\mathrm{PH}-1)$ and $240^{\circ} \mathrm{C}$ for $5 \mathrm{~s}(\mathrm{PH}-2)($ mean $=1.01 \pm 0.07 ; \mathrm{N}=3)$ and $220^{\circ} \mathrm{C}$ for $10 \mathrm{~s}(\mathrm{PH}-1)$ and $220^{\circ} \mathrm{C}$ for $5 \mathrm{~s}(\mathrm{PH}-2)($ mean $=1.00 \pm 0.06, \mathrm{~N}=3)$.

Environmental dose rates were calculated as the sum of the beta, gamma and cosmic-ray dose rates external to the grains, plus a small alpha dose rate from inside the quartz grains $(0.03 \pm 0.01 \mathrm{~Gy} / \mathrm{ka})$. We assumed that present-day radionuclide activities and dose rates have prevailed throughout the period of sample burial. Gamma dose rates were estimated from uranium, thorium and potassium concentrations obtained from a combination of inductively coupled plasma mass spectrometry (ICPMS) and optical emission spectroscopy (ICP-OES) and converted to gamma dose rates using the conversion factors of Guérin et al. (2011). Beta dose rates were estimated from GM-25-5 beta counting using the procedures described and tested previously (Jacobs and Roberts, 2015), including a correction for grain size (Brennan, 2003). Cosmic-ray dose rates were calculated following Prescott and Hutton (1994), adjusting for site altitude, geomagnetic latitude, and the density $\left(1.8 \mathrm{~g} / \mathrm{cm}^{3}\right.$ for sediment and $1.025 \mathrm{~g} / \mathrm{cm}^{3}$ for water) and thickness of sediment overburden and an average 
permanent water depth of $5 \mathrm{~m}$. Beta, gamma and cosmic-ray dose rates were corrected for a moisture content of $40 \pm 10 \%$ for all samples (Nathan and Mauz, 2008). The De divided by the environmental dose rate gives the burial time of the grains in calendar years ago.

\subsection{Magnetic analysis}

Paleomagnetic $8 \mathrm{~cm}^{3}$ cube samples were taken continuously from cores LA, N1-A, N1-B, N1-C, N2-C, and N2-D (Fig. 2A). Core N2-A (24-81.6 cm section depth) was sampled for duplicate measurements. A total of 287 cube samples and 24 discrete samples $(1 \mathrm{~g})$ were analysed at the Australian National University. Magnetic analyses of the cube samples include low field volumetric magnetic susceptibility (klf) measured with an AGICO Kappabridge, and the natural, anhysteretic, and isothermal remanent magnetizations (NRM, ARM, and IRM, respectively) measured with a $2 \mathrm{G}$ cryogenic magnetometer. The NRM was demagnetized in 13 steps to maximum alternating field (AF) of $90 \mathrm{mT}$. The results were analysed in Puffinplot (Lurcock and Wilson, 2012) using unanchored principal component analysis (PCA). The cores were not azimuthally oriented; the declination records are aligned by subtracting the average declination of the non-anomalous values from each section. The ARM was induced using a direct current field of $0.05 \mathrm{mT}$ and peak AF of $100 \mathrm{mT}$ and demagnetized in $7 \mathrm{AF}$ steps. A first IRM was induced in $1 \mathrm{~T}$ field using a $2 \mathrm{G}$ pulse magnetizer and demagnetized in 6 AF steps, and a second IRM was induced in $0.3 \mathrm{~T}$ field in the opposite direction and measured. Useful coercivity indicators from the remanence measurements include the median destructive field (MDF; the field required to demagnetize half the initial remanence; Dankers, 1981), the ARM ratio (KARM/IRM; Peters and Dekkers, 2003), the S-ratio $\left(\right.$ IRM $_{-0.3 T} / I_{R M}$; ; a proxy for the relative contributions of low and high coercivity minerals to the total IRM; Liu et al., 2012) and the HIRM ((IRM $\left.{ }_{1 T}+I_{R M}-0.3 T\right) / 2$; the absolute contribution of high coercivity minerals to the total IRM; Liu et al., 2012).

Magnetic analyses of the 24 discrete samples were used to further characterise the magnetic mineral assemblage. The analyses include hysteresis loops, IRM acquisition and back field curves using a Princeton Measurements Corperation Vibrating Sample Magnetometer (VSM). The remanence ratio (saturation remanence (Mrs)/saturation magnetisation(Ms)) and the coercivity ratio (the remanent coercive force $(\mathrm{Hcr}) /$ bulk coercive force $(\mathrm{Hc})$ ) calculated from hysteresis loop and back field curve data are useful magnetic grain size and mineralogy indicators (Peters and Thompson, 1998; Roberts et al., 2011). IRM acquisition curves were analysed using MAX UnMix (Maxbauer et al., 2016). First-order reversal curves were acquired on 4 samples and processed using FORCinel (Harrison and Feinberg, 2008) with VARIFORC smoothing (Egli, 2013). Thermomagnetic curves were acquired for the representative samples N1-A18 and N1-C37. High-temperature cycling of magnetic susceptibility was measured from room temperature to $700{ }^{\circ} \mathrm{C}$ using a AGICO MFK2, and low-temperature cycling of room-temperature saturation isothermal remanent magnetisation (RTSIRM 5T) was measured down to $10 \mathrm{~K}$ using a Quantum Design Magnetic Property Measurement System (MPMS) at the Australian National University.

\subsection{Beryllium isotopes analysis}

Samples for beryllium isotope analysis were taken from core sections N1-A and N1-B (Fig. 2A) on one side of the trench left by paleomagnetic cube sampling at corresponding depth intervals. A total of 45 samples were analysed at CEREGE National Cosmogenic Nuclides Laboratory following the method established by Bourlès et al. (1989) and revised by Simon et al. (2016b). Authigenic ${ }^{10} \mathrm{Be}$ and its stable isotope ${ }^{9} \mathrm{Be}$ were extracted from $\sim 1 \mathrm{~g}$ dry sample by soaking the samples in $20 \mathrm{ml}$ of 
leaching solution $\left(0.04 \mathrm{M}\right.$ hydroxylamine $(\mathrm{NH} 2 \mathrm{OH}-\mathrm{HCl})$ and $25 \%$ acetic acid) at $95 \pm 5^{\circ} \mathrm{C}$ for $7 \mathrm{~h}$. A 2$\mathrm{ml}$ aliquot of the resulting leaching solution was sampled for measurement of the natural ${ }^{9} \mathrm{Be}$ concentration using a graphite-furnace atomic absorption spectrophotometer (AAS) with a double beam correction (Thermo Scientific ICE 3400). The remaining solution was spiked with $300 \mu \mathrm{l}$ of a $9.8039 \times 10^{-4} \mathrm{~g}^{-1}{ }^{9} \mathrm{Be}$ carrier before Be purification by chromatography to determine accurate ${ }^{10} \mathrm{Be}$ sample concentrations from accelerator mass spectrometer (AMS) measurements of ${ }^{10} \mathrm{Be} /{ }^{9} \mathrm{Be}$ ratios. ${ }^{10} \mathrm{Be}$ sample concentrations were calculated from the measured spiked ${ }^{10} \mathrm{Be} /{ }^{9} \mathrm{Be}$ ratios normalised to the BeO STD-11 in-house standard (1.191 $\pm 0.013 \times 10^{-11}$ ) (Braucher et al., 2015). Authigenic $10 \mathrm{Be}$ concentrations were decay-corrected using the ${ }^{10} \mathrm{Be}$ half-life $\left(\mathrm{T}_{1 / 2}\right)$ of $1.387 \pm 0.012$ Ma (Chmeleff et al., 2010; Korschinek et al., 2010) and the dipole-independent age model (see below).

\subsection{Core correlation}

Core correlation is based on 24 visible stratigraphic tie-points and one inc/coh data tie-point (Fig. $2 A$ ). The correlation of the gravity core (LA) to the Nesje cores (N1 and N2) is set using a large amplitude change in inc/coh ratio at $75 \mathrm{~cm}$ in LA, $29 \mathrm{~cm}$ in N1-A, and $25 \mathrm{~cm}$ in N2-A (Fig. 2B). The inc/coh correlation depths correspond to the maximum inc/coh value after the inflection. The composite depth LAN2 is the reference record (Fig. 2C) used in this work. Data measured on samples from core $\mathrm{N} 1$ (OSL, beryllium, and magnetism) is transferred to the reference depth LAN2 using a transfer function based on linear interpolation and the 24 stratigraphic tie-points (Fig. 2A; cf. Result section 4.1 Lithology; Sup. Mat. 2). This assumes constant sedimentation rates between tie-points within each facies. We note that the stratigraphy of core section N2-A is potentially disturbed; a sediment gap formed (at $114 \mathrm{~cm}$ depth LAN2) during core splitting and two sub-sections were labelled (N2-A-a and -b; Fig. 2A). Thus, the duplicate magnetic data from core section N2-A is represented in the figures by points only.

\section{Results}

\subsection{Lithology}

Sediments from Lake Selina are characterised by two main facies, I and II (Fig. 3). These sedimentary facies have been associated with interglacial and glacial time intervals based on previous coring and radiocarbon dating (Colhoun et al., 1999). Interglacial facies I is homogeneous dark brown to black mud with lower density (RAD), higher organic content (inc/coh), lower ferrimagnetic content (klf, NRM, ARM, IRM) and lower bulk coercivity magnetic minerals assemblage (HIRM, S-ratio) than glacial facies II. Facies II is lighter in color, more clastic (higher $\mathrm{Pb}, \mathrm{Zn}, \mathrm{Rb}, \mathrm{Zr}, \mathrm{Si}, \mathrm{K}$ ) and composed of two main sub-facies (Ila and $\mathrm{Ilb}$ ) that alternate in distinct or mixed layers, sometimes including laminations. The sub-facies Ila is grey-beige mud and has the lowest organic content, the highest ferrimagnetic content and the higher magnetic coercivity assemblage. Sub-facies Ilb is grey-brown mud with occasional lighter mud clasts and intermediate values between facies I and facies Ila. A few pebbles were found during sub-sampling (Fig. 2). Figure 4 illustrates the XRF PCA variables contribution to the principal components PC1 and PC2. The organic matter proxies (inc/coh, RAD, Br) and the elements associated with the clastic fraction of the sediment and the local geology $(\mathrm{Rb}, \mathrm{Zr}$, $\mathrm{Si}, \mathrm{Pb}, \mathrm{Zn}, \mathrm{K}$ ) strongly influence $\mathrm{PC} 1$ and are negatively correlated.

Cores N1 and N2 have the same stratigraphic sequence and are readily correlated visually (Fig. 2). However, some of the facies in N1 and N2 have different thickness (discussed in section 5.1). The 
average facies difference is $1.7 \mathrm{~cm}$ thicker in $\mathrm{N} 1$ and the most outstanding example is the uppermost glacial clastic facies Ila that has a thickness of $1 \mathrm{~cm}$ in N2 and $7 \mathrm{~cm}$ in N1. Yet, the facies alternation provides 24 unambiguous stratigraphic tie-points. The cumulative depth difference is an additional $35 \mathrm{~cm}$ in composite depth LAN1 compared to LAN2 at the deepest tie-point ( $431 \mathrm{~cm}$ depth LAN1 and $396 \mathrm{~cm}$ depth LAN2; Fig. 2; Sup. Mat. 2). There is a series of oblique contacts and a $\mathrm{cm}$-sized dark vertical stain (organic debris) near the base of the core in the lowermost facies II (516-544 cm depth LAN2).

\subsection{Radiometric dating $\left({ }^{14} \mathrm{C}\right.$ and $\left.\mathrm{OSL}\right)$}

A total of $29{ }^{14} \mathrm{C}$ (Table 1) and $12 \mathrm{OSL}$ ages (Table 2) were obtained from the TAS1402 cores. The oldest age is $84 \pm 5 \mathrm{ka}$ at $174.5 \pm 2.5 \mathrm{~cm}$ depth LAN2 (OSL13; Table 2). OSL signals for samples collected below this depth (OSL14 to 23) were in dose saturation, so finite De values and ages could not be obtained. Most samples have overdispersion values $<20 \%$ (Table 2 ), consistent with samples that were well-bleached prior to deposition and remained largely undisturbed. The radial plots show tight distributions of De values, in which the majority lie within \pm 2 standardised estimates of a common value (Sup. Mat. 3). The weighted mean De values for age determination were calculated using the central age model (CAM) of Galbraith et al. (1999) (Table 2). The dose rate data are provided in Table 2 and shown for all OSL and DOS samples between depths of 81 and $190 \mathrm{~cm}$ depth LAN2 in Fig. 5. The total dose rates are similar for different samples, and there are no significant trends with depth or between different sediment facies. A comparison of beta dose rates determined using two independent methods and laboratories verify the reliability of the beta dose rate measurements (Fig. 5D). The final optical ages are presented in Table 2. Uncertainties on the ages are given at $1 \sigma$ (the standard error on the mean) and were estimated by combining, in quadrature, all known and estimated sources of random and systematic error.

Figure 6 presents the radiometric dating results and Bayesian age-depth model (rbacon; Blaauw and Christen, 2011). The OSL ages (ka before 2018) were corrected by 68 years to make it equivalent to the calibrated radiocarbon ages (ka before 1950 - ka cal BP). ${ }^{14} \mathrm{C}$ and OSL samples overlap over the interval 83-177 cm LAN2 depth. Below the first OSL-dated clastic sediment sample at $83-84 \mathrm{~cm}$ LAN2 depth, the calibrated ${ }^{14} \mathrm{C}$ ages return age inversions with apparently too 'old' and too 'young' ages relative to OSL. Calibrated ${ }^{14} \mathrm{C}$ ages reach a plateau at ca. $40 \mathrm{ka}$ cal BP (grey symbols in figure 6). The two calibrated ${ }^{14} \mathrm{C}$ ages (D-AMS 027826 and D-AMS 015350; Table 1) that appear too 'old' may indicate older organic material input to the coring site. The calibrated ${ }^{14} \mathrm{C}$ ages that appear too 'young' can be explained by two processes. First, underestimation of ${ }^{14} \mathrm{C}$ ages by modern carbon contamination (Fig. 6B; Pigati et al., 2007). Contamination has greater impact on older materials (>35 ka $B P$ ) that contain proportionally less radiocarbon than younger materials. Figure $6 B$ shows that true ${ }^{14} \mathrm{C}$ ages $>40$ ka BP with 1-2\% modern carbon contamination always returns ${ }^{14} \mathrm{C}$ ages of about 30-35 ka (32-38 ka cal BP). This likely explains the vertical distribution of 7 calibrated ${ }^{14} \mathrm{C}$ ages below $\sim 110 \mathrm{~cm}$, where 4 other samples returned results not distinguishable from background (NDFB; Table 1, Fig. 6). Second, percolation of carbon down the core through the porous glacial lithologies (e.g. Briant and Bateman, 2009; Long and Shen, 2014). This process may explain ${ }^{14} \mathrm{C}$ ages younger than OSL and <35 ka (D-AMS 027827, D-AMS 027828, D-AMS 009084; Table 1). Unlike modern carbon contamination, the migration of young carbon in sediments is site-specific and difficult to quantify. It is, however, limited by the stratigraphy because percolation takes place through porous material at a lithological boundary. Thus, we can reasonably assume that young carbon migration only affects ${ }^{14} \mathrm{C}$ ages at depths greater than the uppermost porous detrital layer (>83 cm LA-N2 composite depth). 
To investigate further the young carbon effect, we compare two Bayesian age modeling runs (rbacon; Blaauw and Christen, 2011): the first using all calibrated ${ }^{14} \mathrm{C}$ and OSL ages (run 1) and the second using only the 12 calibrated ${ }^{14} \mathrm{C}$ ages from $0-83 \mathrm{~cm}$ and all OSL ages (run 2). With run 2, we assume that the ${ }^{14} \mathrm{C}$ ages at depths $>83 \mathrm{~cm}$ are affected by old or young carbon contamination, and/or downcore percolation, all of which relate to lithological changes during the Last Glacial Period. Run 1 and 2 return quite similar age-depth models, however run 1 shows sharper changes in sedimentation rate constrained by the extra ${ }^{14} \mathrm{C}$ ages at depths $>83 \mathrm{~cm}$. Key to this exercise is that rbacon independently rejected the too 'old' and too 'young' ${ }^{14} \mathrm{C}$ ages as hypothesized from the lithology, providing support to the run 2 sample selection (Sup. Mat. 4). We select the more conservative age-depth model run 2 , based on 12 calibrated ${ }^{14} \mathrm{C}$ and 12 OSL ages, to avoid any bias induced by unknown young carbon migration and old/young carbon contamination. The inclusion of stratigraphic boundaries (Sup. Mat. 2) in the rbacon model to allow for sedimentation changes between facies returns the same result within uncertainty as model runs that do not include stratigraphic boundaries (Sup. Mat. 4). The age-depth model run 2 based on radiometric dating is hereafter referred to as "Radiometric".

\subsection{Magnetic mineral assemblage}

Ferrimagnetic mineral content varies by up to one order of magnitude between sediment facies I and II (Fig. 3; kIf, NRM, IRM). The organic-rich facies I has weak average NRMs of $2 \times 10^{-3} \mathrm{Am}^{-1}$ and klf values of $7 \times 10^{-6} \mathrm{SI}$. The more clastic facies II has average NRM and klf values five to ten times higher, of $21 \times 10^{-3} \mathrm{Am}^{-1}$ and $35 \times 10^{-6} \mathrm{SI}$, respectively. Slightly coarser magnetic grains (KARM/IRM, MDF $_{\text {ARM, }}$, $\mathrm{Mr} / \mathrm{Ms}$ ) and more high coercivity minerals (HIRM) characterize facies II compared to facies I (Fig. 3). The magnetic mineralogy is a mixed magnetic assemblage comprising at least two contrasting coercivity populations as indicated by wasp-waisted hysteresis loops (Fig. 7) and S-ratio varying between 0.4 and 0.8 (Fig. 3). The mineralogy discriminant remanence ratio ARM40mT/SARM (Peters and Thompson, 1998) (Fig. 8) and the average $\mathrm{Hcr} / \mathrm{Hc}$ value of $4.5 \pm 1.5$ indicate that magnetite is the primary remanence carrier (pyrrhotite and greigite have $\mathrm{Hcr} / \mathrm{Hc}<1.5$; Peters and Thompson, 1998; Roberts et al., 2011). Further magnetic mineralogical evidence comes from the temperaturedependant analysis. The low temperature analyses do not reveal a magnetite Verwey transition (a change in remanence at $120 \mathrm{~K}$ ) and the RTSIRM curve is almost reversible (Fig. 7B and F), which is typical of surficially oxidized magnetite (maghemite), titanomagnetite, and/or goethite as remanence carriers (France and Oldfield, 2000; Lacroix and Guyodo, 2017). The goethite Curie temperature $\left(120^{\circ} \mathrm{C}\right)$ is occasionally seen in the thermomagnetic curves of magnetic susceptibility for facies II samples. None of the (not shown). No thermomagnetic curves are reversible and ferrimagnetic minerals are formed and/or grain size changed from about $400{ }^{\circ} \mathrm{C}$ (Fig. $7 \mathrm{~B}$ and F). Yet, $\mathrm{t}$ his transformation is not diagnostic and may result from heating of other iron oxides, iron sulphides, hydroxides, carbonates or silicates originally present in the sediments (Henry, 2007). Finally, five samples from facies II ( $<2 \%$ of the samples) acquired a gyroremanent magnetisation (GRM) during stepwise AF demagnetisation of the NRM in fields $>40 \mathrm{mT}$, indicating presence of some greigite in the lake sediments (e.g., Roberts et al., 2011; Lise-Pronovost et al., 2014).

Unmixing of the 24 IRM acquisition curves using MAX UnMix (Maxbauer et al., 2016) indicates a minimum of three subpopulations of magnetic mineral particles (P1, P2, P3) with average coercivity ranges $<20 \mathrm{mT}$ (P1), of $63 \pm 9 \mathrm{mT}(\mathrm{P} 2)$, and $>270 \mathrm{mT}$ (P3) (Fig. 7). The lower coercivity population P1 may correspond to multidomain particles with an average estimated contribution to the IRM of $10 \%$ (Maxbauer et al., 2016). The high coercivity population P3 has an average estimated contribution to the IRM of $40 \%$ and may correspond to hematite and/or goethite (Egli, 2004). The dominant 
population is $\mathrm{P} 2$ with an estimated contribution of $50 \%$ to the IRM and a medium coercivity range that corresponds to fine iron oxide particles (Egli, 2004). While the P2 range of IRM unmixed coercivities better match biogenic magnetite, the $\mathrm{MDF}_{\text {ARM }}$ values $(20-30 \mathrm{mT})$, ARM ratio $\left(0.38 \mathrm{mmA}^{-}\right.$ ${ }^{1}$ ), and dispersion parameter value (log $D P_{\mathrm{P} 2}=0.4$ ) closely match the typical values for detrital, pedogenic, extracellular, or aeolian sources (Egli, 2004; Maxbauer, 2016). Further support for a nonbiogenic source is provided by the FORC diagrams (Fig. 7F) which indicate vortex and interacting single domain particles (Harrison et al., 2018) based on the absence of a central ridge feature associated with the non-interacting single domain particles, typical of biogenic magnetite (Egli et al., 2010; Heslop et al., 2014). Yet, it is unclear if P2 has a detrital and/or biogenic origin, as biogenic magnetite may have oxidized to maghemite. We note that a dual biogenic and detrital origin for the iron minerals would be consistent with Fe being neutral in the PC1 opposing organic and clastic variables (Fig. 4). The proportion of the primary magnetic population P2 is maximum in facies II and accounts for the higher ferrimagnetic concentration (kIf, NRM, ARM, IRM; Fig. 3). In summary, the magnetic analysis results indicate a principal magnetic population of oxidized detrital (titano-) magnetite (P2) present throughout all sedimentary facies (Fig. 7) and isolated by alternating field demagnetisation of the ARM and IRM (Fig. 8). Up to half the estimated contributions are attributed to combined secondary populations of low coercivity ferrimagnetic material (P1) and high coercivity hematite and/or goethite (P3).

\subsection{Paleomagnetic record}

\subsubsection{Paleomagnetic directions}

The paleomagnetic directions calculated for all demagnetisation steps ( 13 steps from 0 to $90 \mathrm{mT}$ ) show inclinations varying near the expected value $\left(-61^{\circ}\right)$ for the site latitude and a geocentric axial dipole (GAD). However, the inclination and declination demagnetisation data are noisy with maximum angular deviation (MAD) reaching values up to $40^{\circ}$ (Fig. 9A). The MAD is approximately inversely proportional to the NRM intensity, with highest MAD values in weakly magnetic interglacial sediments (facies I) and the most stable directions in glacial sediments (facies II). There is no evidence of inclination shallowing or paleomagnetic directional (in)stability tied to specific facies. Overlapping core sections LA, N1-A and N2-A give reproducible results (Fig. 9A). A two-step selection process was applied to select a paleomagnetic direction record (Fig. 9B). First, the optimum characteristic remanent magnetisation (ChRM) interval is selected for each sample. The demagnetisation steps associated with any viscous overprint $(<20 \mathrm{mT})$, weak noisy values at higher fields and GRM ( $>40 \mathrm{mT}$ ) are left out. Most selected ChRM intervals lie between 10 and $60 \mathrm{mT}$ and include about 9 demagnetisation steps. Second, we select samples having a minimum of 5 consecutive steps and MAD values $<20^{\circ}$. $76 \%$ of the samples pass these selection criteria and the selected paleomagnetic directions data are shown in figure 9B. The selected paleomagnetic directions demonstrate overall small-scale oscillations, in agreement with paleosecular variation, except for few intervals showing large-scale deviations (Fig. 9B). The distinction between secular variation and geomagnetic instabilities (e.g. geomagnetic excursions) is often defined empirically by a deviation of the virtual geomagnetic pole (VGP) by more than $45^{\circ}$ accompanied by paleointensity minima (e.g. Roberts, 2008; Laj and Channell, 2015). Here, we consider that paleomagnetic inclinations departing $>45^{\circ}$ away from the GAD and associated with large amplitude changes in declination correspond to "excursional" events featuress (Fig. 9B). These "excursional" events features are found in the interval 91-116 cm depth LAN2 (facies Ila and IIb), at $302 \mathrm{~cm}$ depth LAN2 (facies I), and at $558 \mathrm{~cm}$ and $565 \mathrm{~cm}$ depth LAN2 (lowermost facies lla). 


\subsubsection{Relative paleointensity (RPI)}

RPI is estimated by normalising the NRM with a rock-magnetic parameter such as the ARM or IRM to isolate the geomagnetic signal, considered to be proportional to the ancient field intensity, from the concentration of the remanence carrying ferrimagnetic mineral. A set of criteria for rock magnetic homogeneity is traditionally used to assess the quality of sediments for RPI reconstruction (King et al., 1983; Roberts et al., 2013). 1) The ferrimagnetic concentration should vary by less than one order of magnitude ( $\mathrm{kIf}, \mathrm{ARM}, \mathrm{IRM}), 2$ ) the ideal magnetic mineral is magnetite, and 3) the ideal magnetic particle size is single domain (SD). The magnetic mineralogy results indicate that the sediments from Lake Selina barely fulfill these criteria (Figures 3, 7, and 8 ). The ferrimagnetic content of facies I and II differs by one order of magnitude and although fine magnetite particles (P2) dominate the magnetic mineral assemblage, magnetite is not the only ferrimagnetic mineral. Downcore homogeneity of the magnetic mineral assemblage is crucial for RPI reconstruction because different magnetic particles can have different recording efficiencies that are difficult to reconcile into a continuous RPI record (e.g. Chen et al., 2017). Figures $9 C$ and $D$ compares four RPI estimates. The raw data in Figure $9 \mathrm{C}$ illustrates efficiency differences in the sediments of Lake Selina, with RPI values varying over one order of magnitude. Data deemed unsuitable for RPI include isolated peak RPI values up to 5 reflecting NRM overprint (Fig. 9C) and high $\mathrm{NRM}_{20 \mathrm{mT}} / \mathrm{ARM}_{20 \mathrm{mT}}$ values $>0.4$ corresponding to high $\mathrm{MDF}_{\mathrm{NRM}}$ values $>30 \mathrm{mT}$ (not shown). These intervals have a distinct remanence efficiency apparently associated with some of the facies Ila; they are highlighted in grey in figures 3 and 9. Figure 10D presents the selected RPI estimates (without data from the grey intervals). The RPI estimates include NRM normalisation by ARM and IRM at $20 \mathrm{mT}$ demagnetisation $\left(\mathrm{NRM}_{20 \mathrm{mT}} / \mathrm{ARM}_{20 \mathrm{mT}}\right.$ and $\left.\mathrm{NRM}_{20 \mathrm{mT}} / \mathrm{IRM}_{20 \mathrm{mT}}\right)$ and by the portion of remanence removed between 10 $\mathrm{mT}$ and $60 \mathrm{mT}$ demagnetisation ( $\mathrm{NRM}_{10-60 \mathrm{mT}} / \mathrm{ARM}_{10-60 \mathrm{mT}}, \mathrm{NRM}_{10-60 \mathrm{mT}} / \mathrm{IRM}_{10-60 \mathrm{mT}}$ ) to specifically target the P2 magnetic population. The four RPI proxies are similar (Fig. 9C-D), which supports P2 as the main remanence carrier isolated in laboratory AF fields. The interval 10-60 mT has the best reproducibility between cores (LA, N1 and N2 overlap; Fig. 9D) and therefore $\mathrm{NRM}_{10-60 \mathrm{mT}} / \mathrm{ARM}_{10-60 \mathrm{mT}}$ is selected as the preferred RPI estimate. In the interval displaying excursional directions, eight RPI data ( 3 cubes from core N1 and 5 cubes from N2) did not pass the selection criteria because of their different remanence efficiency. A total of six samples ( 3 cubes from core N1 and 3 cubes from N2) have both reliable RPI and excursional directions, including the low RPI interval from 110 to $116 \mathrm{~cm}$ depth LAN2 (Fig. 10).

\subsubsection{Beryllium isotopes}

The authigenic $9 \mathrm{Be}$ concentrations range from 0.1 to $2.2 \times 1016$ at. $\mathrm{g}^{-1}$, with an average value of $0.6 \pm$ $0.4 \times 10^{16}$ at. $\mathrm{g}^{-1}$ (Fig. 3). The authigenic ${ }^{10} \mathrm{Be}$ (decay-corrected) concentrations range from 3.1 to 36.7 $\times 10^{8}$ at. ${ }^{-1}$, with an average value of $12.6 \pm 7.1 \times 10^{8}$ at. $\mathrm{g}^{-1}$. These ${ }^{10} \mathrm{Be}$ and ${ }^{9} \mathrm{Be}$ concentrations and variation ranges are larger than those found in most marine records (e.g. Simon et al., 2016a and references therein) or existing lacustrine sediments (e.g. Horiuchi et al.., 2001; Czymzik et al., 2015; Du et al., 2018; Tang et al., 2019), except from the closest lacustrine record (i.e. Lake Pupuke in New Zealand; Nilsson et al., 2011). Such large-scale concentration variations indicate large changes of Be inputs into the lake controlled by transport and deposition processes, but not associated with ${ }^{10} \mathrm{Be}$ production rates (e.g. Simon et al., 2016b). The fact that both ${ }^{9} \mathrm{Be}$ and ${ }^{10} \mathrm{Be}$ concentrations vary similarly (correlation coefficient $r=0.97$; Sup. Mat. 5 ) and display two peak intervals also found in elemental ratios (e.g. Pb/AI) and magnetic properties (e.g. magnetic susceptibility, HIRM) associated with local runoff (Fig. 3), suggests that ${ }^{9} \mathrm{Be}$ and ${ }^{10} \mathrm{Be}$ have the same transport pathway to the lake as clastic detrital particles. 
The ${ }^{10} \mathrm{Be}$ is used for reconstructing geomagnetic dipole moment variations by normalising ${ }^{10} \mathrm{Be}$ concentration by its stable isotope ${ }^{9} \mathrm{Be}$ (hereinafter Be ratio) to try minimizing environmental influences (Bourlès et al., 1989). The Be ratio varies from $14.7 \times 10^{-8}$ to $23.7 \times 10^{-8}$, with an average of $20.7 \pm 2.3 \times 10^{-8}$. One single Be ratio peak reaching $28 \pm 1.0 \times 10^{-8}$ at $95 \mathrm{~cm}$ depth LAN2 was identified in a first batch, but not reproduced by a replicate measurement (Table 3). Excluding this measurement outlier, the highest Be ratio values $\left(>22 \times 10^{-8}\right)$ are found in the intervals $91-95 \mathrm{~cm}$ and 110-117 cm depth LAN2. The latter interval is coeval with the RPI low and excursional paleomagnetic inclinations (Fig. 10). In the top $90 \mathrm{~cm}$ of the core (Holocene facies I), the Be ratio decreases significantly and reaches its lowest values $(<18 \times 10-8)$. These low Be ratio values are explained by a dilution of ${ }^{10} \mathrm{Be}$ inputs between the Holocene interval and the Last Glacial Period (Willenbring and von Blanckenburg, 2010; Sup. Mat. 5). This is likely associated with large-scale atmospheric reorganization and environmental change within the lake watershed since the last glacial to interglacial climate transition (Fig. 3) and higher sedimentation rates. Excluding these Holocene results, Be ratio and RPI have a correlation coefficient of $r=-0.36$, and $r=-0.5$ for the grey shading interval of figure 10. Considering the large lithological changes observed during the Last Glacial Period, these moderately good correlations may relate to unaccounted for environmental biases on both geomagnetic field intensity proxies and/or to unknown lock-in-depth affecting the RPI (Roberts and Winklhofer, 2004; Nilsson et al., 2018; Simon et al., 2018, 2020b). The phasing between RPI low and Be ratio peak between 110-117 cm depth LAN2 suggests a very limited lock-in depth, but data resolution and lithological changes prevent any strong inference.

\section{Discussion}

\subsection{Depositional processes in Lake Selina and instability of the Last Glacial Period}

The difference in facies thickness between the two cores could point to event deposits as suggested by the occasional mm-sized pebbles in facies Ila (black lozenge on Fig. 2 stratigraphic logs). However, a pebble is also found in facies I and there are no clear and systematic geochemical, magnetic, and physical evidence for event deposits as reported elsewhere in lakes, fjords and harbour sediments (e.g. St-Onge et al., 2004; Guyard et al., 2007; Lisé-Pronovost et al., 2014; 2019b). No basal erosive contacts are observed and the base of facies units contains no vegetal debris, nor present any systematically higher density (RAD; Fig. 3), higher concentration of ferrimagnetic minerals (ARM, IRM; Fig. 3), or abnormally shallow paleomagnetic inclinations as would be expected for instantaneous event deposits such as floods, extreme precipitation or melt runoff. The facies lla from lowermost part of core N2 (516-544 cm depth LAN2) is the only one standing out as a likely event or disturbed deposit because it has oblique structures (visible in the radiograph and photo, Sup. Mat. 1), a 3-cm vertical black stain, pebbles, flattened inclinations and sharp large amplitude

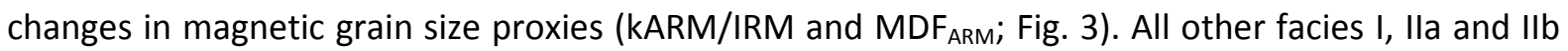
are interpreted as distinct types of normal lake sediment deposits and the pebbles are assumed to have reached the coring sites through a process independent of facies type (e.g. isolated meteorological event). The difference in facies thickness between cores can alternatively be attributed to the coring site N1 being closer than N2 to gullies from Lake Westwood to Lake Selina (Fig. 1C). This is supported by glacial facies (Ila and IIb) being on average 1.6 times thicker in N1 than $\mathrm{N} 2$ (N1/N2) and coarser magnetic particles deposited at coring site N1 than N2 (KARM/IRM and $\mathrm{MDF}_{\text {ARM }}$ data of overlapping sections N2-A; Fig. 3). Detrital input from the gullies likely also accounts for the southwest of Lake Selina being filled in the modern wetland (Fig. 1C). Future geophysical surveys will be useful to find out the total sediment thickness accumulated in Lake Selina. 
The Last Glacial Period (MIS 2, 3 and 4) also stands out as more unstable than the previous glacial period (MIS 6), with greater and more variable facies thickness differences between cores (N1/N2 ratio of facies thicknesses are $1.82 \pm 1.68$ for the Last Glacial Period and $1.17 \pm 0.16$ for MIS 6$)$. The relatively unstable stratigraphy of the Last Glacial Period may be linked to climate and/or human influence on the transport of clastic sediments to the lake. The distinct climatic signal of the two last glacial periods in the Lake Selina data may be attributed to their different orbital configurations (e.g. Ruddiman, 2006) and the global distribution of continental ice (Rohling et al., 2017). Distinct regional climate signals for the two last glacials are similarly reported elsewhere (e.g. de Abreu, 2003, Fritz et al., 2004; Roucoux et al., 2011). While MIS 6 is poorly documented in the Australian region, dramatic climate changes are documented for the Last Glacial Period in the marine and continental temperate regions of Australia, from cold MIS 4 (de Deckker et al., 2019) to wet MIS 3, and cold and arid MIS 2 (Fletcher and Thomas, 2010; Bostock et al., 2013; Falster et al., 2018; Kemp et al., 2019; Sniderman et al., 2019). Lake Mungo, in the Willandra Lakes system on mainland Australia (900 km north from Lake Selina), was permanent during MIS 4 and 2 and underwent large-scale oscillating lake levels during MIS 3 (Fitzsimmons et al., 2015). At Lake Selina, the frequent alternation of the more clastic facies Ila and the more organic facies Ilb may suggest similar lake level fluctuations with changing conditions controlled by an on/off type of control. Examples of on/off switches include temperatures near freezing point and the hydrological connection from Lake Westwood to Lake Selina. Gullies may have only been active at temperatures above the freezing point at the altitude of Lake Westwood, less active during arid periods (e.g. MIS 2), and much more active in wet climate (e.g. wet MIS 3; Falster et al., 2018; Kemp et al., 2019). While there is no evidence for ice cover on lakes Selina and Westwood, a sedimentary hiatus in the highest altitude Lake Julia (616 m asl) (Fig. 1C) suggests it was permanently ice-covered during MIS 2 (M.-S. Fletcher unpublished data). In addition to climate, the second non-exclusive hypothesis for the unstable signal of the Last Glacial Period is Indigenous land use practices such as vegetation burning in the lake catchment that would have impacted the availability of clastic material for erosion, since humans have occupied Tasmania for the last 43,000 years (Kiernan et al., 1983; Cosgrove, 1999). These hypotheses on the conditions controlling the depositional types will be addressed elsewhere using multi-proxy biotic and abiotic investigations from Lake Selina and Lake Westwood.

\subsection{Radiometric dating}

The heterogeneous lithology of the Last Glacial Period in Lake Selina is problematic for radiocarbon dating (Fig. 6). Downcore movement of humic acid and contamination has previously been reported at Lake Selina by Colhoun et al. (1999), precluding the determination of reliable sedimentation rates. The Radiometric age model obtained here by combining radiocarbon and OSL ages indicates an average sedimentation rate of $1.5 \mathrm{~cm} / \mathrm{ka}$ for the Last Glacial Period (MIS 2, 3, 4) and $5.3 \mathrm{~cm} / \mathrm{ka}$ for the uppermost facies I (MIS 1) (Fig. 6; Table 4). The average uncertainty of the radiocarbon and OSLdated intervals is $0.8 \pm 0.4 \mathrm{ka}$ and is $8.2 \pm 1.9 \mathrm{ka}$ at $2 \sigma$, respectively. The OSL dating uncertainty and low sedimentation rates at Lake Selina prevent resolving any difference in accumulation rates between the glacial facies Ila and Ilb.

MIS 2 is arguably the best dated interval of the Last Glacial Period because it is bracketed by the precisely radiocarbon-dated Holocene and a stratigraphic change from facies Ila to Ilb dated at $30 \mathrm{ka}$ BP (27,361-33,758 cal BP; Radiometric age model) in agreement with the accepted MIS 3/2 global boundary (29 ka; Lisiecki and Raymo, 2005). The Radiometric age model indicates that the uppermost facies IIb accumulated during MIS 2, the coldest period of the Last Glacial Cycle and a presumably arid period in the southeast of mainland Australia (Falster et al., 2018). In contrast, MIS 
3 includes a series of clastic facies Ila interbedded with facies IIb. This stratigraphy may be linked to wetter conditions influenced by Southern Westerly Winds during MIS 3 (Kemp et al., 2019), with increased runoff episodes capable of transporting more detrital particles to the lake. A local source for the detrital material is supported by the magnetic, beryllium, and elemental data (Fig. 3). The magnetic assemblage has a detrital signature, with the same magnetic subpopulations present throughout sediment facies (Fig. 7), and the elemental composition is closely tied to the local geology (e.g. Pb/Al maxima in facies Ila; Fig. 3). The interpretation of these depositional processes inferred from the lithology and environmental magnetism results therefore concur to known climate variability in southeast Australia since MIS 4 using the radiometric age model. Radiometric dating in Lake Selina sediments is however limited to the uppermost $1.74 \mathrm{~m}$ (ca. $80 \mathrm{ka}$; Fig. 6).

\subsection{Dating the full record with climate comparison}

The environmental sensitivity reflected by contrasting sediment facies in Lake Selina is a challenge for radiocarbon dating but can be an advantage for climate-based relative dating. To explore this idea, we use Match dynamic programming (Lisiecki and Lisiecki, 2002) to synchronize climate proxies from Lake Selina with well-dated Antarctic ice core climate records. This is based on the assumption of linked millennial-scale climate in Antarctica and Tasmania, as documented in paleo-records from the Southern Hemisphere mid-latitudes (e.g. Pahnke, 2003; Barrows et al., 2007; Pugh et al., 2009; Fletcher and Moreno, 2012; Petherick et al., 2013; Abram et al., 2014) and the modern Southern Annular Mode (Garreaud, 2007; Hendon et al., 2007). Fletcher and Thomas (2010) further use a pollen transfer function to estimate temperature change from the Colhoun et al. (1999) pollen record from Lake Selina, identifying a tight coherence between Antarctic and Tasmanian temperature changes over the Last Glacial Cycle. This coherence supports our assumption of strong correlation between Tasmanian and Antarctic climatic variations.

Dynamic programming allows time series compression and expansion to account for varying sedimentation rates between compared natural archives, e.g. ice accumulates faster in cold glacial climates in Antarctica, while lake sediment accumulates faster during warm interglacial climates in Tasmania. The method is most efficient for large amplitude changes such as glacial/interglacial climate transitions. Taking this into account, the proxy data are selected based on their superficial similarity and six tie-points located at large amplitude changes are chosen (Fig. 11A). We use a double approach matching concurrently a) the inc/coh organic matter proxy from Lake Selina (Fig. 1) to the dD temperature proxy from EPICA Dome C (EDC; Jouzel et al., 2007; Fig. 11A) and b) the Pb/Al local runoff proxy from Lake Selina (Fig. 1) to the EDC dust flux (Lambert et al., 2012; Fig. 11B). The Southern Hemisphere atmospheric circulation links these proxies, with increased winds over the continental masses generating more atmospheric dust and more rainfall in western Tasmania (Fig. $1 \mathrm{~A}$ and $\mathrm{B})$. The Match-Climate age model is presented in Figure 12 and gives a basal sediment age of $266 \mathrm{ka}$. The average estimated sedimentation rates of Match-Climate are $5.2 \mathrm{~cm} / \mathrm{ka}$ for interglacial facies I (MIS 5 and 7) and $2.6 \mathrm{~cm} / \mathrm{ka}$ for glacial facies II (MIS 2, 3, 4, 6, and 8) (Table 4). These sedimentation rate estimates are similar to those using the Radiometric age model; however, the Match-Climate age model returns higher estimates for the Last Glacial Period.

Despite recognisable patterns of multi-millennial variability through glacial and interglacial climates, the low variance of climatic proxies over the interval 20-60 ka prevents any reliable visual matching in this interval (Fig. 11). The inc/coh comparison is poor over that period, with an $\mathrm{R}$ value of 0.25 compared to 0.84 for the entire record (Fig. 11). This compromises the applicability of MatchClimate age model over MIS 2-3. Providing there are no unidentified event deposits obscuring the 
climate signal in the Lake Selina sequence, this mismatch may be linked to differences in regional climates in western Tasmania and in Antarctica over the Last Glacial Period, however, a close alignment between the climate of these regions is reported in the literature (Williams et al., 2009; Petherick et al., 2013; Kemp et al., 2019; Sniderman et al., 2019). Another possible explanation for the mismatch is a misinterpretation of the climate proxies. Additional local factors may influence one of the proxies in addition to the common climate forcing component. For instance, the ratio inc/coh in Lake Selina may not be solely controlled by atmospheric temperature. Therefore, the assumption that more organic sediments reflecting warmer temperatures does not hold for moderate variations, resulting in low $\mathrm{R}$ value during MIS 2-3. As discussed in section 5.1, precipitation and/or Aboriginal landscape management may have played a crucial role in the transport of clastic material to Lake Selina over the Last Glacial Period, thus decoupling the sedimentary record from climate through this interval of relatively small-scale climate fluctuations in the Antarctic record (when compared to the large orbital-scale glacial-interglacial oscillations).

\subsection{Dating with paleomagnetism}

\subsubsection{Geomagnetic excursions}

Up to 10 geomagnetic excursions have been recognised in the past $270 \mathrm{ka}$ (Channell et al., 2020 and references therein). Of these, the Blake (120 ka), Laschamp (41 ka), and Mono Lake (32 ka) excursions are amongst the most globally documented from sedimentary and volcanic archives, but previously not from Australia. At Lake Selina, the interval 110-117 cm depth LAN2 is characterised by Be ratio maxima, RPI low, and excursional paleodirections associated with the Laschamp geomagnetic excursion (Fig. 10). While the dipole moment modulates the amount of beryllium isotopes ${ }^{10} \mathrm{Be}$ produced in the atmosphere, the total field intensity (dipolar and non-dipolar fields) can be recorded in sediments. Yet due to low sedimentation rates at Lake Selina, the RPI signal is likely to be dominated by dipolar variations only. Thus, the Be ratio and RPI records from Lake Selina are expected to vary similarly and are here referred to as geomagnetic field intensity proxies. The geomagnetic field intensity low attributed to the Laschamp has an estimated duration of about $5 \mathrm{ka}$ based on the radiometric age model and the excursional directions interval extends over a longer period of about $10 \mathrm{ka}$. These durations are higher than the generally accepted $<2 \mathrm{ka}$ for the Laschamp excursion (Channell et al., 2020). While this result may indicate undetected higher sedimentation rates in Lake Selina, a longer overall process duration for the Laschamp excursion was also reported from the closest available record, derived from volcanic rocks in New Zealand (Ingham et al., 2017). Korte et al. (2019) show that duration of the Laschamp can vary regionally depending on its definition and the model used. Such records of the Laschamp excursion in the Australasian region are therefore useful to document the non-uniform expression at the Earth's surface of a global phenomenon.

A second Be ratio maxima (91-95 cm depth LAN2, yellow highlight Fig. 10) does not correlate with an RPI low, but corresponds to a slight inclination shift above the GAD $+45^{\circ}$ limit and large amplitude declination change seen in N2 (however, not in N1). Thus, attributing this second event to a geomagnetic excursional feature seems speculative. We note however that its occurrence (from $26,632-32,747$ cal BP to $23,812-29,041$ cal BP; Radiometric age model) corresponds to a time period where geomagnetic intensity drops have been noted in different records, with the suggestion of two excursions at ca. 32 ka (e.g. Liddicoat and Coe, 1979; Lund et al., 2017) and ca. 26 ka (Channell et al., 2016). This timing also corresponds to a moderate Be ratio increase in core MD05-2930 from the Gulf of Papua, ca. $3500 \mathrm{~km}$ north of the Selina Lake (Simon et al., 2016a). Finally, one data point (302 $\mathrm{cm}$ depth LAN2) returning a paleomagnetic inclination departure $>45^{\circ}$ from the GAD together with 
663

664

665

666

667

668

669

670

671

672

673

674

675

676

677

678

679

680

681

682

683

684

685

686

687

688

689

690

691

692

693

694

695

696

697

698

699

700

701

702

703

704

705

706

707

large declination variations and low RPI values during MIS 5e (Fig. 9D) correspond to the age of the Blake geomagnetic excursion (ca. $125 \mathrm{ka}$ ) according to the Match-Climate age model (Fig. 12). However, due to the high organic content and low ferrimagnetic content of the interglacial sediments (facies I; Fig. 3), the paleomagnetic directions are too poorly defined (Fig. 9) to confidently attribute these results to a geomagnetic excursion. Future beryllium isotopes analysis over this interval could be useful to test this interpretation, providing that Be ratio does not suffer from ${ }^{10} \mathrm{Be}$ dilution as during the Holocene facies I (see section 4.4.3).

\subsubsection{Geomagnetic field intensity proxies}

The best agreement of the two geomagnetic field intensity proxies (RPI and Be ratio) is found over the period 20-60 ka (80-140 cm depth LAN2; Fig. 10), the same interval where Match-Climate applicability is compromised (c.f. section 5.3). We use the Be ratio as our most reliable geomagnetic field intensity proxy for Match dynamic programming (Lisiecki and Lisiecki, 2002) because it is not affected by unknown lock-in delay and can be compared to the marine Be ratio stack of similar resolution (Simon et al., 2016a). The Match-Dipole age model covers the period 20-111 ka and falls within the Radiometric age model uncertainty for the period of overlap (Fig. 12). The average estimated sedimentation rate of Match-Dipole is $1.5 \mathrm{~cm} / \mathrm{ka}$ for the Last Glacial Period facies II (MIS 2, 3, and 4), which is the same as the Radiometric age model estimate (Table 4). We note that running Match with the Lake Selina RPI data and other independent paleointensity references (GGF100k, Panovska et al., 2018; GLOPIS, Laj et al., 2014) returns similar results. Comparison of the Lake Selina geomagnetic field intensity proxies with the reference stack GLOPIS and the geomagnetic field model GGF100k (Fig. 13) illustrates that Match-Climate overestimates the age of the geomagnetic field intensity low associated with the Laschamp geomagnetic excursion ( $41 \mathrm{ka}$ ) by about $6 \mathrm{ka}$. Prior to $60 \mathrm{ka}$ and back to $80 \mathrm{ka}$, the reference curves are not readily correlatable (Fig. 13; Laj et al., 2004; Simon et al., 2016a; Panovska et al., 2018), which may reflect dating difficulties in those records and limits the performance of Match dynamic programming.

\subsection{Age models and uncertainties}

There is an overall agreement within age uncertainties between all age models developed in this study, with an overlap of two to three age models (Radiometric, Match-dipole and Match-climate) for the interval between 81-223 cm depth LAN2 (Fig. 12). An average age model can be calculated for that interval, or more practically, the appropriate chronology can be selected for a given purpose, e.g. a climate-independent chronology for paleoclimate investigations (up to $111 \mathrm{ka}$ ), and a geomagnetic-independent chronology for paleomagnetic investigations (full record) (GEOMAGIA50, Brown et al., 2015; Maglc; https://www2.earthref.org/MagIC). Our preferred age model is the combination of Radiometric (0-70 ka) and Match-Climate (70-265 ka), independently supported by the Laschamp geomagnetic excursion. This choice is based on i) the Radiometric age model having age uncertainties encompassing Match-Dipole and most of Match-Climate age models (Fig. 12), and ii) Match-Climate being considered more reliable than Match-Dipole before $60 \mathrm{ka}$, where Be ratio and RPI are not synchronized (Fig. 10) and do not agree with other dipole reconstructions (Fig. 13). We select $70 \mathrm{ka}$ as the transition point between our optimal age models (Fig. 12). For paleoclimate discussions, a second preferred age model is the combination of Radiometric (20-0 ka), MatchDipole (20-70 or $111 \mathrm{ka}$ ) and Match-Climate (70 or 111-265 ka). This second option is aligned to global dipole millennial-scale variability and the Laschamp geomagnetic excursion (Fig. 13), and it is independent of climate over the longest possible period. 
The overlap in independent age models during MIS 2-3-4 gives a means to estimate the uncertainty on ages obtained from the Match dynamic programming algorithm at Lake Selina. Match dynamic programming is deterministic; it gives one best solution and does not provide age uncertainties (Lisiecki and Lisiecki, 2002). Yet estimate of age uncertainty is desirable for the lowermost interval between 223-44 cm (111-265 ka) that only has one age model based on climate comparison (Fig. 12). The average age difference between the three overlapping chronologies is $4.4 \pm 1.6 \mathrm{ka}$ (Fig. 12 inset), which is smaller than the average uncertainty of the OSL-dated interval ( $8.2 \pm 1.9 \mathrm{ka}$ ). We use the average deviation of the Match-Climate age to the other age models (Radiometric and MatchDipole) over the interval where the three age models overlap to estimate the uncertainty on age of Match-Climate within the lowermost interval exclusively based on climate tuning. An estimated age uncertainty of $5.3 \pm 2.3 \mathrm{ka}$ is obtained. This age uncertainty estimate is comparable to the average age differences of $4.1 \pm 2.8$ ka between the Lake Selina stratigraphic transitions and the globally recognized MIS boundary ages (Lisiecki and Raymo, 2005) (Figure 12).

\section{Conclusions}

This work presents a chronostratigraphic model of Lake Selina core TAS1402, which is the oldest continuous continental archive in Tasmania. Radiometric dating (radiocarbon and OSL) and relative dating (paleomagnetism, authigenic ${ }^{10} \mathrm{Be} / 9 \mathrm{Be}$ ratio and climate comparisons) were combined to construct a chronology extending to $266 \pm 8$ ka (MIS 8). The $5.5 \mathrm{~m}$ lake sediment archive is longer than the previously recovered $4 \mathrm{~m}$ core (Colhoun et al., 1999), and the sedimentation rate estimates are $5 \mathrm{~cm} / \mathrm{ka}$ for interglacial periods and $1.5 \mathrm{~cm} /$ ka for glacial periods.

High-resolution XRF core scanning, beryllium isotopes and magnetic properties enable a matching of the sediment archive from Tasmania to ice core records of climate proxies in Antarctica. This agreement was used as a basis to date material beyond the range of radiometric methods ( $>80 \mathrm{ka}$ ) via a dynamic programming algorithm (Match; Lisiecki and Lisiecki, 2002). The interval 20-60 ka (MIS 2-3), however, returns poor correlations of climate proxies from Lake Selina to Antarctic records, in contrast to the rest of the record, and limits the application of climate comparison dating over that interval. We interpret the misfit to be caused by local controls, other than temperature, on the Lake Selina proxy inc/coh during a period of rapid climate oscillations and the arrival of humans in Tasmania (at ca. $43 \mathrm{ka}$ ). Paleomagnetic comparison over the interval 20-60 ka effectively constrains the chronology with geomagnetic field intensity proxies; authigenic ${ }^{10} \mathrm{Be} /{ }^{9} \mathrm{Be}$ ratio and relative paleointensity (RPI). The multi-method age modeling approach used here provided two preferred age models, nearly indiscernible within their uncertainties, which allows the use of a dipoleindependent ( $270 \mathrm{ka}$ to present) or a climate-independent age model (111 ka to present). The age uncertainties are lowest in the radiocarbon-dated uppermost $83 \mathrm{~cm}$ of the core $(0.8 \pm 0.4 \mathrm{ka})$ and are estimated to be within 8 ka for the entire sequence.

The period 45-35 ka (defined by the Radiometric age model) is a $14 \mathrm{~cm}$ interval that spans human arrival in Tasmania and the demise of the last remaining megafauna in this region. It has an average Radiometric age model uncertainty of $7.2 \pm 0.4 \mathrm{ka}$ and the average age difference for the three overlapping age models (Radiometric, Match-Climate, and Match-Dipole) is $2.5 \pm 1.1 \mathrm{ka}$.

This work presents the first full-vector paleomagnetic record and environmental magnetism study in Tasmania. Despite a complex magnetic mineral assemblage with magnetic concentration changes up to one order of magnitude between glacial and interglacial sediment facies, the main paleomagnetic remanence carrier is detrital oxidised (titano)magnetite throughout all sediment facies. A set of 
quality criteria were used to select the most reliable data. The paleomagnetic record from Lake Selina returns transitional paleomagnetic directions and low geomagnetic field intensity proxies (RPI and authigenic ${ }^{10} \mathrm{Be} /{ }^{9} \mathrm{Be}$ ratio) at the time of the Laschamp geomagnetic excursion. Comparison of the RPI and Be ratio with published virtual axial dipole moment reconstructions over the Last Glacial Period indicates negligible lock-in-depth and supports a genuine geomagnetic signal. Thus, providing a practical example for combining authigenic ${ }^{10} \mathrm{Be} /{ }^{9} \mathrm{Be}$ ratio and paleomagnetism to constrain the chronology of lake sediments.

\section{Data availability}

The data presented here will be available on PANGAEA: https://www.pangaea.de/. The paleomagnetic data will also be archived with the Magnetics Information Consortium (MagIC): http://earthref.org/MagIC/16529.

\section{Acknowledgements}

Thanks to the TAS1402 drilling team (Kristen K. Beck, Alexa Benson, Angelica Ramirez, William Rapuc, Anthony Romano) and the data science support team (Milan Korbel, Shashwat Pathak, Lachlan Simpson). This research was supported by use of the Nectar Research Cloud; a collaborative Australian research platform supported by the National Collaborative Research Infrastructure Strategy (NCRIS). We thank Maarten Blaauw for support with rbacon and Xiang Zhao and Andrew Roberts for assistance at the Paleomagnetism Laboratory at the Australian National University. This project was funded by the Australian Research Council Discovery Indigenous IN140100050 to M.-S. Fletcher and IN170100062 to M.-S. Fletcher and A. Lisé-Pronovost. A. Lisé-Pronovost was supported by a La Trobe University DVCR Fellowship and a University of Melbourne McKenzie Fellowship. D. Heslop was supported by the Australian Research Council (DP190100874). The ASTER AMS national facility (CEREGE, Aix en Provence) is supported by INSU/CNRS, ANR through the EQUIPEX "ASTERCEREGE" action, and IRD.

\section{References}

Abram, N, Mulvaney, R, Vimeux, F et al. 2014, Evolution of the Southern Annular Mode during the past millennium, Nature Climate Change 4 (7), 564-569.

Aitken, M.J., 1985. Thermoluminescence Dating. Academic Press, London.

Aitken, M.J., 1998. An Introduction to Optical Dating. Oxford University Press, Oxford.

Anker, S. A., Colhoun, E. A., Barton, C. E., Petersen, M., Barbetti, M., 2001. Holocene vegetation and paleoclimatic and Paleomagnetic history from Lake Johnston, Tasmania. Quatern. Res. 56, 264-274. doi: $10.1006 /$ qres.2001.2233

Augustinus, P., Fink, D., Fletcher, M., Thomas, I., 2017. Re-assessment of the mid to late Quaternary glacial and environmental history of the Boco Plain, western Tasmania. Quaternary Science Reviews, 160, 31. doi: 10.1016/j.quascirev.2017.01.015 
Barrows,T.T., John O Stone, L.Keith Fifield, Richard G Cresswell, 2002. The timing of the Last Glacial Maximum in Australia, Quaternary Science Reviews 21, 1-3, 159-173.

Barrows, T.T., Juggins, S., de Deckker, P., Calvo, E., Pelejero, C., 2007. Long-term sea surface temperature and climate change in the Australian-New Zealand region: Australian-New Zealand climate change. Paleoceanography 22 (2), PA2215.

Barton, C. E., and McElhinny, M.W., 1981. A 10,000 year geomagnetic secular variation record from three Australian maars. Geophysical Journal of the Royal Astronomical Society 67, 465-485.

Beer, J., 2012. Cosmogenic Radionuclides: Theory and Applications in the Terrestrial and Space Environments. Springer Berlin.

Blaauw, M., and Christen, J.A., 2011. Flexible paleoclimate age-depth models using an autoregressive gamma process. Bayesian Analysis 6, 457-474

Blaauw, M., 2012. Out of tune: the dangers of aligning proxy archives. Quaternary Science Reviews 36, 38-49.

Bostock, H.C., T.T. Barrows, L. Carter, Z. Chase, G. Cortese, G.B. Dunbar, M. Ellwood, B. Hayward, W. Howard, H.L. Neil, T.L. Noble, A. Mackintosh, P.T. Moss, A.D. Moy, D. White, M.J.M. Williams, L.K. Armand, 2013. A review of the Australian-New Zealand sector of the Southern Ocean over the last 30 ka (Aus-INTIMATE project), Quaternary Science Reviews 74, 35-57, https://doi.org/10.1016/j.quascirev.2012.07.018.

Bøtter-Jensen, L., Bulur, E., Duler, G. A. T., and Murray, A. S., 2000. Advances in luminescence instrument systems. Radiation Measurements, 32, 523-528.

Bourlès, D.L., Raisbeck, G.M., Yiou, F., 1989. 10Be and 9Be in Marine sediments and their potential for dating. Geochim. Cosmochim. Acta53 (2), 443-452.

Bradley, J., 1954. Geology of the West Coast Range of Tasmania. Papers and Proceedings of the Royal Society of Tasmania, Vol. 88, p. 193-243.

Braucher, R., Guillou, V., Bourlès, D.L., Arnold, M., Aumaître, G., Keddadouche, K., Nottoli, E., 2015. Preparation of ASTER in-house 10Be/9Be standard solutions. Nucl. Instrum. Methods Phys. Res., Sect. B, Beam Interact. Mater. Atoms361, 335-340.

Brennan, B. J. Beta doses to spherical grains. Radiat. Meas. 37, 299-303 (2003).

Briant, R., and Bateman, M.D., 2009. Luminescence dating indicates radiocarbon age underestimation in late Pleistocene fluvial deposits from eastern England. Journal of Quaternary Science. DOI: 10.1002/jqs.1258

Brown, M.C., F. Donadini, M. Korte, A. Nilsson, K. Korhonen, A. Lodge, S.N. Lengyel, C.G. Constable, 2015. GEOMAGIA50.v3: 1. General structure and modifications to the archeological and volcanic database, Earth Planets Space 67:83, doi:10.1186/s40623-015-0232-0.

Channell, J.E.T., Singer, B.S., Jicha, B.R., 2020. Timing of Quaternary geomagnetic reversals and excursions in volcanic and sedimentary archives, Quaternary Science Reviews 228, 106114,https://doi.org/10.1016/j.quascirev.2019.106114.

Channell, J.E.T., R.J. Harrison, I. Lascu, I.N. McCave, F.D. Hibbert, W.E.N. Austin, 2016. Magnetic record of deglaciation using FORC-PCA, sortable-silt grain size, and magnetic excursion at $26 \mathrm{ka}$, from 

doi:10.1002/2016GC006300.

Chen, L., Heslop, D., Roberts, A. P., Chang, L., Zhao, X., McGregor, H. V., Marino, G., Rodriguez-Sanz, magnetite and recording of geomagnetic paleointensity. Geochemistry, Geophysics, Geosystems, 18, 1435- 1450. https://doi.org/10.1002/2016GC006753

Chmeleff, J., von Blanckenburg, F, Kossert, K., Jakob, D., 2010. Determination of the 10Be half-life by multicollector ICP-MS and liquid scintillation counting. Nucl. Instrum. Methods Phys. Res., Sect. B, Beam Interact. Mater. Atoms268 (2), 192-199.

Clarkson, C., Jacobs, Z., Marwick, B. et al. Human occupation of northern Australia by 65,000 years ago. Nature 547, 306-310 (2017). https://doi.org/10.1038/nature22968

Colhoun, E.A., Pola, J.S., Barton, C.E. and Heijnis, H. 1999. Late Pleistocene vegetation and climate history of Lake Selina, western Tasmania. Quaternary International 57/58:5-23.

Colman, S.M., Kaufman, D.S., Bright, J., Heil, C., King, J.W., Dean, W.E., Rosenbaum, J.G., Forester, 843 R.M., Bischoff, J.L., Perkins, M., McGeehin, J.P., 2006. Age model for a continuous, ca 250-ka Quaternary lacustrine record from Bear Lake, Utah-Idaho. Quaternary Science Reviews 25, 22712282.

Constable, C.G., 1985. Eastern Australian geomagnetic field intensity over the past $14000 \mathrm{yr}$. Geophys. J. R. astr. Soc. 81, 121-130.

Constable, C.G., and M. W. McElhinny, 1985. Holocene geomagnetic secular variation records from north-eastern Australian lake sediments, Geophysical Journal International 81 (1), 103-120, https://doi.org/10.1111/j.1365-246X.1985.tb01353.x

Constable, C.G., Korte, M., Panovska, S., 2016. Persistent high paleosecular variation activity in southern hemisphere for at least 10000 years, Earth and Planetary Science Letters 453, 78-86.

Cosgrove, R 1999. Forty-two degrees south: the archaeology of Late Pleistocene Tasmania, Journal of World Prehistory 13, 357-402.

Czymzik, M., Muscheler, R., Brauer, A., Adolphi, F., Ott, F., Kienel, U., et al., 2015. Solar cycles and depositional processes in annual Be-10 from two varved lake sediment records. Earth and Planetary Science Letters 428, 44-51. https://doi.org/10.1016/j.epsl.2015.07.037

Dankers, P., 1981. Relationship between median destructive field and remanent coercive forces for dispersed natural magnetite, titanomagnetite and hematite. Geophys. J. R. Astron. Soc. 64, 447-461. climate variability off the Western Iberian margin during the last two glacial periods, Marine Geology 196 (1-2), 1-20, https://doi.org/10.1016/S0025-3227(03)00046-X. glacial culminating 65,000 years ago - Global connections and implications for human dispersal, Quaternary Science Reviews 204, 187-207. 
869

870

871

872

873

874

875

876

877

878

879

880

881

882

883

884

885

886

887

888

889

890

891

892

893

894

895

896

897

898

899

900

901

902

903

904

905

906

907

Duller, G.A.T., 2003. Distinguishing quartz and feldspar in single grain luminescence measurements. Radiation Measurements 37, 161-165.

Duller, G.A.T., 2004. Luminescence dating of Quaternary sediments: recent advances. Journal of Quaternary Science 19, 183-192.

Egli, R., 2004. Characterization of individual rock magnetic components by analysis of remanence curves, 1. Unmixing natural sediments. Stud Geophys Geod 48, 391-446

Egli, R., Chen, A. P., Winklhofer, M., Kodama, K. P., and Horng, C.-S. (2010), Detection of noninteracting single domain particles using first-order reversal curve diagrams, Geochem. Geophys. Geosyst., 11, Q01Z11, doi:10.1029/2009GC002916.Egli, R., 2013. VARIFORC: An optimized protocol for calculating non-regular first-order reversal curve (FORC) diagrams. Global and Planetary Change, 110, 302-320. https://doi.org/10.1016/j.gloplacha.2013.08.003

Falster, G., Tyler, J., Grant, K., Tibby, J., Turney, C., Löhr, S., Jacobsen, G., Kershaw, A.P., 2018. Millennial-scale variability in south-east Australian hydroclimate between 30,000 and 10,000 years ago, Quaternary Science Reviews 192, 106-122. https://doi.org/10.1016/j.quascirev.2018.05.031.

Fitzsimmons, K.E., Stern, N., Murray-Wallace, C.V., Truscott, W., Pop, C., 2015. The Mungo MegaLake Event, Semi-Arid Australia: Non-Linear Descent into the Last Ice Age, Implications for Human Behaviour. PLOS ONE 10 (6), 0127008. https://doi.org/10.1371/journal.pone.0127008

Fletcher, M.-S., and Thomas, I., 2010. A Holocene record of sea level, vegetation, people and fire from western Tasmania, Australia. The Holocene 20 (3), 351-361. https://doi.org/10.1177/0959683609351903

Fletcher, M.-S., and Moreno, P.I., 2012. Have the Southern Westerlies changed in a zonally symmetric manner over the last 14,000 years? A hemisphere-wide take on a controversial problem, Quaternary International 253, 32-46, https://doi.org/10.1016/j.quaint.2011.04.042.

Francus, P., 2015. Standardization and Calibration of X-Radiographs Acquired with the ITRAX Core Scanner. In book: (Eds Pierre Francus, Kinuyo Kanamaru, David Fortin) Micro-XRF Studies of Sediment Cores. 10.1007/978-94-017-9849-5_20

France, D. E., and F. Oldfield (2000), Identifying goethite and hematite from rock magnetic measurements of soils and sediments, J. Geophys. Res., 105, 2781- 2795.

Frank, M., Schwarz, B., Baumann, S., Kubik, P.K., Suter, M., Mangini, A., 1997. A 200 ka record of cosmogenic radionuclide production rate and geomagnetic field intensity from $10 \mathrm{Be}$ in globally stacked deep-sea sediments. Earth Planet. Sci. Lett. 149, 121-129.

Fritz, S., Baker, P., Lowenstein, T., Seltzer, G., Rigsby, C., Dwyer, G., Tapia, P.M., Arnold, K.K., Ku, T.-L., Luo, S., 2004. Hydrologic variation during the last 170,000 years in the southern hemisphere tropics of South America. Quaternary Research, 61(1), 95-104. doi:10.1016/j.yqres.2003.08.007

Galbraith, R.F., Roberts, R.G., Laslett, G.M., Yoshida, H., Olley, J.M., 1999. Optical dating of single and multiple grains of quartz from Jinmium rock shelter, northern Australia: Part I, experimental design and statistical models. Archaeometry 41, 339-364.

Gale, S.J., Cook, D., Dorrington, N.J., 2013. The eastern Australian magnetic inclination record: Dating the recent past and re-assessing the historical geomagnetic archive. The Holocene 23, 398-415. 
Garreaud, R., 2007: Precipitation and Circulation Covariability in the Extratropics. J. Climate, 20, 4789-4797, https://doi.org/10.1175/JCLI4257.1

Guerin, G., Mercier, N., Adamiec, G. (2011) Dose-rate conversion factors: update. Ancient TL 29, 5-8.

Guyard H., St-Onge G., Chapron E., Anselmetti F.S., Francus P. (2007) The Ad 1881 EarthquakeTriggered Slump And Late Holocene Flood-Induced Turbidites From Proglacial Lake Bramant, Western French Alps. In: Lykousis V., Sakellariou D., Locat J. (eds) Submarine Mass Movements and Their Consequences. Advances in Natural and Technological Hazards Research, vol 27. Springer, Dordrecht

Harrison, R.J., and Feinberg, J.M., 2008. FORCinel: an improved algorithm for calculating first-order reversal curve distributions using locally weighted regression smoothing. Geochem. Geophys. Geosystems 9, Q05016. https://doi.org/10.1029/2008GC001987.

Harrison, R., Muraszko, J., Heslop, D., Lascu, I., Muxworthy, A., \& Roberts, A., 2018. An Improved Algorithm For Unmixing First-Order Reversal Curve Diagrams Using Principal Component Analysis. Geochemistry, Geophysics, Geosystems, 19 (5), 1595-1610. https://doi.org/10.1029/2018GC007511

Hendon, H.H., Thompson, D.W.J., Wheeler, M.C., 2007. Australian rainfall and surface temperature variations associated with the Southern Hemisphere annular mode. Journal of Climate 20 (11), 24522467.

Henry, B. (2007). Magnetic Mineralogy, Changes due to Heating. In D. Gubbins \& E. Herrero-Bervera (Eds.), Encyclopedia of Geomagnetism and Paleomagnetism (pp. 512-515). Springer Netherlands. https://doi.org/10.1007/978-1-4020-4423-6_179Heslop, D., Roberts, A., Chang, L., 2014. Characterizing magnetofossils from first-order reversal curve (FORC) central ridge signatures. Geochemistry, Geophysics, Geosystems. 15. 10.1002/2014GC005291.

Hogg, A., Heaton, T., Hua, Q., Palmer, J., Turney, C., Southon, J., Bayliss, A., Blackwell, P., Boswijk, G., Bronk Ramsey, C., Petchey, F., Reimer, P., Reimer, R., \& Wacker, L. (2020). SHCal20 Southern Hemisphere calibration, 0-55,000 years cal BP. Radiocarbon, 62.

Horiuchi, K., E.L. Goldberg, K. Kobayashi, T. Oda, T. Nakamura, T. Kawai, 2001. Climate-induced variations of cosmogenic beryllium-10 in the sediments of Lake Baikal of the last 150ky from AMS, SRXRF and NAA data. Nuclear Instruments and Methods in Physics Research Section A: Accelerators, Spectrometers, Detectors and Associated Equipment 470, 1-2, 396-404, https://doi.org/10.1016/S0168-9002(01)01085-3.

Horiuchi, K., K. Kamata, S. Maejima, S. Sasaki, N. Sasaki, T. Yamazaki, S. Fujita, H. Motoyama, H. Matsuzaki, 2016. Multiple 10Be records revealing the history of cosmic-ray variations across the Iceland Basin excursion. Earth Planet. Sci. Lett. 440, 105-114.

Howard, K., and Haines, P., 2007. The geology of Darwin Crater, western Tasmania, Australia. Earth and Planetary Science Letters 260, 328-339. 10.1016/j.epsl.2007.06.007.

Huntley, D.J., Godfreysmith, D.I., Thewalt, M.L.W., 1985. Optical dating of sediments. Nature 313, 105-107.

Ingham, E., Turner, G. M., Conway, C. E., Heslop, D., Roberts, A. P., Leonard, G., Townsend, D., \& Calvert, A. (2017). Volcanic records of the Laschamp geomagnetic excursion from Mt Ruapehu, New Zealand. Earth and Planetary Science Letters, 472, 131-141. https://doi.org/10.1016/j.epsl.2017.05.023 
Jacobs, Z. \& Roberts, R. G. (2015). An improved single grain OSL chronology for the sedimentary deposits from Diepkloof Rockshelter, Western Cape, South Africa. J. Archaeol. Sci. 63, 175-192

Jouzel, J., V. Masson-Delmotte, O. Cattani, G. Dreyfus, S. Falourd, G. Hoffmann, B. Minster, J. Nouet, J. M. Barnola, J. Chappellaz, H. Fischer, J. C. Gallet, S. Johnsen, M. Leuenberger, L. Loulergue, D. Luethi, H. Oerter, F. Parrenin, G. Raisbeck, D. Raynaud, A. Schilt, J. Schwander, E. Selmo, R. Souchez, R. Spahni, B. Stauffer, J. P. Steffensen, B. Stenni, T. F. Stocker, J. L. Tison, M. Werner, E. W. Wolff, 2007. Orbital and Millennial Antarctic Climate Variability over the Past 800,000 Years. Science 10 Aug 2007: 793-796.

Kemp, C., Tibby, J., Arnold, L., Barr, C., 2019. Australian hydroclimate during Marine Isotope Stage 3: A synthesis and review. Quaternary Science Reviews 204. 10.1016/j.quascirev.2018.11.016.

Kiernan, K., Jones, R. and Ranson, D. 1983. New evidence from Fraser Cave for glacial age man in Southwest Tasmania. Nature 301:28-32

King, J.W., Banerjee, S.K., Marvin, J., 1983. A new rock-magnetic approach to selecting sediments for geomagnetic paleointensity studies: application to paleointensity for the last 4000 years. J. Geophys. Res. 88, 5911-5921.

Kirschvink, J.L., 1980. The least-squares line and plane and the analysis of paleomagnetic data. Geophys. J. Roy. Astr. Soc. 62, 699-718.

Korschinek, G., Bergmaier, A., Faestermann, T., Gerstmann, U.C., Knie, K., Rugel, G., Wallner, A., Dillmann, I., Dollinger, G., Lierse von Gostomski, Ch., Kossert, K., Maiti, M., Poutivtsev, M., Remmert, A., 2010. A new value for the half-life of $10 \mathrm{Be}$ by heavy-ion elastic recoil detection and liquid scintillation counting. Nucl. Instrum. Methods Phys. Res. B268 (2), 187-191.

Korte, M., Maxwell C. Brown, Sydney R. Gunnarson, Andreas Nilsson, Sanja Panovska, Ingo Wardinski, Catherine G. Constable, 2019. Refining Holocene geochronologies using palaeomagnetic records, Quaternary Geochronology 50, 47-74. https://doi.org/10.1016/j.quageo.2018.11.004. Mineral Assemblages from Low Temperature Magnetic Behavior. Frontiers in Earth Science, 5, 61.

Laj, C., and Channell, J. E. T., 2015. "Geomagnetic excursions," Treatise in Geophysics, 2nd Edition, Vol. 5: Geomagnetism, eds G. Schubert and M. Kono (Amsterdam: Elsevier), 343-386.

977 Laj, C., Kissel, C., Beer, J., 2004. High Resolution Global Paleointensity Stack since 75 kas (GLOPIS-75) 978 calibrated to absolute values, in Timescales of the Geomagnetic Field, eds J. E. T. Channell, D. V. K. 979 Kent, W. Lowrie, and J. G. Meert (AGU Monogr. Ser. vol. 145) (Washington, DC: American 980 Geophysical Union), 255-265. doi: 10.1029/145gm19

981 Lal, D. and Peters, B., 1967. Cosmic rays produced radioactivity on the Earth. Cosmic Rays II, Handbuch der Physik / Encyclopedia of Physick, Vol. 46, No. 2, pp. 551-612 Berlin, Springer-Verlag variability in high-resolution ice core data from Dome C, Antarctica, Clim. Past 8, 609-623, https://doi.org/10.5194/cp-8-609-2012 
Lisé-Pronovost, A, G. St-Onge, C. Gogorza, G. Jouve, P. Francus, B. Zolitschka, 2014. Rock-magnetic signature of precipitation and extreme runoff events in south-eastern Patagonia since 51,200 cal BP from the sediments of Laguna Potrok Aike, Quaternary Science Reviews 98, 110-125, https://doi.org/10.1016/j.quascirev.2014.05.029.

Lisé-Pronovost, A., Fletcher, M.S., Mallett, T., Mariani, M., Lewis, R., Gadd, P., Herries, A., Blaauw, M., Heijnis, H., Hodgson, D., Pedro, J., 2019a. Scientific Drilling of Lake Sediments at Darwin Crater, Tasmania. Scientific Drilling 25, 1-14. https://doi.org/10.5194/sd-25-1-2019

Lisé-Pronovost, A., F. Salomon, J.-P. Goiran, G. St-Onge, A.I.R. Herries, J.-C. Montero-Serrano, D. Heslop, A.P. Roberts, V. Levchenko, A. Zawadzki, H. Heijnis, 2019b. Dredging and canal gate technologies in Portus, the ancient harbour of Rome, reconstructed from event stratigraphy and multi-proxy sediment analysis. Quaternary International 511, 78-93.

Lisiecki, L. E., and Lisiecki, P. A., 2002. Application of dynamic programming to the correlation of paleoclimate records, Paleoceanography, 17(D4), 1049, doi:10.1029/2001PA000733.

Lisiecki, L. E., and M. E. Raymo, 2005. A Pliocene-Pleistocene stack of 57 globally distributed benthic d180 records, Paleoceanography 20, PA1003, doi:10.1029/2004PA001071.

Liu, Q., Roberts, A.P., Larrasoana, J.C., Banerjee, S.K., Guyodo, Y., Tauxe, L. and Oldfield, F., 2012. Environmental magnetism: principles and applications. Reviews of Geophysics, 50(4).

Lund, S., L. Benson, R. Negrini, J. Liddicoat, S. Mensing, 2017. A full-vector paleomagnetic secular variation record (PSV) from Pyramid Lake (Nevada) from 47-17 ka: Evidence for the successive Mono Lake and Laschamp Excursions, Earth and Planetary Science Letters 458, 120-129, https://doi.org/10.1016/j.epsl.2016.09.036.

Lurcock, P. C. and G. S. Wilson, 2012. PuffinPlot: A versatile, user-friendly program for paleomagnetic analysis, Geochemistry, Geophysics, Geosystems, 13, Q06Z45, doi:10.1029/2012GC004098

Long, H. and Shen, J., 2014. Underestimated 14C-based chronology of late Pleistocene high lake-level events over the Tibetan Plateau and adjacent areas: Evidence from the Qaidam Basin and Tengger Desert. Science China: Earth Sciences, doi: 10.1007/s11430-014-4993-2.

Mackintosh, A. N., Barrows, T. T., Colhoun, E. A. and Fifield, L. K. 2006. Exposure dating and glacial reconstruction at Mt. Field, Tasmania, Australia, identifies MIS 3 and MIS 2 glacial advances and climatic variability. J. Quaternary Sci. 21, 363-376. ISSN 0267-8179

Maxbauer, D.P., Feinberg, J.M., Fox, D.L., 2016. MAX UnMix: A web application for unmixing magnetic coercivity distributions. Computers \& Geosciences 95, 140-145.

Muscheler, R., Jürg Beer, Peter W. Kubik, H.-A. Synal, 2005. Geomagnetic field intensity during the last 60,000 years based on $10 \mathrm{Be}$ and $36 \mathrm{Cl}$ from the Summit ice cores and $14 \mathrm{C}$, Quaternary Science Reviews 24, 16-17, 1849-1860, https://doi.org/10.1016/j.quascirev.2005.01.012.

Nathan, R.P., Mauz, B., 2008. On the dose-rate estimate of carbonate-rich sediments for trapped charge dating. Radiation Measurements 43, 14-25.

Nesje, A., 1992. A Piston Corer for Lacustrine and Marine Sediments. Arct. Alp. Res. 24, 603 257259.https://doi.org/10.1080/00040851.1992.12002956

Nilsson, A., Muscheler, R, Snowball, I, Aldahan, A, Possnert, G, Augustinus, P, Atkin, D., Stephens, T., 2011, Multi-proxy identification of the Laschamp geomagnetic field excursion in Lake Pupuke, New 
Zealand, Earth and Planetary

Science

Letters

311,

1-2,

155-164.

1029 https://doi.org/10.1016/j.epsl.2011.08.050

1030

Nilsson, A., Suttie Neil, Hill Mimi J., 2018. Short-Term Magnetic Field Variations From the Postdepositional Remanence of Lake Sediments. Frontiers in Earth Science 6, 1-39. DOI=10.3389/feart.2018.00039

1033

O'Connell, C.S., Ruan, L. \& Silver, W.L, 2018. Drought drives rapid shifts in tropical rainforest soil

1034 biogeochemistry and greenhouse gas emissions. Nat Commun 9, 1348. https://doi.org/10.1038/s41467-018-03352-3

1036

1037

1038

1039

1040

1041

1042

1043

1044

1045

1046

1047

1048

1049

1050

1051

1052

1053

1054

1055

1056

1057

1058

1059

1060

1061

1062

1063

1064

1065

1066

1067

Pahnke, K., 2003. 340,000-Year centennial-scale marine record of Southern Hemisphere climatic oscillation. Science 301, 948-952.

Panovska, S., M. Korte, C. C. Finlay, C. G. Constable, 2015. Limitations in paleomagnetic data and modelling techniques and their impact on Holocene geomagnetic field models, Geophysical Journal International 202, Issue 1, 402-418, https://doi.org/10.1093/gji/ggv137

Panovska, S., Constable, C. G., Korte, M., 2018. Extending global continuous geomagnetic field reconstructions on timescales beyond human civilization. Geochem. Geophys. Geosys. 19, 47574772. doi: $10.1029 / 2018 G C 007966$

Peters, C. and Thompson, R., 1998. Magnetic Identification of Selected Natural Iron Oxides and Sulphides, Journal of Magnetism and Magnetic Materials, Vol. 183, No. 4, 365-374. doi:10.1016/S0304-8853(97)01097-4

Peters, C., and M. J. Dekkers, 2003. Selected room temperature magnetic parameters as a function of mineralogy, concentration and grain size, Phys. Chem. Earth 28, 659-667, doi:10.1016/S14747065(03)00120-7.

Petherick, L., Bostock, H., Cohen, T. J., Fitzsimmons, K., Tibby, J., Fletcher, M. -S., Moss, P., Reeves, J., Mooney, S., Barrows, T., Kemp, J., Jansen, J., Nanson, G. \& Dosseto, A. (2013). Climatic records over the past 30 ka from temperate Australia - a synthesis from the Oz-INTIMATE workgroup. Quaternary Science Reviews 74 58-77.

Pigati, J.S., et al. 2007. Development of low-background vacuum extraction and graphitization systems for $14 \mathrm{C}$ dating of old (40-60 ka) samples. Quaternary International 166, 4-14.

Prescott, J.R., Hutton, J.T., 1994. Cosmic-ray contributions to dose rates for luminescence and ESR dating: large depths and long-term time variations. Radiation Measurements 23, 497-500.

Pugh, R., Mccave, I., Hillenbrand, Claus-Dieter, Kuhn, Gerhard, 2009. Circum-Antarctic age modelling of Quaternary marine cores under the Antarctic Circumpolar Current: Ice-core dust-magnetic correlation. Earth and Planetary Science Letters 284, 113-123. 10.1016/j.epsl.2009.04.016.

Roberts, A.P., 2008. Geomagnetic excursions: Knowns and unknowns, Geophys. Res. Lett., 35, L17307, doi:10.1029/2008GL034719.

Roberts, A.P., and Winklhofer, M., 2004. Why are geomagnetic excursions not always recorded in sediments? Constraints from post-depositional remanent magnetization lock-in modelling. Earth Planet. Sci. Lett. 227, 345-359. doi: 10.1016/j.epsl.2004.07.040

Roberts, A.P., Chang, L., Rowan, C. J., Horng, C.-S., and Florindo, F., 2011. Magnetic properties of sedimentary greigite (Fe3S4): An update, Rev. Geophys. 49, RG1002, doi:10.1029/2010RG000336 
1068

1069

1070

1071

1072

1073

1074

1075

1076

1077

1078

1079

1080

1081

1082

1083

1084

1085

1086

1087

1088

1089

1090

1091

1092

1093

1094

1095

1096

1097

1098

1099

1100

1101

1102

1103

1104

1105

1106

1107

Roberts, A.P., L. Tauxe, D. Heslop, 2013. Magnetic paleointensity stratigraphy and high-resolution Quaternary geochronology: successes and future challenges. Quat. Sci. Rev. 61, 1-16

Roberts, R.G., Jacobs, Z., Li, B., Jankowski, N.R., Cunningham, A.C., Rosenfeld, A.B., 2015. Optical dating in archaeology: thirty years in retrospect and grand challenges for the future. Journal of Archaeological Science 56, 41-60.

Roberts, R.G., Flannery, T.F., Ayliffe, L.K., Yoshida, H., Olley, J.M., Prideaux, G.J., Laslett, G.M., Baynes, A., Smith, M.A., Jones, R., Smith, B.L., 2001. New Ages for the Last Australian Megafauna: Continent-Wide Extinction About 46,000 Years Ago, Science 292, 5523, 1888-1892. 10.1126/science.1060264

Rohling E.J., et al. 2017. Differences between the last two glacial maxima and implications for icesheet, 8180, and sea-level reconstructions. Quat. Sci. Rev. 2017;176:1-28. doi: 10.1016/j.quascirev.2017.09.009.

Roucoux, K. H., Tzedakis, P. C., Lawson, I. T., \& Margari, V., 2011. Vegetation history of the penultimate glacial period (Marine Isotope Stage 6) at loannina, north-west Greece. Journal of Quaternary Science 26, 616-626.https://doi.org/10.1002/jqs.1483

Ruddiman, W. F., 2006. Orbital changes and climate, Quaternary Science Reviews 25 (23-24), 30923112, https://doi.org/10.1016/j.quascirev.2006.09.001

Rule, S., B. W. Brook, S. G. Haberle, C. S. M. Turney, A. P. Kershaw, C. N. Johnson, 2012. The aftermath of megafaunal extinction: Ecosystem transformation in Pleistocene Australia. Science 335, $1483-1486$.

Saltré, F., Chadoeuf, J., Peters, K.J. et al. 2019. Climate-human interaction associated with southeast Australian megafauna extinction patterns. Nat Commun 10, 5311 doi:10.1038/s41467-019-13277-0

Shanahan, T.M., J.A. Peck, N. McKay, C.W. Heil, J. King, S.L. Forman, D.L. Hoffmann, D.A. Richards, J.T. Overpeck, C.A. Scholz, 2012. Age models for long lacustrine sediment records using multiple dating approaches - an example from Lake Bosumtwi, Ghana. Quat. Geochronol., 15, 47-60.

Simon, Q., Ledru, M.-P., Sawakuchi, A. O., Favier, C., Mineli, T. D., Grohmann, C. H., Guedes, M., Bard, E., Thouveny, N., Garcia, M., Tachikawa, K., \& Rodríguez-Zorro, P. A ., 2020a . Chronostratigraphy of a 1.5 $\pm 0.1 \mathrm{Ma}$ composite sedimentary record from Colônia basin (SE Brazil): Bayesian modeling based on paleomagnetic, authigenic $10 \mathrm{Be} / 9 \mathrm{Be}$, radiocarbon and luminescence $\begin{array}{llll}\text { dating. } & \text { Quaternary } & \text { Geochronology, } & \end{array}$ https://doi.org/https://doi.org/10.1016/j.quageo.2020.101081

Simon, Q., Thouveny, N., Bourlès, D.L., Valet, J-P., Bassinot, F., 2020b. Cosmogenic 10Be production records reveal dynamics of geomagnetic dipole moment (GDM) over the Laschamp excursion (20-60 ka). Earth Planet. Sci. Lett. 550, 116547.

Simon, Q., Suganuma, Y., Okada, M., Haneda, Y., ASTER Team, 2019. High-resolution 10Be and paleomagnetic recording of the last polarity reversal in the Chiba composite section: Dynamics of the Matuyama-Brunhes transition. Earth Planet. Sci. Lett. $\quad$ 519, 92-100.

Simon, Q., Bourlès, D.L., Thouveny, N., Horng, J., Valet, J-P., Bassinot, F., Choy, S., 2018 Cosmogenic signature of geomagnetic reversals and excursions from the Réuion event to the Matuyama-Brunhes transition (0.7 - 2.14 Ma interval). Earth Planet. Sci. Lett. $\quad$ 482, 510-524. 
Simon, Q., Thouveny, N., Bourlès, D.L., Bassinot, F., Valet, J -P., Ménabréaz, L., Guillou, V., Choy, S., Beaufort, L., 2016a. Authigenic $10 \mathrm{Be} / 9 \mathrm{Be}$ ratio signatures of the cosmogenic nuclide production linked to geomagnetic dipole moment variation since the Brunhes/Matuyama boundary, J. Geophys. Res. Solid Earth 121, 10.1002/2016JB013335.

Simon, Q., Thouveny, N., Bourlès, D.L., Nuttin, L., St-Onge, G., Hillaire-Marcel, C., 2016b. Authigenic 10Be/9Be ratios and 10Be-fluxes (230Thxs-normalized) in central Baffin Bay during the last glacial cycle: Paleoenvironmental implications. Quat. Sci. Rev. 140, 142-162.

Sniderman, J. M. K., Hellstrom, J., Woodhead, J. D., Drysdale, R. N., Bajo, P., Archer, M., Hatcher, L., 2019. Vegetation and climate change in southwestern Australia during the Last Glacial Maximum. Geophysical Research Letters 46, 1709-1720. https://doi.org/10.1029/2018GL080832

St-Onge, G., Mulder, T., Piper, D.J.W., Hillaire-Marcel, C. \& Stoner, J.S., 2004. Earthquake and flood induced turbidites on the Saguenay Fjord (Québec): a Holocene paleoseismicity record. Quaternary Science Reviews, 23, 283-294.

Suganuma, Y., Y. Yokoyama, T. Yamazaki, K. Kawamura, C.-S. Horng, H. Matsuzaki, 2010. 10Be evidence for delayed acquisition of remanent magnetization in marine sediments: implication for a new age for the Matuyama-Brunhes boundary. Earth Planet. Sci. Lett., 296. 443450,10.1016/j.epsl.2010.05.031

Suganuma, Y., Okuno, J., Heslop, D., Roberts, A.P., Yamazaki, T., Yokoyama, Y., 2011. Postdepositional remanent magnetization lock-in for marine sediments deduced from 10Be and paleomagnetic records through the Matuyama-Brunhes boundary. Earth Planet. Sci. Lett. 311, 39-52.

Tang, L., Zhou, W., Wang, X., Xian, F., Du, Y., Zhou, J., et al., 2019. Multidecadal- to centennial-scale 10Be variations in Holocene sediments of Huguangyan Maar Lake, South China. Geophysical Research Letters 46, 7634-7642. https://doi.org/10.1029/2019GL082863

Valet, J -P, F. Bassinot, A. Bouilloux, D.L. Bourlès, S. Nomade, V. Guillou, F. Lopes, N. Thouveny, F. Dewilde, 2014. Geomagnetic, cosmogenic and climatic changes across the last geomagnetic reversal from Equatorial Indian Ocean sediments. Earth Planet. Sci. Lett., 397, 67-79.

Valet, J-P., Bassinot, F., Simon, Q., Savranskaia, T., Thouveny, N., Bourlès, D.L., 2019. Constraining the age of the last geomagnetic reversal from geochemical and magnetic analyses of Atlantic, Indian, and Pacific Ocean sediments. Earth Planet. Sci. Lett. 506, 323-331.

Van der Kaars, S., Miller, G., Turney, C., Cook, E., Nuernberg, D., Schönfeld, J., Kershaw, P., Lehman, S., 2017. Humans rather than climate the primary cause of Pleistocene megafaunal extinction in Australia. Nature Communications 8. 14142. 10.1038/ncomms14142.

Veres, D., Bazin, L., Landais, A., Toye Mahamadou Kele,H., Lemieux-Dudon, B., Parrenin, F., Martinerie, P., Blayo, E., Blunier, T., Capron, E., Chappellaz, J., Rasmussen, S., Severi, M., Svensson, A., Vinther, B., and Wolff, E., 2013. The Antarctic ice core chronology (AICC2012): an optimized multi-parameter and multi-site dating approach for the last 120 thousand years, Climate of the Past 9, 1733-1748, doi:10.5194/cp-9-1733-2013

Willenbring, J.K., von Blanckenburg, F., 2010. Meteoric cosmogenic beryllium-10 adsorbed to river sediment and soil: applications for Earth-surface dynamics. Earth-Sci. Rev. 98, 105-122. 
Williams, M., Cook, E., van der Kaars, S., Barrows, T., Shulmeister, J., Kershaw, P., 2009. Glacial and 1148 deglacial climatic patterns in Australia and surrounding regions from 35000 to 10000 years ago 1149 reconstructed from terrestrial and nearshore proxy data. Quat. Sci. Rev. 28, 2398-2419.

1150 Wintle, A.G., 2014. Luminescence dating methods. In: Holland, H.D., Turekian, K.K. (Eds), Treatise on 1151 Geochemistry (second edition), vol. 14, pp. 17-35. Elsevier, Oxford.

1152 Wintle A.G., 1997. Luminescence dating: laboratory procedures and protocols. Radiation 1153 Measurements 27, 769-817.

1154 Wintle, A.G. and Murray, A., 2006. A review of optically stimulated luminescence characteristic and 1155 their relevance in single-aliquot regeneration dating protocols. Radiation Measurements 41. 3691156 391.10.1016/j.radmeas.2005.11.001.

1157 Woodward, C.A. and Gadd, P.S. 2018. The potential power and pitfalls of using the X-ray 1158 fluorescence molybdenum incoherent: Coherent scattering ratio as a proxy for sediment organic 1159 content, Quaternary International 514, 30-43.10.1016/j.quaint.2018.11.031

1160 Wroe, S. and Field, J., 2006. A review of the evidence for a human role in the extinction of Australian 1161 Megafauna and an alternative explanation. Quaternary Science Reviews 25. 2692-2703. 


\section{FIGURE CAPTIONS}

Figure 1. Site location A) in the Southern Hemisphere mid-latitudes and B) in the West Coast Range of Tasmania where rainfall is strongly correlated to the westerly winds. A and B are modified from LisePronovost et al (2019). C) Two sites were cored in the approximate center of Lake Selina. The $10 \mathrm{~m}$ contours and hydrographic data are from Land Information System Tasmania (LIST) and the satellite imagery from ESRI.

Figure 2. A) Cores LA, N1 and N2 simplified lithology, correlation and sampling. Note the different thickness of the Last Glacial Period sediment facies in cores N1 and N2. Individual core sections are indicated to the left of each lithology log. Core section N2-A was divided in sub-sections a and b after a sediment gap formed during splitting. Black zones indicate sampling locations for radiocarbon $\left({ }^{14} \mathrm{C}\right)$, magnetic analysis (mag), optically stimulated luminescence (OSL), and beryllium isotopes (Be). B) Large amplitude change in the XRF ratio Inc/coh is used to correlate the gravity core LA with the Nesje cores N1 and N2. C) The composite depth LAN2 is the reference depth scale used in this work. Data from core N1 is transferred to LAN2 depth using a series of 24 stratigraphic tie-points (they are the horizontal lines of the stratigraphic log) and linear interpolation.

Figure 3. Physical, elemental and magnetic properties of core TAS1402. Upper panel: XRF and beryllium data including pass-through radiation (RAD; density proxy), incoherence/coherence (Inc/coh; organic content proxy), authigenic ${ }^{10} \mathrm{Be}$ and ${ }^{9} \mathrm{Be}$ isotopes and elemental ratio $\mathrm{Pb} / \mathrm{Al}$ (local runoff proxies), and $\mathrm{Ti} / \mathrm{K}$ (detrital grain size proxy). Middle panel: magnetic properties including the remanence ratio kARM/IRM, median destructive field of the anhysteretic remanent magnetisation $\left(\mathrm{MDF}_{\mathrm{ARM}}\right)$, and magnetisation ratio (Mr/Ms) (magnetic grain size proxies), S-ratio (proportion of low coercivity minerals), HIRM (content of high coercivity minerals). Lower panel: ferrimagnetic content proxies including the volumetric magnetic susceptibility $\left(k_{L F}\right)$, natural remanent magnetisation (NRM) on log and linear scales, anhysteretic and isothermal remanent magnetizations (ARM and IRM). The simple lithology log with sediment facies is shown for the reference depth LAN2. The overlapping section N2-A for the magnetic grain size proxies is shown to illustrate finer particles are deposited at site N2 compared to site N1. Grey shading indicates facies IIa intervals with approximately one order of magnitude greater remanence acquisition efficiency.

Figure 4. Principal component analysis biplot of the micro-XRF core scanning data. The length and color of the arrow reflect the contribution per variable.

Figure 5. A) Measured moisture contents for OSL and DOS samples between 81 and $190 \mathrm{~cm}$ depth LAN2, where OSL ages were obtained. B) Gamma dose rates for the same OSL and DOS samples derived from ICPMS(OES) measurements of $U$, Th and $K$ and used for age determination. $C$ ) Beta dose rates for the same OSL and DOS samples obtained from GM-25-5 beta counting and used for age determination. D) The ratio of beta dose rates derived from GM-25-5 beta counting and ICP-MS(OES) measurements for the same OSL and DOS samples. The stippled line denotes unity. Error bars are all one standard error. The simple lithology log with sediment facies is shown.

Figure 6. A) Age-depth model from Bayesian modeling (rbacon; Blaauw and Christen, 2011) of calibrated radiocarbon $\left({ }^{14} \mathrm{C}\right.$ ) and optically stimulated luminescence (OSL) ages (Tables 1 and 2). The OSL ages are 
obtained from core $\mathrm{N} 1$ and transferred to the reference depth LAN2 based on stratigraphic correlations (Supplementary Material 2). B) Contamination effect on radiocarbon ages (Pigati et al., 2007) explains the excluded "too young" ${ }^{14} \mathrm{C}$ ages that plateau at ca. $40 \mathrm{ka} \mathrm{BP.}$

Figure 7. Magnetic mineralogy of Lake Selina interglacial sediments (facies I) and glacial sediment (facies II). Representative sample N1-A18 (81.8 cm depth LAN2) for facies I includes A) hysteresis loop, B) thermomagnetic curves of (top panel) magnetic remanence measured from room temperature to 10 Kelvin saturation isothermal remanent magnetisation (RTSIRM), and (base panel) magnetic susceptibility up to 700 ${ }^{\circ} \mathrm{C}$, C) unmixed magnetic populations (P1, P2, P3) of the isothermal remanent magnetisation (IRM) acquisition curve (MaxUnmix; Maxbauer et al., 2016), and D) first order reversal curve (FORC) diagram (FORCinel; Harrison and Feinberg, 2008). Representative sample N1-C37 (365.3 cm depth LAN2) for facies II includes E) hysteresis loop, F) thermomagnetic curves, G) unmixed magnetic populations (MaxUnmix; Maxbauer et al., 2016), and H) FORC diagram (FORCinel; Harrison and Feinberg, 2008).

Figure 8. The biplot of the magnetic remanence ratios IRM(-300mT)/SIRM and ARM(40mT)/SARM informs on the mineralogy of the remanence carriers (Peters and Thompson, 1998). Greater ARM hardness (ARM(40mT)/SARM) in facies I also reflects finer magnetic grain size than in facies II (visible in Fig. 2).

Figure 9. Paleomagnetic directions results for $\mathrm{A}$ ) raw data and B) data after selection criteria, and relative paleointensity estimates for $C$ ) raw data and $D$ ) selected data. A line is not used to connect the data points from duplicate core N2-A (blue) because of possibly disturbed stratigraphy. Grey shading indicates the nonselected intervals with approximately one order of magnitude greater remanence acquisition efficiency (cf. Figure 3). A few individual samples display peak values (out of scale) interpreted as having NRM overprint.

Figure 10. The paleomagnetic record from Lake Selina uppermost $2.25 \mathrm{~m}$ combines sediment magnetic remanence and authigenic beryllium isotopes. From left to right; the paleomagnetic inclination, relative declination and geomagnetic field intensity proxies (Be ratio and RPI). A line is not used to connect the data points from duplicate core N2-A (blue) because of possibly disturbed stratigraphy. The yellow rectangle at 100-117 cm depth LAN2 indicates excursional directions (duration about $10 \mathrm{kyr}$ ) and intensity (duration about $5 \mathrm{kry}$ ) at the time of the Laschamp geomagnetic excursion. The yellow rectangle at $91-95 \mathrm{~cm}$ depth LAN2 indicates a younger Be ratio maxima, however with inconclusive magnetic remanence results. The geomagnetic field intensity proxies are scaled and the Be ratio axis is reversed. The grey highlight indicates the best fit among geomagnetic field intensity proxies where lock-in depth in RPI appears to be absent.

Figure 11. Proxy data from Lake Selina (this study) and Antarctica EDC ice core (Jouzel et al, 2007; Lambert et al, 2012; Veres et al, 2013) used to build the Match-Climate age model using Match dynamic programing (Liesicki and Liesicki, 2002). A) Temperature proxies incoherence/coherence (inc/coh; this study) and dD (Jouzel et al, 2007), and B) atmospheric circulation proxies Pb/Al (this study) and dust flux (Lambert et al, 2012). The top two curves from Lake Selina are versus depth and Match-Climate age, and the lower curves are the reference proxy data from Antarctica on the Antarctic Ice Core Chronology 2012 (Veres et al, 2013). Vertical dashed lines indicate the six tie-points used for Match programming. Correlation coefficients are indicated for the Match-Climate dated interval 18-266 ka and for the highlighted interval in grey representing the period 20-60 ka (MIS2 and 3). 
Figure 12. Lake Selina age-depth models. Age of selected stratigraphic changes are indicated on the right according to the age models Radiometric, Match-Climate and Match-Dipole, and compared to the MIS boundary ages (Liesicki and Raymo, 2005). The interpreted MIS for Lake Selina are indicated next to the simplified stratigraphic log.

Figure 13. Lake Selina geomagnetic field intensity proxies (Be ratio and RPI) on the age-depth models A) Radiometric, B) Match-Climate, and C) Match-Dipole, compared to D) dipole references (Be stack, Simon et al., 2016; GLOPIS, Laj et al, 2014; GGF100k, Panovska et al, 2018). The highlighted interval in grey represents the period 20-60 ka (MIS2 and 3) and the best fit interval between RPI and Be ratio defined in Fig. 10. Yellow shading indicates the geomagnetic intensity low associated to the Laschamp excursion (41 ka). The comparison illustrates the age overestimation of Match-Climate over the period 20-60 ka BP because of poor correlation in climate proxies (Fig. 9) and possibly disturbed stratigraphy of core N2-A. Note the different trends in dipole references for the period 60-80 ka BP. 
Table 1. Radiocarbon ages from TAS1402. The selected samples for age-depth modelling are bold.

\begin{tabular}{|c|c|c|c|c|c|c|c|c|c|}
\hline Lab ID & Core & $\begin{array}{c}\text { Section } \\
\text { depth }(\mathrm{cm})\end{array}$ & $\begin{array}{c}\text { Depth } \\
\text { LAN2 }(\mathrm{cm})\end{array}$ & $\begin{array}{c}\text { +/- error } \\
\text { depth }\end{array}$ & $\begin{array}{c}\text { Radiocarbon } \\
\text { age }\end{array}$ & $\begin{array}{r}\text { error (1 } \\
\text { sigma) }\end{array}$ & $\begin{array}{c}\text { Min } \\
\text { Calibrated } \\
\text { age (cal } \\
\text { BP) }\end{array}$ & $\begin{array}{c}\text { Max } \\
\text { Calibrated } \\
\text { age (cal } \\
\text { BP) } \\
\end{array}$ & $\begin{array}{c}\text { Mean Age } \\
\text { (cal BP) }\end{array}$ \\
\hline surface & & & 0.0 & & -64 & & & & -64 \\
\hline D-AMS 009187 & LA & $11-11.5$ & 11.3 & 0.3 & 2614 & 27 & 2548 & 2756 & 2652 \\
\hline D-AMS 012498 & LA & $13.75-14$ & 13.9 & 0.1 & 3649 & 28 & 3876 & 3978 & 3927 \\
\hline D-AMS 017905 & LA & $17.25-18$ & 17.6 & 0.4 & 4589 & 26 & 5063 & 5317 & 5190 \\
\hline D-AMS 017906 & LA & $30.5-31$ & 30.8 & 0.3 & 7194 & 33 & 7945 & 8010 & 7978 \\
\hline D-AMS 009086 & LA & $37-37.5$ & 37.3 & 0.3 & 8515 & 39 & 9478 & 9531 & 9505 \\
\hline D-AMS 014240 & LA & $42.25-42.5$ & 42.4 & 0.1 & 8723 & 36 & 9553 & 9672 & 9613 \\
\hline D-AMS 014241 & LA & $52.25-52.5$ & 52.4 & 0.1 & 10414 & 35 & 12147 & 12462 & 12305 \\
\hline D-AMS 014242 & LA & $62.25-62.5$ & 62.4 & 0.1 & 11726 & 41 & 13496 & 13594 & 13545 \\
\hline D-AMS 014243 & LA & $67.75-68$ & 67.9 & 0.1 & 12123 & 40 & 13860 & 14060 & 13960 \\
\hline D-AMS 014244 & LA & 72.25-72.5 & 72.4 & 0.1 & 12457 & 53 & 14327 & 14834 & 14581 \\
\hline D-AMS 015348 & N2-A & $23-23.25$ & 73.1 & 0.1 & 12965 & 44 & 15356 & 15556 & 15456 \\
\hline D-AMS 015349 & N2-A & $30-30.25$ & 80.1 & 0.1 & 14736 & 50 & 17948 & 18144 & 18046 \\
\hline D-AMS 015350 & N2-A & $34-34.25$ & 84.1 & 0.1 & 22857 & 86 & 27135 & 27259 & 27197 \\
\hline D-AMS 009079 & N2-A & $37-37.5$ & 87.3 & 0.3 & 19048 & 71 & 22909 & 23016 & 22963 \\
\hline D-AMS 027826 & $\mathrm{~N} 2-\mathrm{A}$ & $38-38.25$ & 88.1 & 0.1 & 25130 & 106 & 29158 & 29503 & 29331 \\
\hline D-AMS 027827 & $\mathrm{~N} 2-\mathrm{A}$ & $46.5-46.75$ & 96.6 & 0.1 & 16581 & 61 & 19893 & 20087 & 19990 \\
\hline D-AMS 027828 & $\mathrm{~N} 2-\mathrm{A}$ & $56.75-57$ & 106.9 & 0.1 & 18510 & 68 & 22333 & 22449 & 22391 \\
\hline D-AMS 027829 & $\mathrm{~N} 2-\mathrm{A}$ & $62.5-62.75$ & 112.6 & 0.1 & 32971 & 180 & 37067 & 37557 & 37312 \\
\hline D-AMS 009080 & N2-A & $64.75-65.25$ & 115.0 & 0.3 & 32778 & 181 & 36881 & 37380 & 37131 \\
\hline D-AMS 027830 & N2-A & $70-70.25$ & 120.1 & 0.1 & 37330 & 276 & 41859 & 42160 & 42010 \\
\hline D-AMS 027831 & $\mathrm{~N} 2-\mathrm{A}$ & $77-77.25$ & 127.1 & 0.1 & NDFB & & & & \\
\hline D-AMS 015351 & $\mathrm{~N} 2-\mathrm{A}$ & $84-84.25$ & 134.1 & 0.1 & 34529 & 219 & 39396 & 39829 & 39613 \\
\hline D-AMS 009082 & $\mathrm{~N} 2-\mathrm{A}$ & $94.25-94.5$ & 144.4 & 0.1 & 37542 & 249 & 41985 & 42214 & 42100 \\
\hline D-AMS 015352 & $\mathrm{~N} 2-\mathrm{A}$ & $102-102.25$ & 152.1 & 0.1 & 35920 & 246 & 40794 & 41205 & 41000 \\
\hline D-AMS 009084 & $\mathrm{~N} 2-\mathrm{A}$ & $110-110.5$ & 160.3 & 0.3 & 14883 & 51 & 18146 & 18244 & 18195 \\
\hline D-AMS 015335 & $\mathrm{~N} 2-\mathrm{A}$ & $118-118.25$ & 168.1 & 0.1 & NDFB & & & & \\
\hline D-AMS 009088 & N2-B & $12.5-13$ & 183.8 & 0.3 & 33494 & 182 & 37750 & 38718 & 38234 \\
\hline D-AMS 015354 & $\mathrm{~N} 2-\mathrm{B}$ & $24.5-24.75$ & 195.6 & 0.1 & NDFB & & & & \\
\hline D-AMS 015355 & N2-B & $48.25-48.5$ & 219.4 & 0.1 & NDFB & & & & \\
\hline
\end{tabular}


Table 2. Dose rate data, equivalent dose $\left(D_{e}\right)$ and overdispersion (OD) values, and ages from core TAS1402-N1. The samples core section depths were transferred to LAN2 equivalent depth (Sup. Mat. Table 1).

Environmental dose rate (Gy/ka)

Average Water

Section depth LAN2 content

No of

Sample Core depth $(\mathrm{cm})$

(cm)

\begin{tabular}{cccccc} 
(\%) & Gamma & Beta & Cosmic & Alpha & Total \\
\hline $40(30)$ & $0.75 \pm 0.05$ & $1.26 \pm 0.07$ & $0.13 \pm 0.02$ & 0.03 & $2.17 \pm 0.09$
\end{tabular}

aliquots

OSL2/3 N1-A 55-61

83.5

$\begin{array}{llllll}40(32) & 0.73 \pm 0.03 & 1.15 \pm 0.07 & 0.13 \pm 0.02 & 0.03 & 2.04 \pm 0.08\end{array}$

$10 / 10$

$55.7 \pm 2.7$

Overdispersion OSL age

OSL4 N1-A $67-74$

1022

$\begin{array}{lllllll}40(22) & 0.64 \pm 0.04 & 0.99 \pm 0.05 & 0.12 \pm 0.02 & 0.03 & 1.78 \pm 0.06 & 10 / 10\end{array}$

$49.2 \pm 1.9$

OSL5 N1-A 74-80

111.2

$\begin{array}{lllllll}40(20) & 0.64 \pm 0.03 & 1.04 \pm 0.05 & 0.12 \pm 0.02 & 0.03 & 1.83 \pm 0.06 & 9 / 10\end{array}$

$62.2 \pm 2.8$

117.2

$\begin{array}{lllllll}40(25) & 0.67 \pm 0.04 & 1.05 \pm 0.05 & 0.12 \pm 0.02 & 0.03 & 1.87 \pm 0.07 & 10 / 10\end{array}$

$75.6 \pm 4.8$

(\%)

(ka)

OSL6 N1-A 80-86

123.5

$\begin{array}{llllll}40(31) & 0.67 \pm 0.04 & 1.11 \pm 0.07 & 0.12 \pm 0.02 & 0.03 & 1.93 \pm 0.08\end{array}$

$9 / 10$

$102.1 \pm 11.5$

$113.6 \pm 7.0$

40 (32) $\quad 0.73 \pm 0.05 \quad 1.12 \pm 0.07 \quad 0.12 \pm 0.02 \quad 0.03 \quad 2.01 \pm 0.09$

$10 / 10$

$113.7 \pm 8.0$

137.3

$\begin{array}{llllll}40(30) & 0.71 \pm 0.05 & 1.27 \pm 0.07 & 0.12 \pm 0.02 & 0.03 & 2.13 \pm 0.09\end{array}$

$9 / 10$

$\begin{array}{lllllll}40(29) & 0.71 \pm 0.05 & 1.12 \pm 0.06 & 0.12 \pm 0.02 & 0.03 & 1.99 \pm 0.08 & 9 / 10\end{array}$

$144.7 \pm 7.9$

139.8

$\begin{array}{llllll}40(26) & 0.68 \pm 0.04 & 1.00 \pm 0.05 & 0.12 \pm 0.02 & 0.03 & 1.83 \pm 0.07\end{array}$

$10 / 10$

$126.4 \pm 7.5$

OSL11 N1-B 0-5

OSL12 N1-B 5-10

163.8

$\begin{array}{llllll}40(25) & 0.67 \pm 0.04 & 0.99 \pm 0.05 & 0.12 \pm 0.02 & 0.03 & 1.81 \pm 0.07\end{array}$

$9 / 10$

$138.9 \pm 5.5$

175.0

$\begin{array}{llllll}40(24) & 0.64 \pm 0.04 & 0.93 \pm 0.05 & 0.12 \pm 0.02 & 0.03 & 1.72 \pm 0.06\end{array}$

$9 / 10 \quad 143.9 \pm 6.1$

$4.8 \pm 7.6$

$4.8 \pm 7.6$

$25.7 \pm 1.7$

$14.5 \pm 5.8 \quad 35 \pm 2.1$

$11.6 \pm 6.9 \quad 41.3 \pm 3.1$

$32.2 \pm 8.7 \quad 54.6 \pm 6.6$

$14.6 \pm 5.4 \quad 58.9 \pm 4.6$

$18.8 \pm 5.7 \quad 56.7 \pm 4.8$

$11.0 \pm 5.3 \quad 67.9 \pm 4.9$

$15.6 \pm 4.8 \quad 63.6 \pm 4.8$

$5.8 \pm 5.6 \quad 75.8 \pm 4.4$

$30.0 \pm 8.9 \quad 79.8 \pm 9.7$

$21.7 \pm 6.3 \quad 83.6 \pm 5$ 
Table 3. Beryllium isotopes results. Replicate measurements are italic.

\begin{tabular}{|c|c|c|c|c|c|c|c|c|c|c|c|c|c|c|c|}
\hline \multirow{2}{*}{$\frac{\text { Sample }}{1}$} & \multirow{2}{*}{$\frac{\text { Core }}{\text { N1-A }}$} & \multirow{2}{*}{$\begin{array}{c}\begin{array}{c}\text { Section } \\
\text { depth } \\
\text { (cm) }\end{array} \\
1.2\end{array}$} & \multirow{2}{*}{$\begin{array}{l}\text { Depth } \\
\text { LAN2 } \\
\text { (cm) } \\
43.7\end{array}$} & \multicolumn{3}{|c|}{$\begin{array}{c}\text { Measured }{ }^{10} \mathrm{Be} \\
\quad /{ }^{9} \mathrm{Be}\left(10^{-11}\right)\end{array}$} & \multicolumn{3}{|c|}{$\begin{array}{c}\text { Authigenic decay } \\
\text { corrected }{ }^{10} \mathrm{Be}\left(10^{8}\right. \\
\left.\text { at. }^{-1}\right)\end{array}$} & \multicolumn{3}{|c|}{$\begin{array}{c}\text { Authigenic }{ }^{9} \text { Be } \\
\left(10^{16} \text { at. }^{-1}\right)\end{array}$} & \multicolumn{3}{|c|}{$\begin{array}{c}\text { Authigenic decay } \\
\text { corrected }{ }^{10} \mathrm{Be} / /^{9} \mathrm{Be} \\
\left(10^{-8}\right)\end{array}$} \\
\hline & & & & 3.146 & \pm & 0.046 & 8.38 & \pm & 0.124 & 0.508 & \pm & 0.014 & 16.513 & & 0.514 \\
\hline 4 & N1-A & 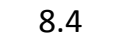 & 50.6 & & \pm & 0.0 & & & & 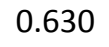 & - & (1) & & & \\
\hline 6 & $1-A$ & 13.2 & 5.3 & 951 & \pm & 0.087 & 21 & \pm & 31 & .790 & \pm & 0.006 & 603 & & $.31 \varepsilon$ \\
\hline 9 & $1-A$ & & 6 & 52 & \pm & 0.122 & 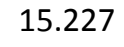 & \pm & 0.264 & .833 & \pm & 0.012 & 81 & & . \\
\hline 12 & N1-A & 27.6 & 69.1 & 7.927 & \pm & 0.130 & 26.103 & \pm & 0.427 & 1.771 & \pm & 0.021 & .738 & & 298 \\
\hline 15 & $1-A$ & 34.8 & 6.1 & 6.770 & \pm & 0.280 & 36 & \pm & & .173 & \pm & 0.065 & & & \\
\hline 18 & $1-A$ & 4 & 81.8 & 803 & \pm & 0.168 & 96 & \pm & 35 & .073 & \pm & 0.021 & & & 473 \\
\hline 20 & $1-A$ & 6 & & 504 & \pm & 0.07 & & \pm & & 484 & \pm & 0.010 & & - & 49 \\
\hline 22 & $1-A$ & & 84. & 45 & \pm & 0.105 & & \pm & & 726 & \pm & .004 & & & \\
\hline 24 & I-A & & & 0 & \pm & 0.1 & & \pm & & 758 & \pm & U & & & \\
\hline 25 & I-A & 58.8 & 89.2 & 5.744 & \pm & 0.073 & 1 & \pm & 0.176 & 35 & + & .021 & & & 000 \\
\hline 26 & N1-A & 61.2 & 91.0 & 61 & \pm & 0.170 & 91 & \pm & 0. & 352 & \pm & 013 & & 1 & 60 \\
\hline 27 & $\mathrm{~N}$ & & & 2 & \pm & 0.0 & 20.083 & \pm & & 0.869 & \pm & 24 & & & \\
\hline 27 & $-A$ & 63.6 & 2.8 & 6.084 & \pm & 0.076 & 12 & \pm & & 908 & \pm & 0.026 & & I & 139 \\
\hline $2 \varepsilon$ & & & & & \pm & & & \pm & & & - & & & & \\
\hline 28 & $N$ & & & 3.716 & \pm & 0.04 & 12.041 & \pm & & 0.521 & \pm & 0.013 & & I & 45 \\
\hline 25 & & & & & \pm & 0.0 & & \pm & & & \pm & & & & \\
\hline 30 & $1-A$ & & 0.0 & 199 & \pm & 0.0 & 3 & \pm & & 0.158 & \pm & .004 & & & $6 / 1$ \\
\hline 3 & & & & & \pm & 0.0 & & \pm & 0. & 0.262 & \pm & 008 & & & \\
\hline 32 & N1-A & 75.6 & 6.7 & 494 & \pm & 0.065 & 1 & \pm & 0.146 & 0.257 & \pm & 0.006 & 1.793 & $\perp$ & .742 \\
\hline 33 & N1-A & & & 84 & \pm & 0.089 & & \pm & 0.1 & 0.332 & \pm & .009 & & & 369 \\
\hline $34 \mathrm{~b}$ & $-A$ & & .3 & 795 & \pm & 0.071 & 96 & \pm & 0.1 & 0.252 & \pm & 0.002 & 3.760 & $I$ & .648 \\
\hline $34 a$ & N1-A & 82.8 & & 9 & \pm & 0.109 & & \pm & 0.247 & .421 & \pm & 0.007 & .121 & \pm & 705 \\
\hline & & & & & \pm & & & 1 & & & & & & & \\
\hline & & & & & & & & & & & & & & & \\
\hline & & & & & \pm & & & + & & & \pm & 009 & & & 498 \\
\hline 10 & NI-A & 2.4 & $1<3.5$ & 5.875 & \pm & 0.148 & 13.196 & 1 & 0.052 & 0.626 & - & 0.007 & 21.087 & & 0.579 \\
\hline
\end{tabular}




$\begin{array}{ccccccccccccccc}\text { N1-A } & 94.8 & 125.9 & 13.422 & \pm & 0.178 & 29.021 & \pm & 0.385 & 1.481 & \pm & 0.043 & 19.601 & \pm & 0.629 \\ \text { N1-A } & 97.2 & 128.3 & 9.994 & \pm & 0.250 & 23.112 & \pm & 0.577 & 1.087 & \pm & 0.006 & 21.257 & \pm & 0.544 \\ \text { N1-A } & 99.6 & 130.7 & 6.179 & \pm & 0.078 & 15.911 & \pm & 0.200 & 0.817 & \pm & 0.017 & 19.479 & \pm & 0.478 \\ \text { N1-A } & 102 & 132.6 & 10.647 & \pm & 0.268 & 23.735 & \pm & 0.597 & 1.092 & \pm & 0.006 & 21.736 & \pm & 0.560 \\ \text { N1-A } & 106.8 & 135.9 & 7.579 & \pm & 0.190 & 16.865 & \pm & 0.423 & 0.761 & \pm & 0.008 & 22.160 & \pm & 0.599 \\ \text { N1-A } & 111.6 & 139.9 & 6.864 & \pm & 0.114 & 15.245 & \pm & 0.254 & 0.761 & \pm & 0.011 & 20.030 & \pm & 0.449 \\ \text { N1-A } & 116.4 & 143.5 & 6.020 & \pm & 0.099 & 13.467 & \pm & 0.221 & 0.694 & \pm & 0.012 & 19.419 & \pm & 0.469 \\ \text { N1-A } & 121.2 & 146.9 & 5.447 & \pm & 0.091 & 10.664 & \pm & 0.179 & 0.499 & \pm & 0.008 & 21.375 & \pm & 0.499 \\ \text { N1-A } & 128.4 & 151.9 & 5.124 & \pm & 0.091 & 11.807 & \pm & 0.209 & 0.528 & \pm & 0.014 & 22.370 & \pm & 0.704 \\ \text { N1-B } & 1.2 & 156.8 & 5.452 & \pm & 0.090 & 11.620 & \pm & 0.193 & 0.561 & \pm & 0.004 & 20.700 & \pm & 0.367 \\ \text { N1-B } & 8.4 & 164.9 & 2.020 & \pm & 0.035 & 4.663 & \pm & 0.080 & 0.221 & \pm & 0.005 & 21.108 & \pm & 0.632 \\ \text { N1-B } & 15.6 & 172.0 & 3.862 & \pm & 0.065 & 8.867 & \pm & 0.150 & 0.392 & \pm & 0.004 & 22.630 & \pm & 0.445 \\ \text { N1-B } & 20.4 & 175.0 & 1.265 & \pm & 0.021 & 3.099 & \pm & 0.051 & 0.135 & \pm & 0.004 & 23.007 & \pm & 0.749 \\ \text { N1-B } & 27.6 & 182.7 & 3.137 & \pm & 0.046 & 6.992 & \pm & 0.103 & 0.361 & \pm & 0.011 & 19.352 & \pm & 0.642 \\ \text { N1-B } & 34.8 & 189.4 & 3.298 & \pm & 0.047 & 7.783 & \pm & 0.111 & 0.390 & \pm & 0.005 & 19.940 & \pm & 0.368 \\ \text { N1-B } & 42 & 196.2 & 4.689 & \pm & 0.069 & 10.606 & \pm & 0.156 & 0.500 & \pm & 0.010 & 21.197 & \pm & 0.532 \\ \text { N1-B } & 49.2 & 202.9 & 2.719 & \pm & 0.041 & 6.123 & \pm & 0.091 & 0.279 & \pm & 0.006 & 21.972 & \pm & 0.571 \\ \text { N1-B } & 56.4 & 209.7 & 1.891 & \pm & 0.030 & 4.484 & \pm & 0.072 & 0.198 & \pm & 0.005 & 22.694 & \pm & 0.655 \\ \text { N1-B } & 63.6 & 217.6 & 2.246 & \pm & 0.038 & 5.231 & \pm & 0.088 & 0.226 & \pm & 0.005 & 23.136 & \pm & 0.630 \\ \text { N1-B } & 68.4 & 222.3 & 3.661 & \pm & 0.053 & 8.328 & \pm & 0.120 & 0.400 & \pm & 0.008 & 20.825 & \pm & 0.518\end{array}$


Table 4. Average estimated sedimentation rates for each age model. The assigned marine isotope stages (MIS) for Lake Selina are shown in Figure 11. In cases where an age model does not cover an entire MIS, the covered substages are indicted in parentheses.

Average sedimentation rate $(\mathrm{cm} / \mathrm{ka})$

Radiometric Match-Climate Match-Dipole

\begin{tabular}{lccc}
\multicolumn{1}{c}{ Facies } & & & \\
\cline { 2 - 4 } I & 5.1 & 5.2 & 1.6 \\
\multicolumn{1}{r}{ MIS } & 1.5 & 2.6 & 1.5 \\
MIS 1 & & & \\
MIS 2, 3, 4 & 1.5 & & \\
MIS 5 & 1.9 (MIS 5a) & 6.2 & 1.6 (MIS 5a, 5c) \\
MIS 6 & & 2.4 & \\
MIS 7 & & 3.0 & \\
MIS 8 & & 1.9 &
\end{tabular}


A)

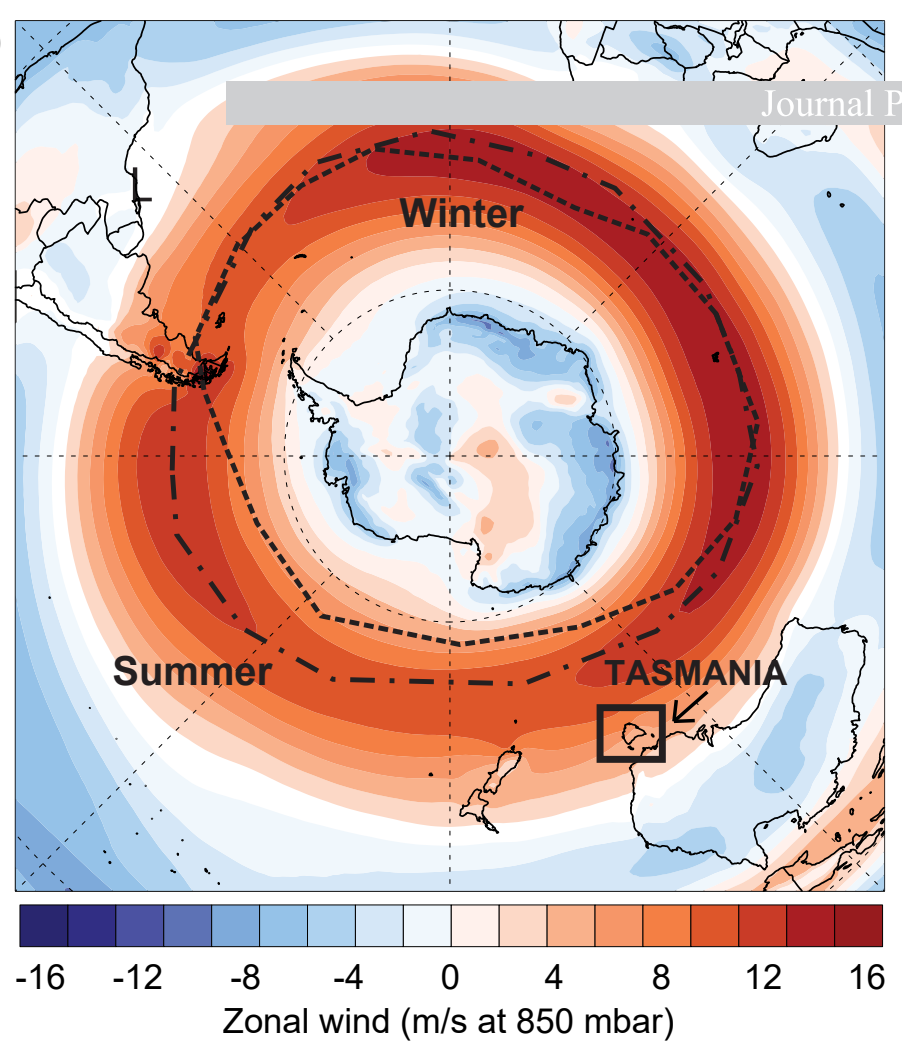

C)
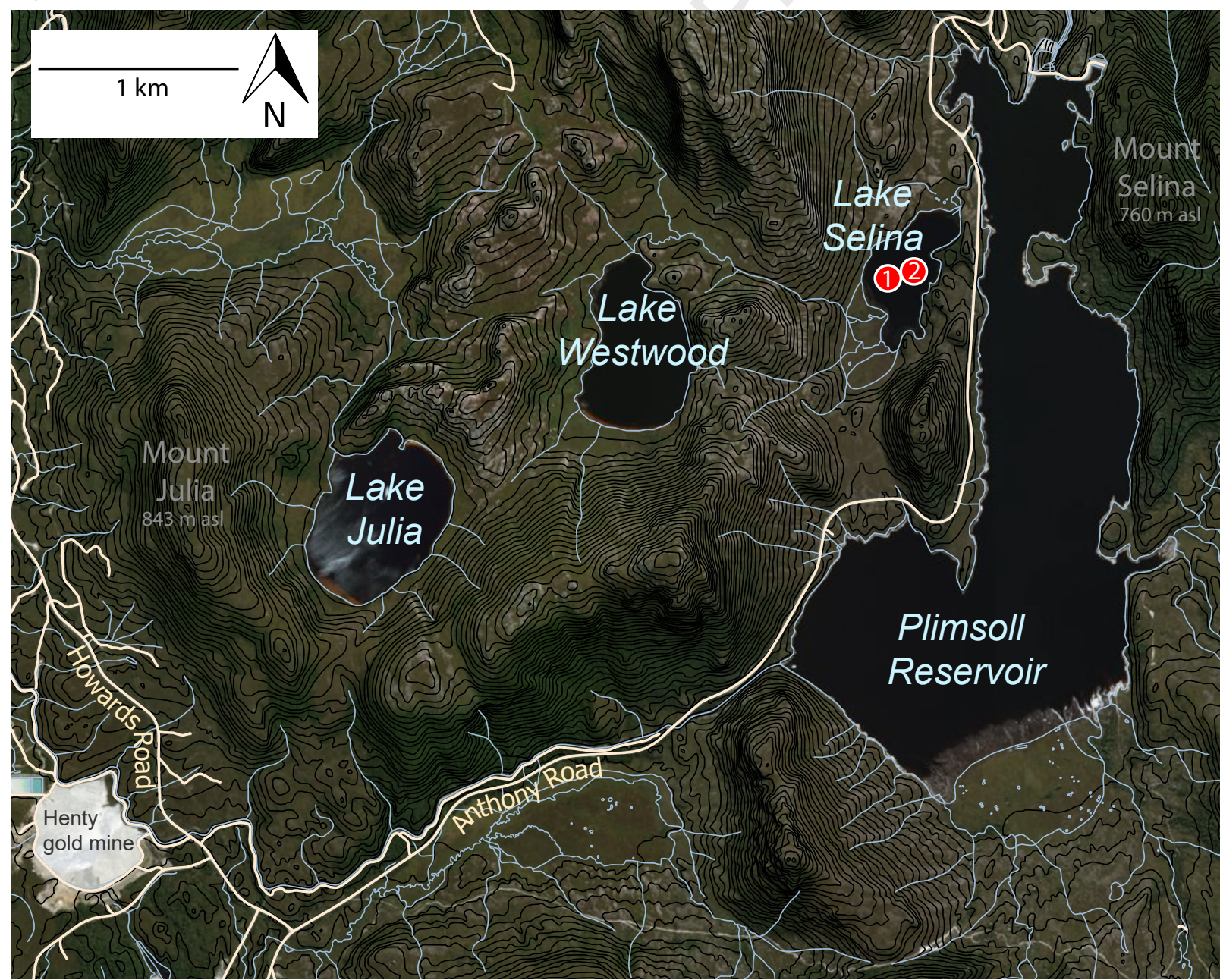

TACM $\triangle \mathrm{NII}$

-0.5 Correlation 0.5

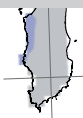
Rain - Wind speed
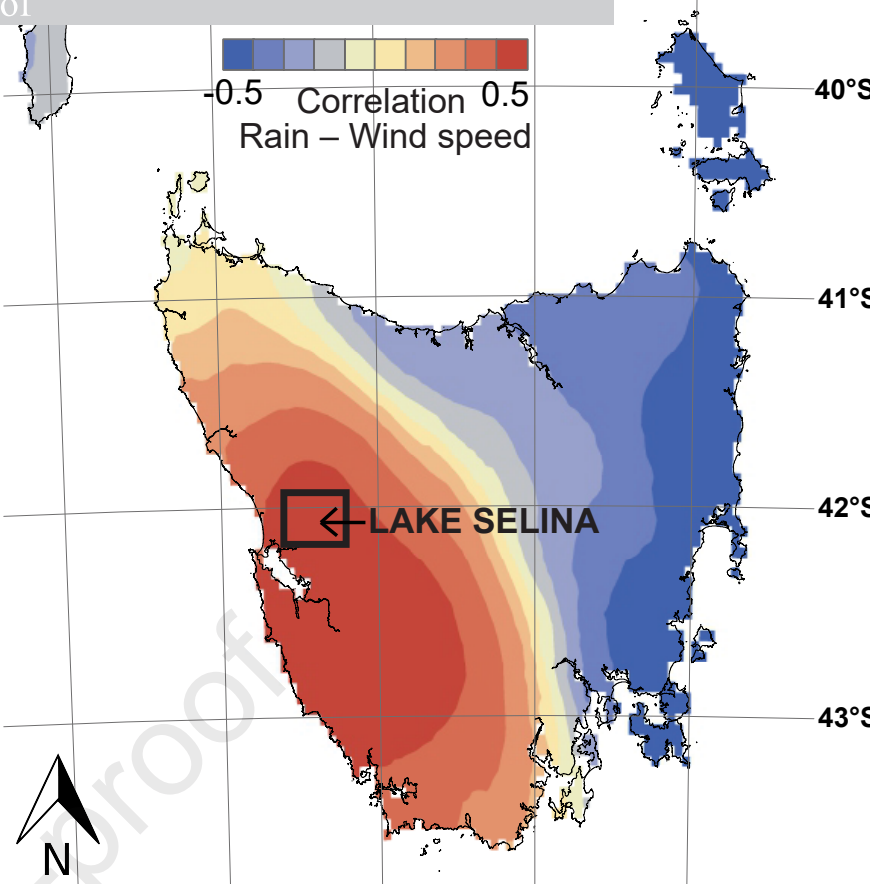

$41^{\circ} \mathrm{S}$

$42^{\circ} \mathrm{S}$

$145^{\circ} \mathrm{E}$

$147^{\circ} \mathrm{E}$ 


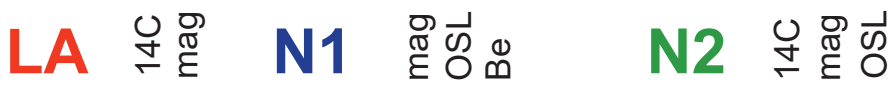
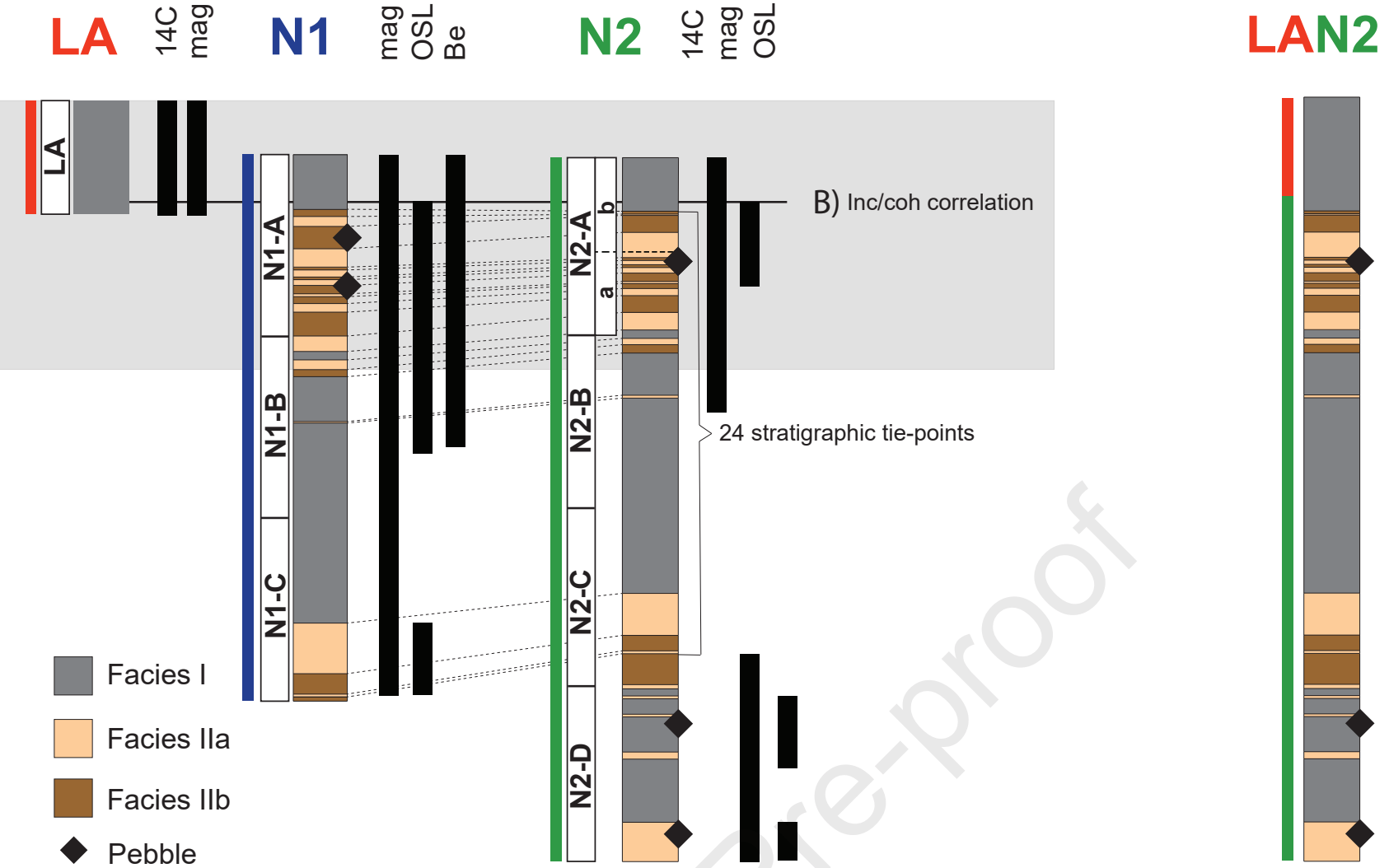

B) Inc/coh correlation

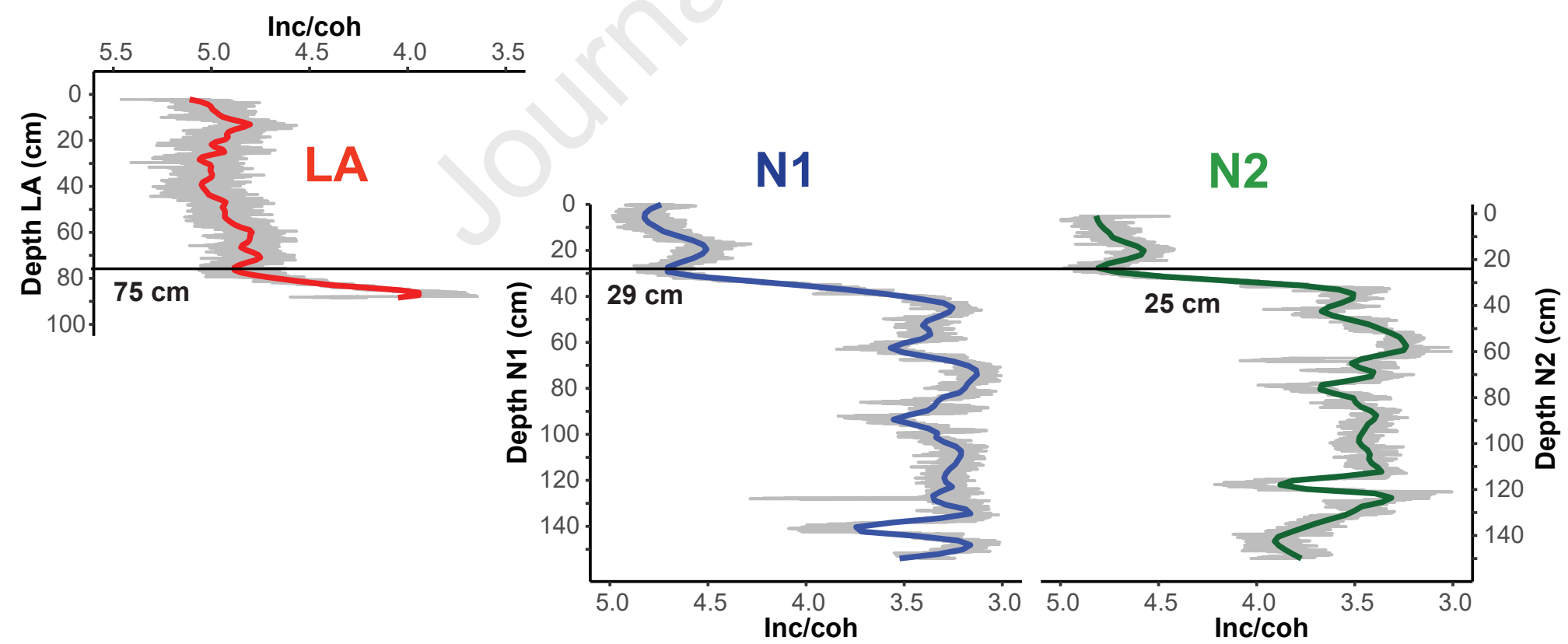




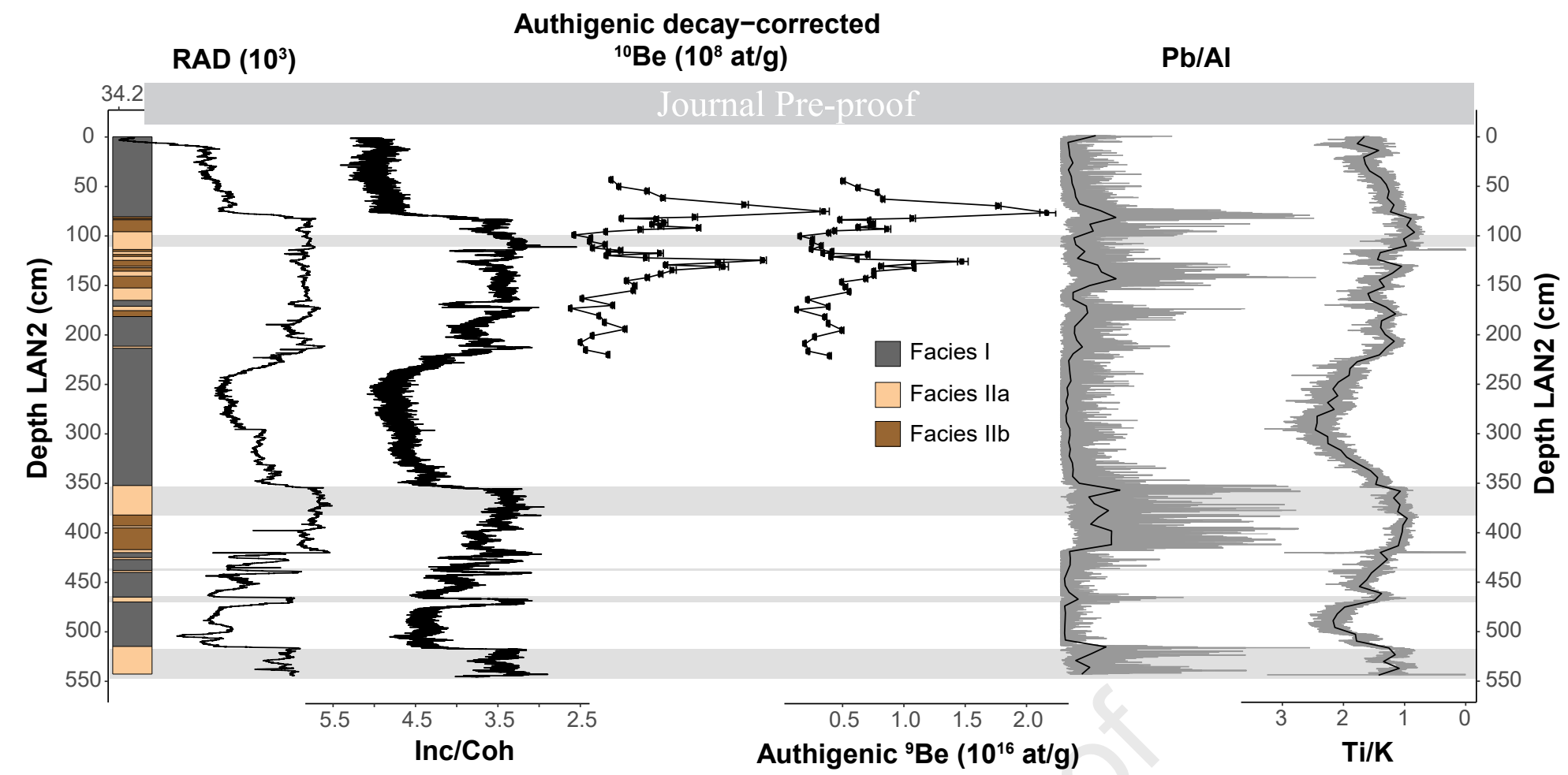

KARM/IRM $\left(\mathbf{1 0}^{-\mathbf{3}} \mathrm{mA}^{-1}\right)$

Mr/Ms
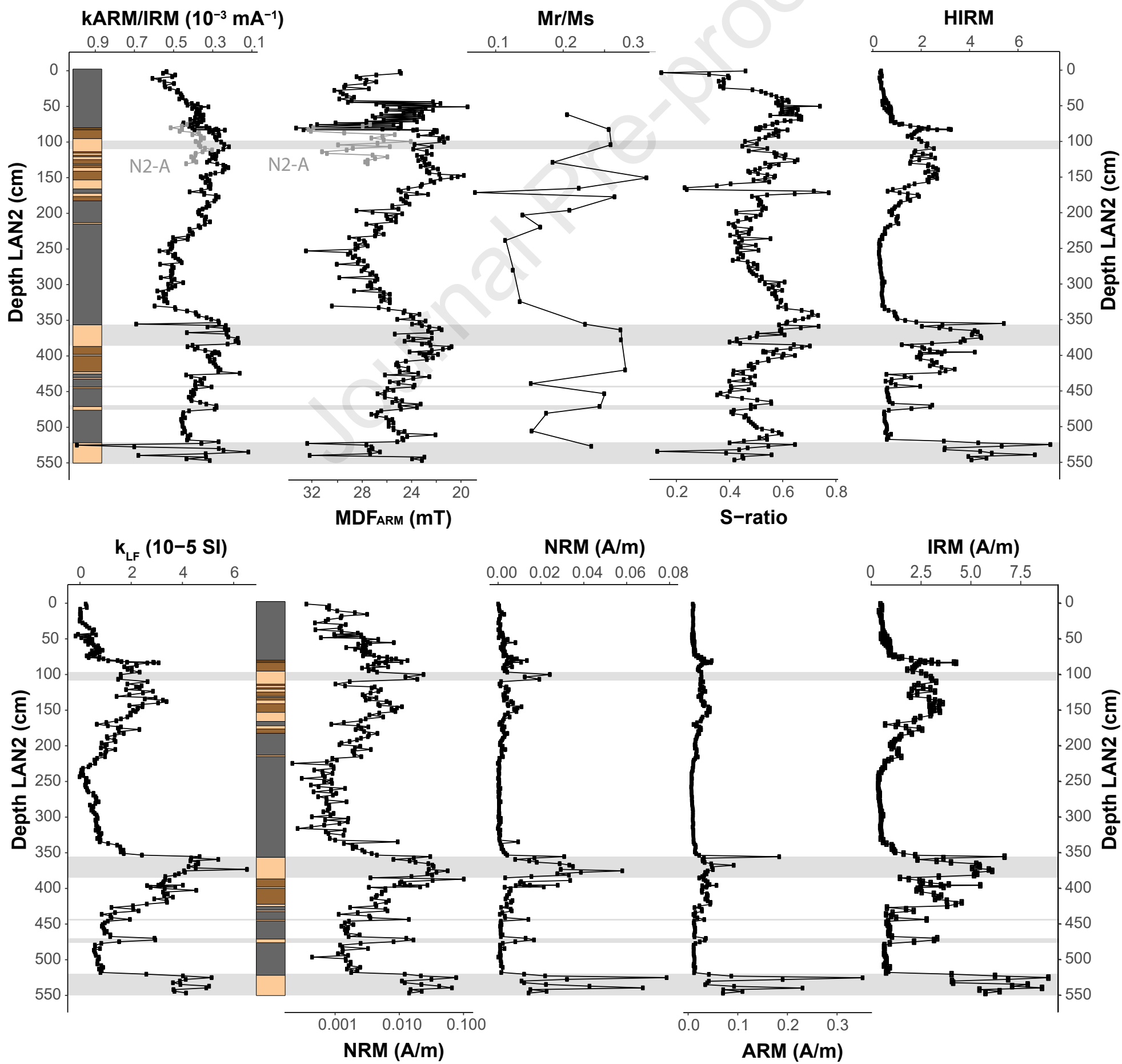


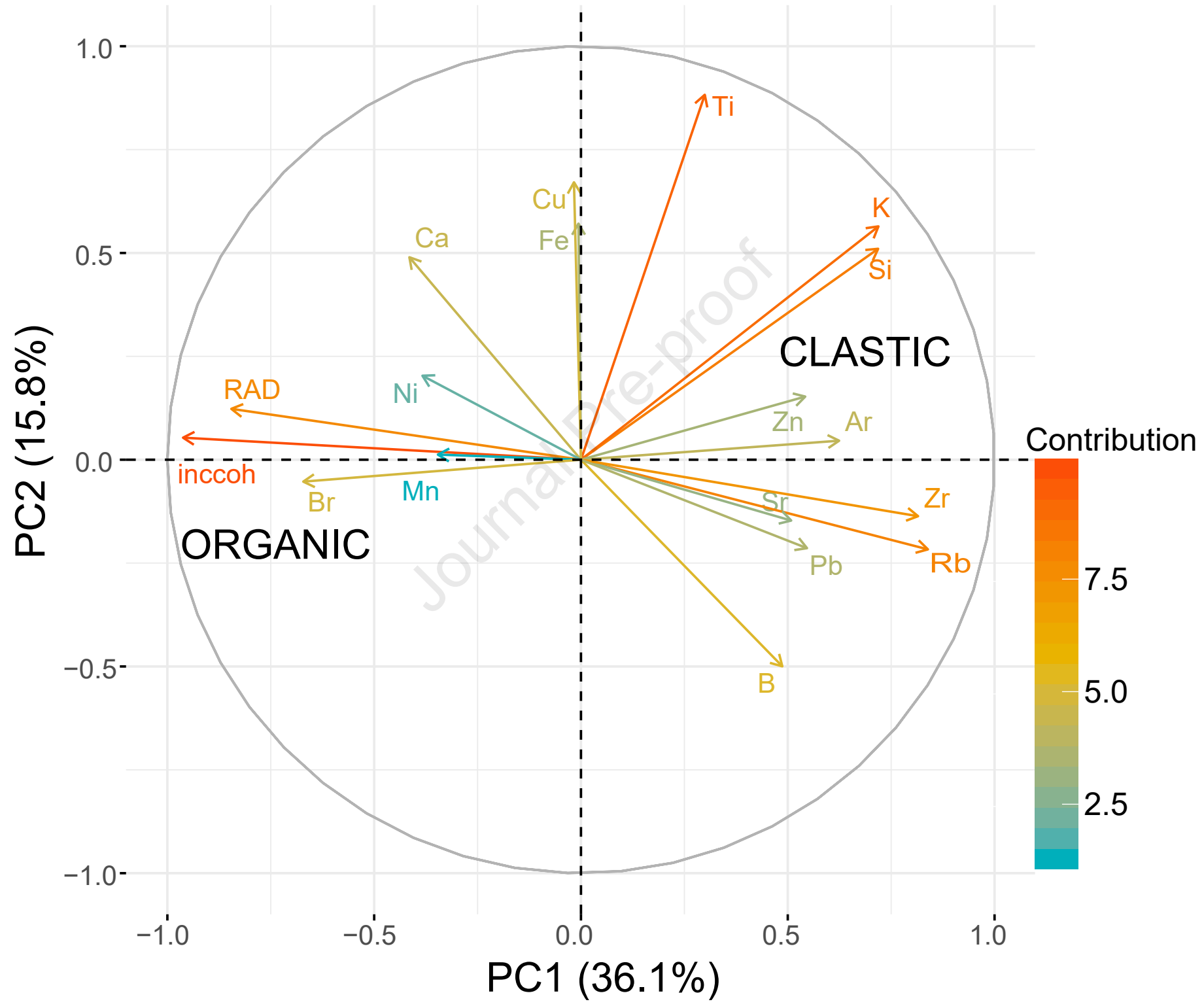




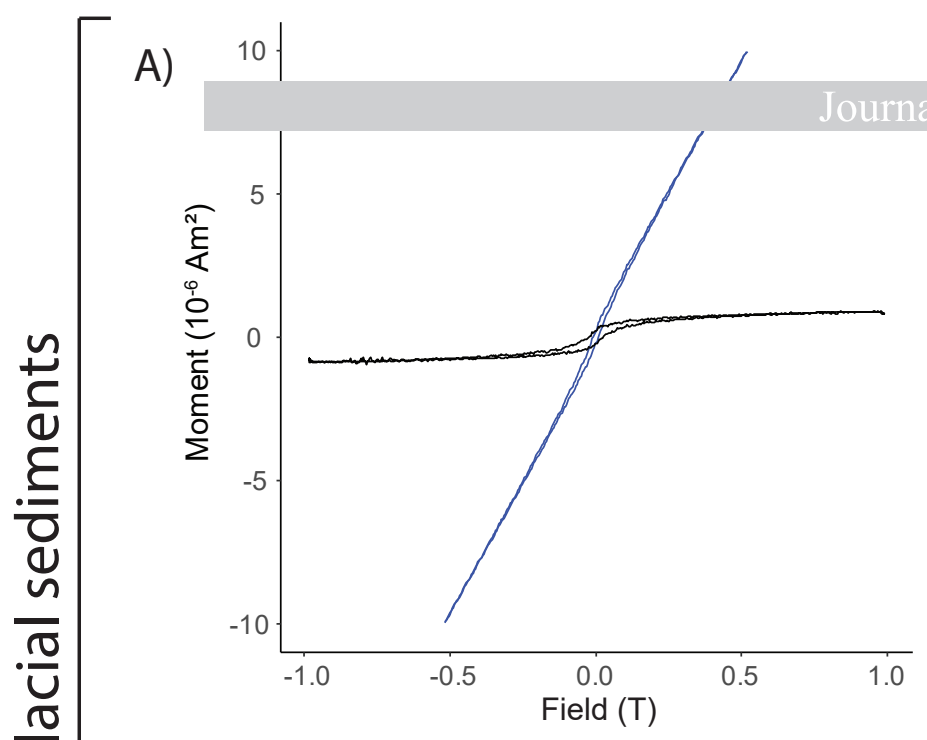

造 3.01
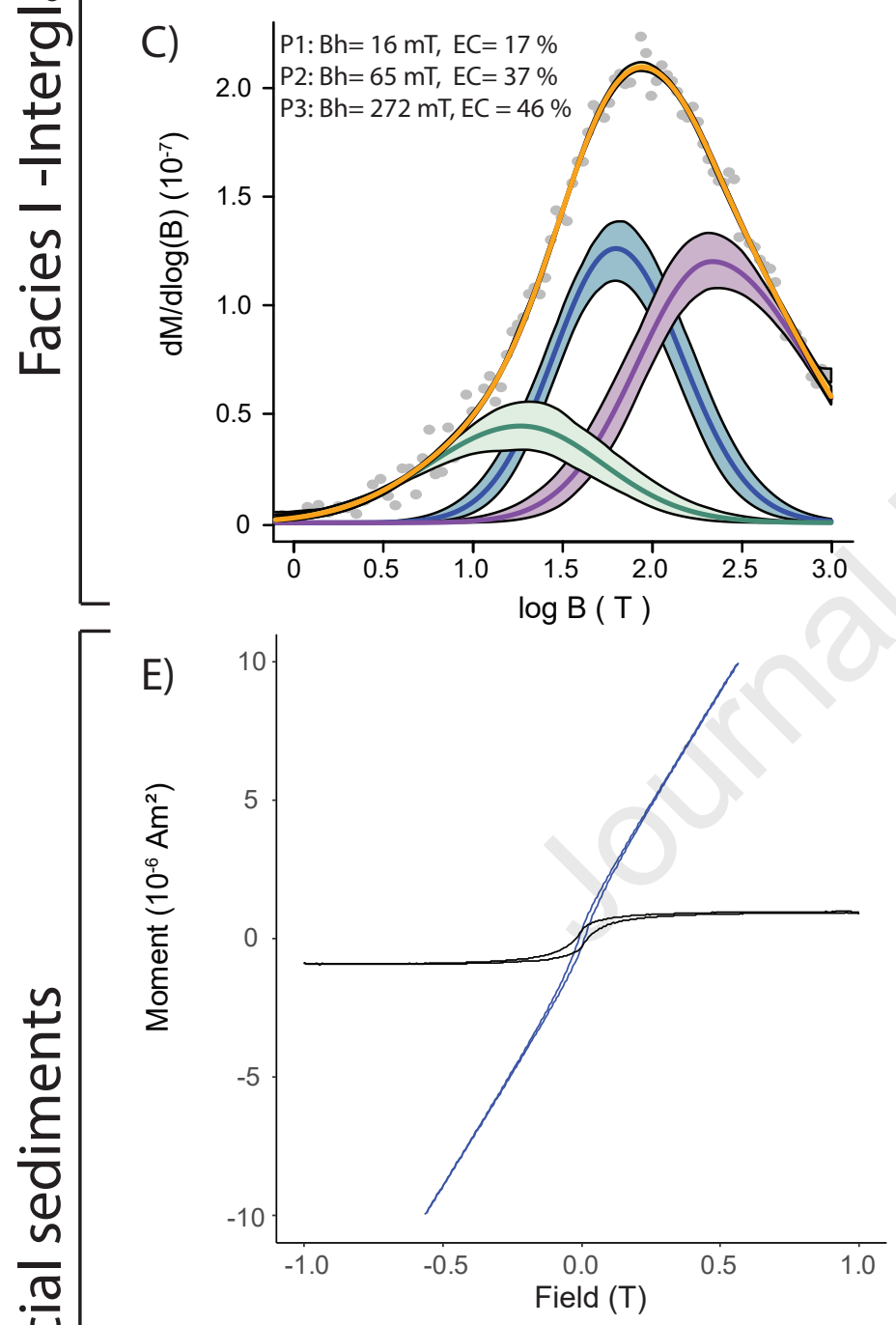

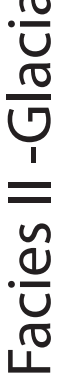
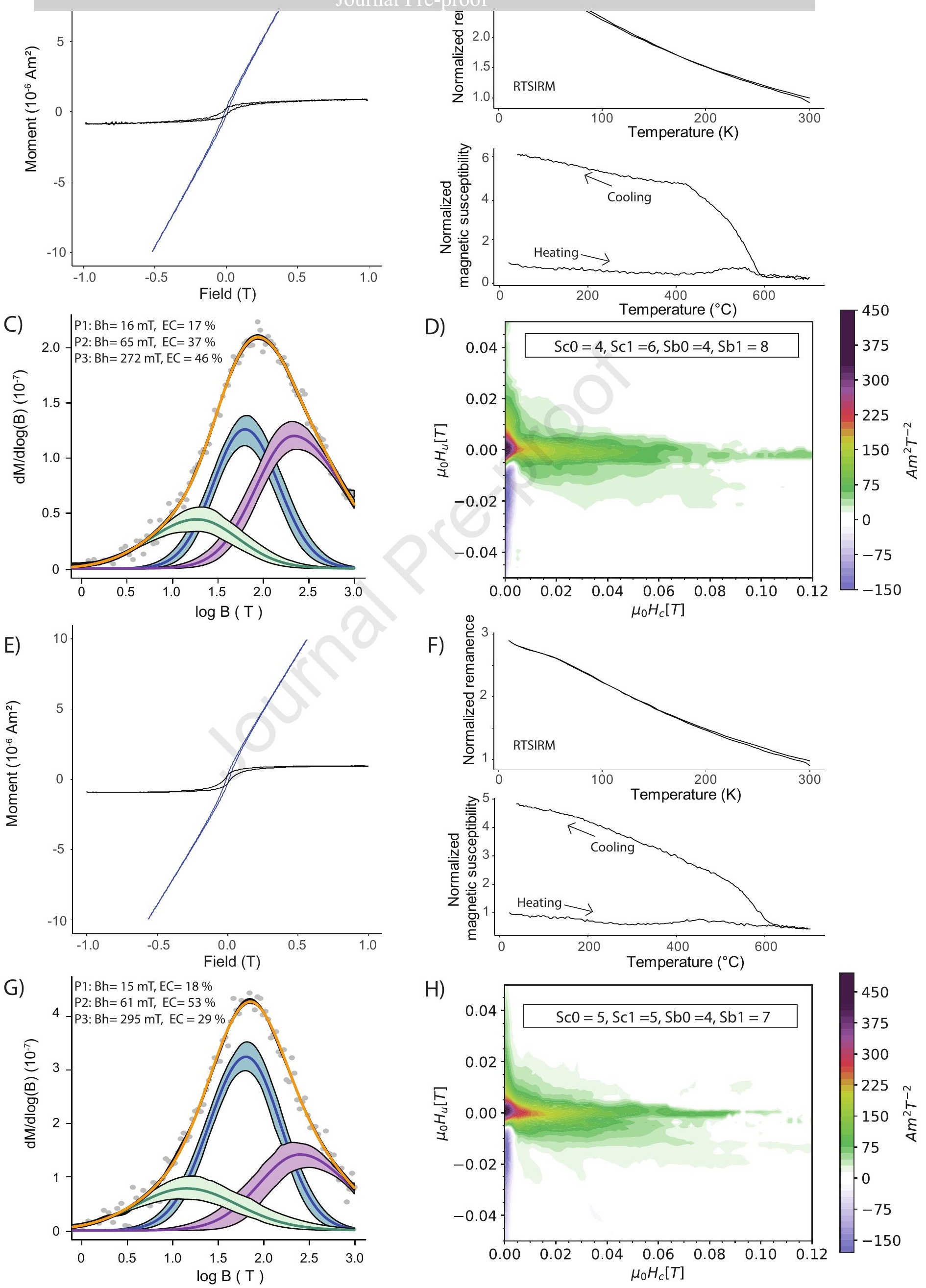


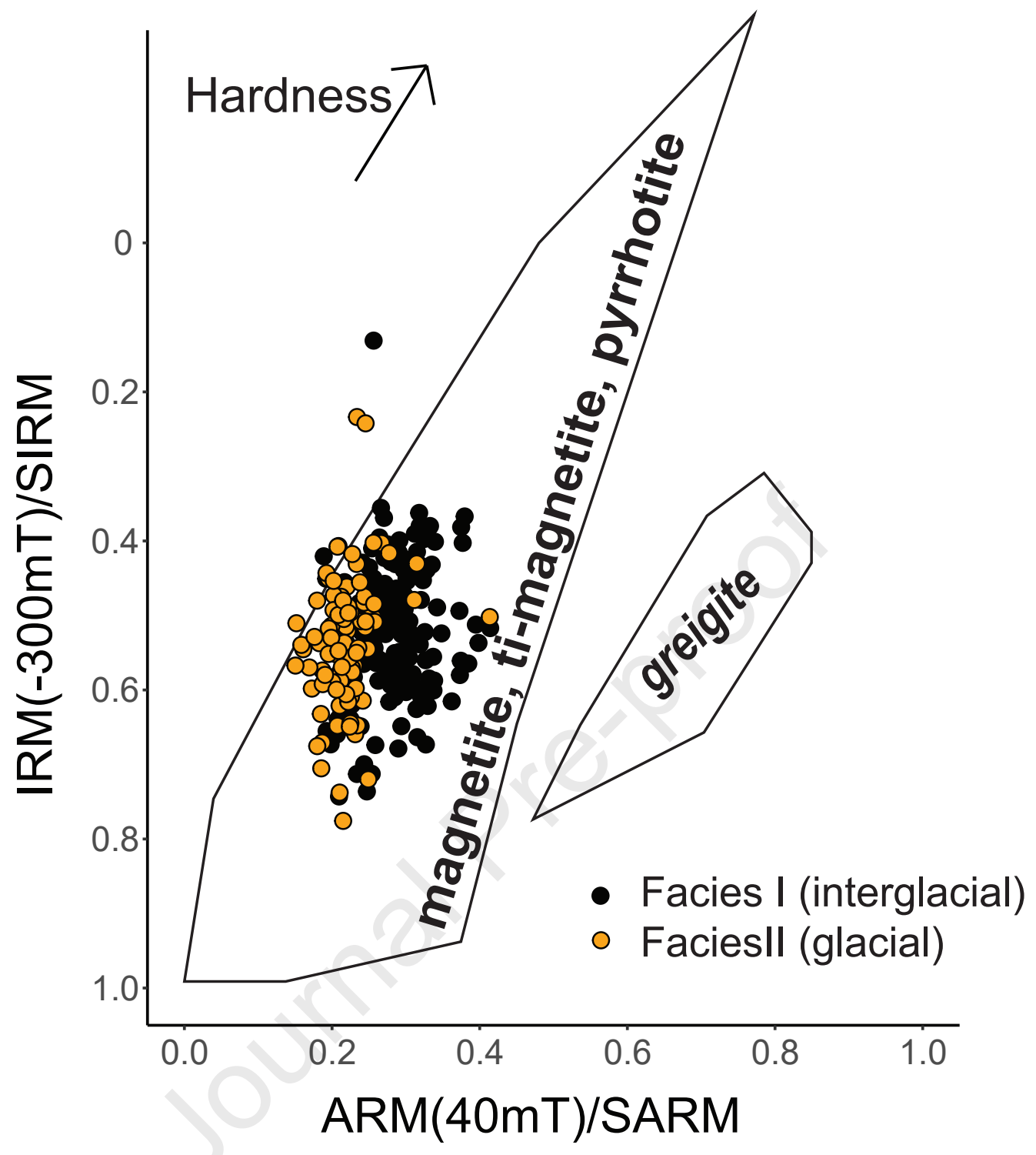


Inclination $\left({ }^{\circ}\right) \quad$ Relative declination $\left({ }^{\circ}\right) \quad \operatorname{MAD}\left({ }^{\circ}\right)$

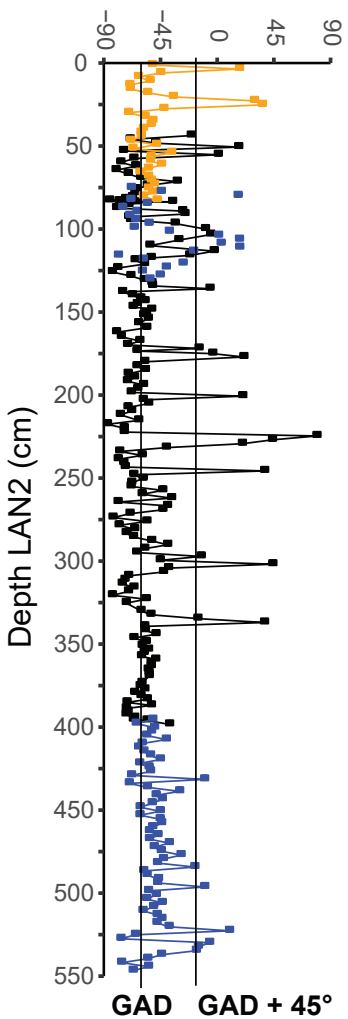

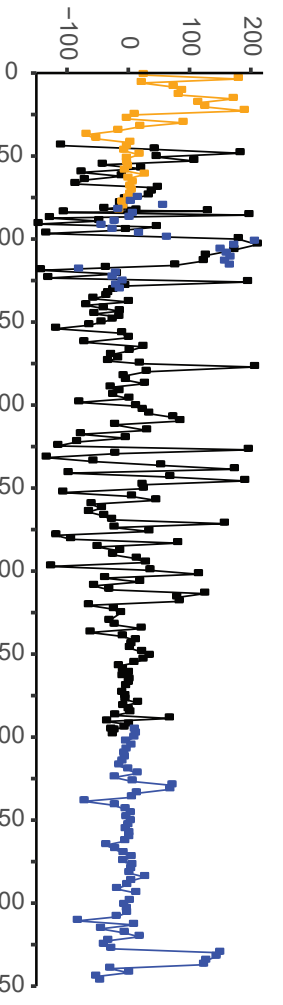

Inclination $\left({ }^{\circ}\right)$

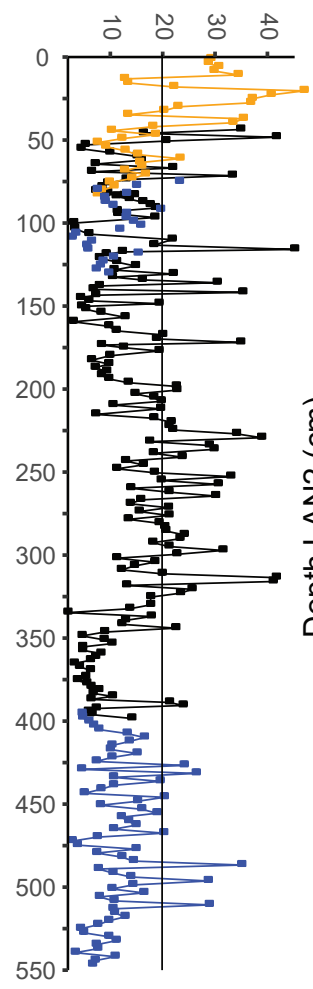

\section{RELATIVE PALEOINTENSITY ESTIMATES}

C) RAW DATA

$\begin{array}{llll}\mathrm{NRM}_{20 \mathrm{mT}} / & \mathrm{NRM}_{20 \mathrm{mT}} / & \mathrm{NRM}_{10-60 \mathrm{mT}} / & \mathrm{NRM}_{10-60 \mathrm{mT}} / \\ \mathrm{ARM}_{20 \mathrm{mT}} & \mathrm{IRM}_{20 \mathrm{mT}} & \mathrm{ARM}_{10-60 \mathrm{mT}} & \text { IRM }_{10-60 \mathrm{mT}}\end{array}$

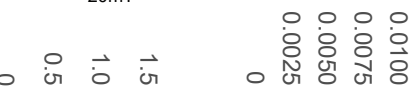

غ

200

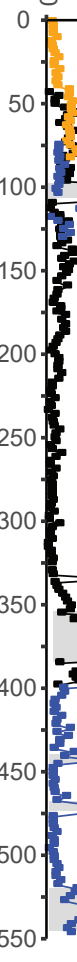

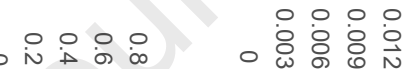

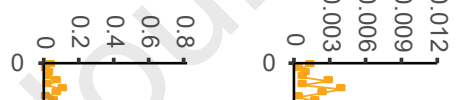

8 जे $\circ$ जे 8

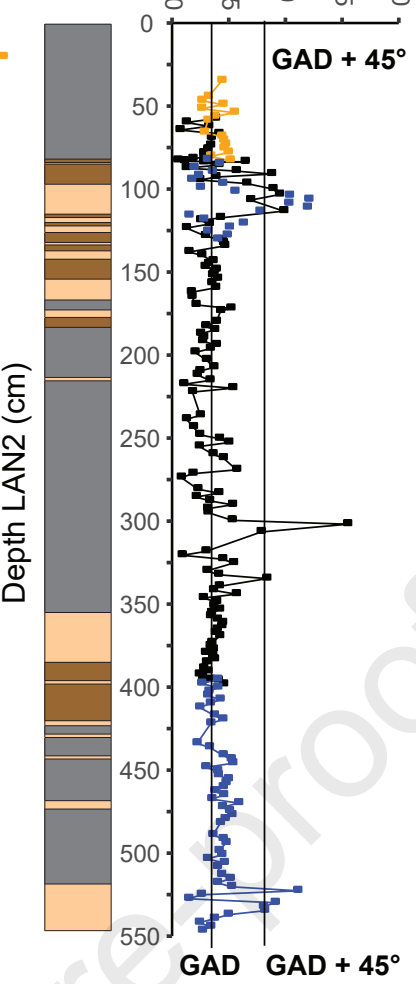

Relative declination $\left(^{\circ}\right)$

$\operatorname{MAD}\left({ }^{\circ}\right)$
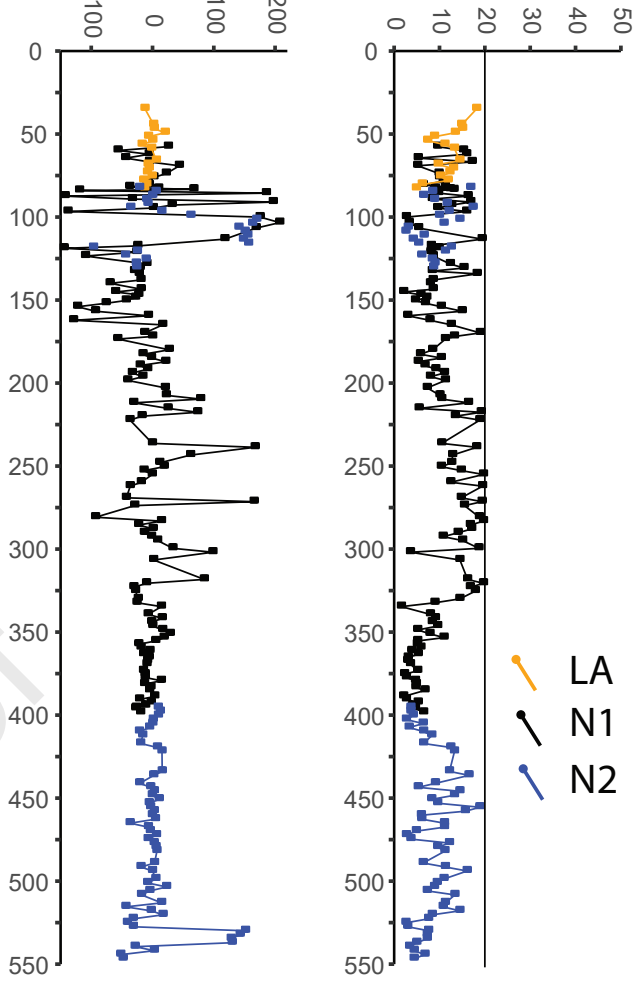

D) SELECTED

$\begin{array}{llll}\mathrm{NRM}_{20 \mathrm{mT}} / & \mathrm{NRM}_{20 \mathrm{mT}} / & \mathrm{NRM}_{10-60 \mathrm{mT}} / & \mathrm{NRM}_{10-60 \mathrm{mT}} / \\ \mathrm{ARM}_{20 \mathrm{mT}} & \mathrm{IRM}_{20 \mathrm{mT}} & \mathrm{ARM}_{10-60 \mathrm{mT}} & \mathrm{IRM}_{10-60 \mathrm{mT}}\end{array}$

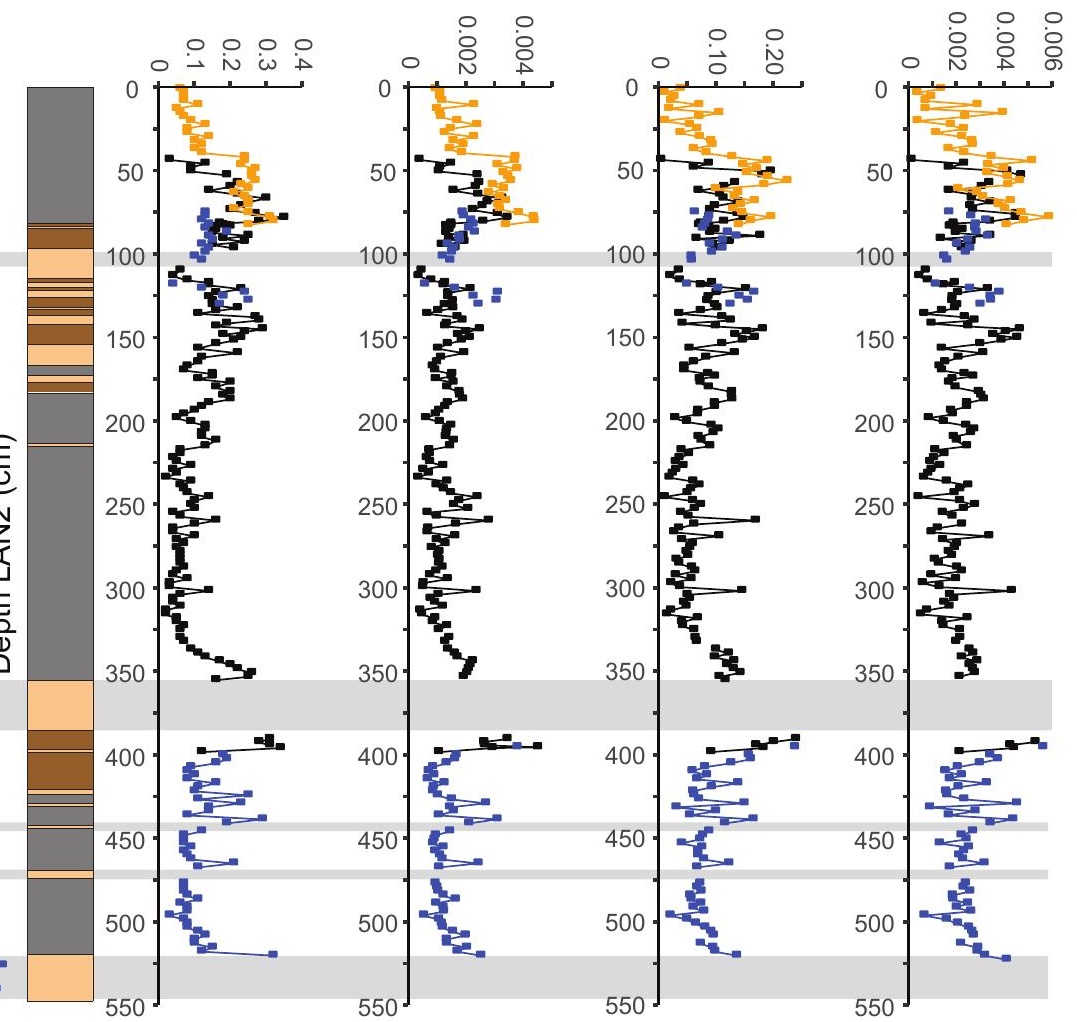

Facies I

Facies Ila

Facies Ilb 
Relative declination $\left({ }^{\circ}\right)$

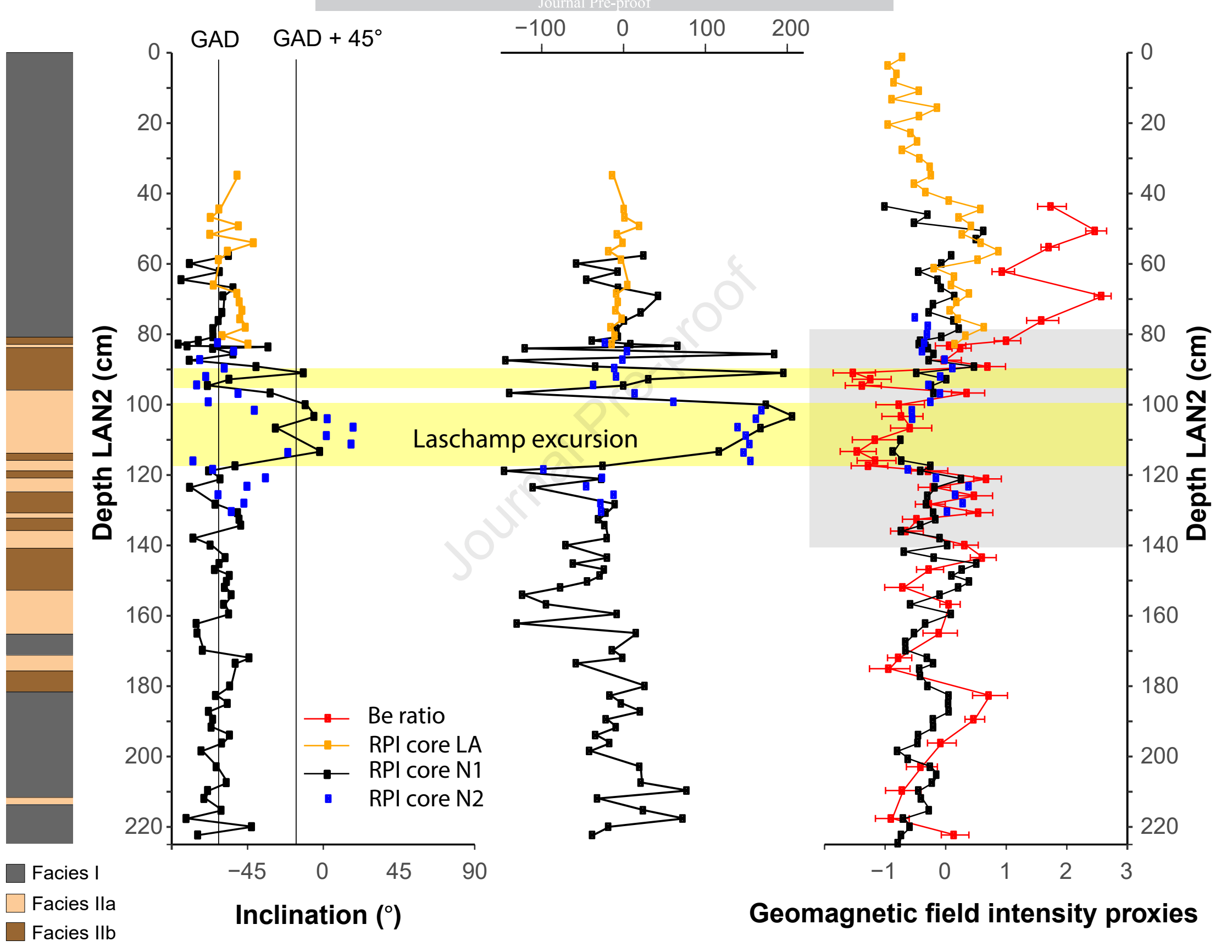




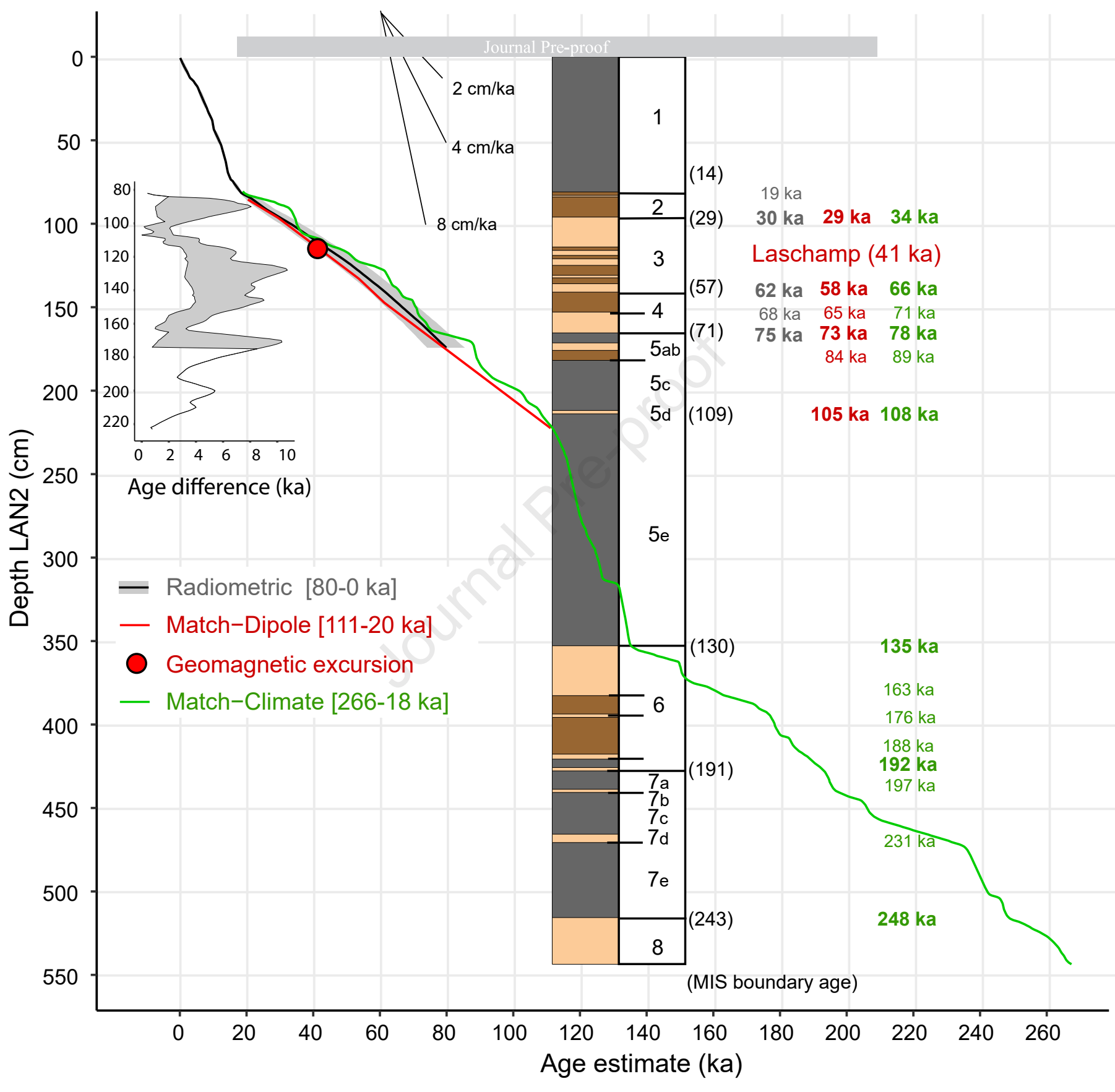


A)

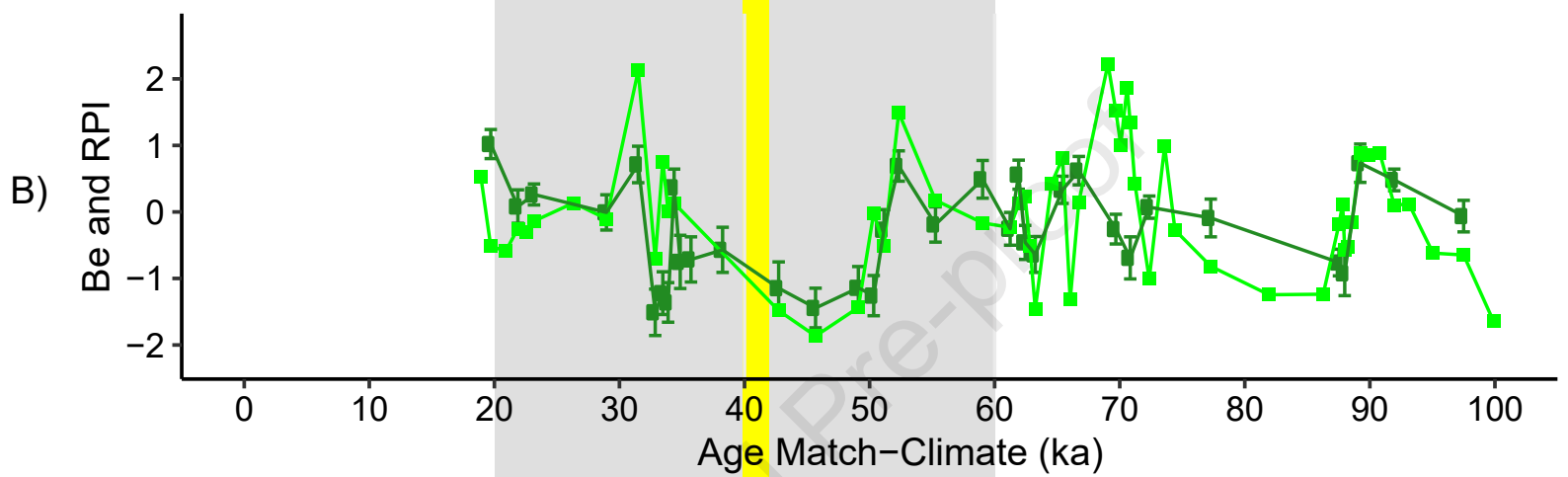

$\Phi$ Be ratio

- RPI

$\Phi$ Be ratio

- RPI

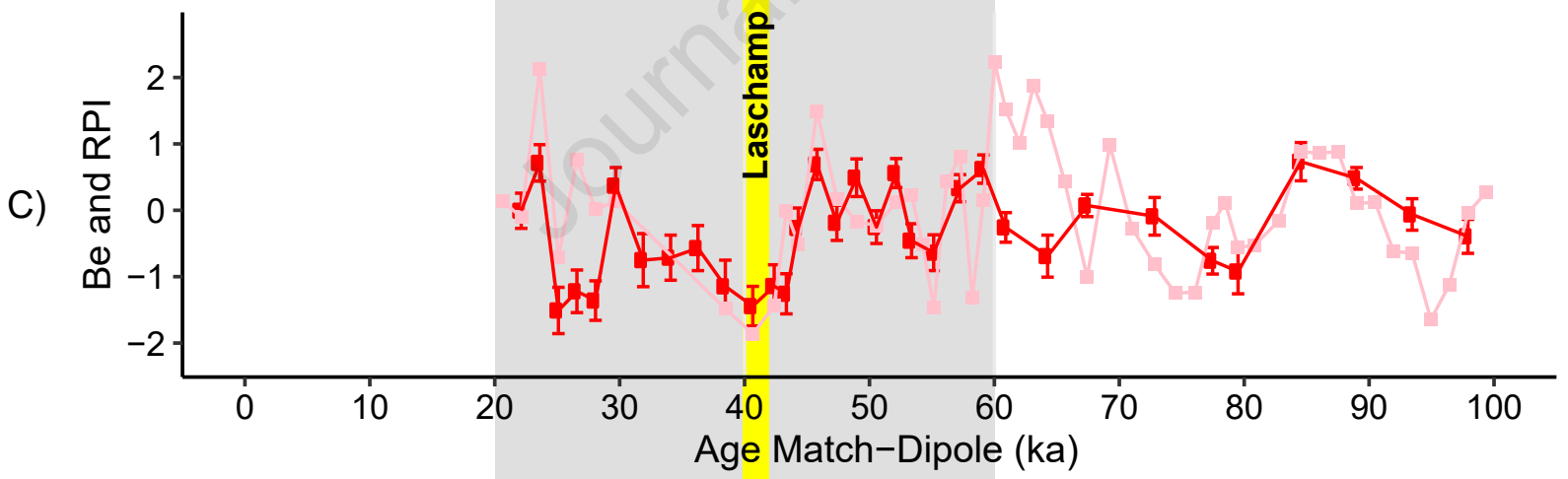

§ Be ratio

RPI

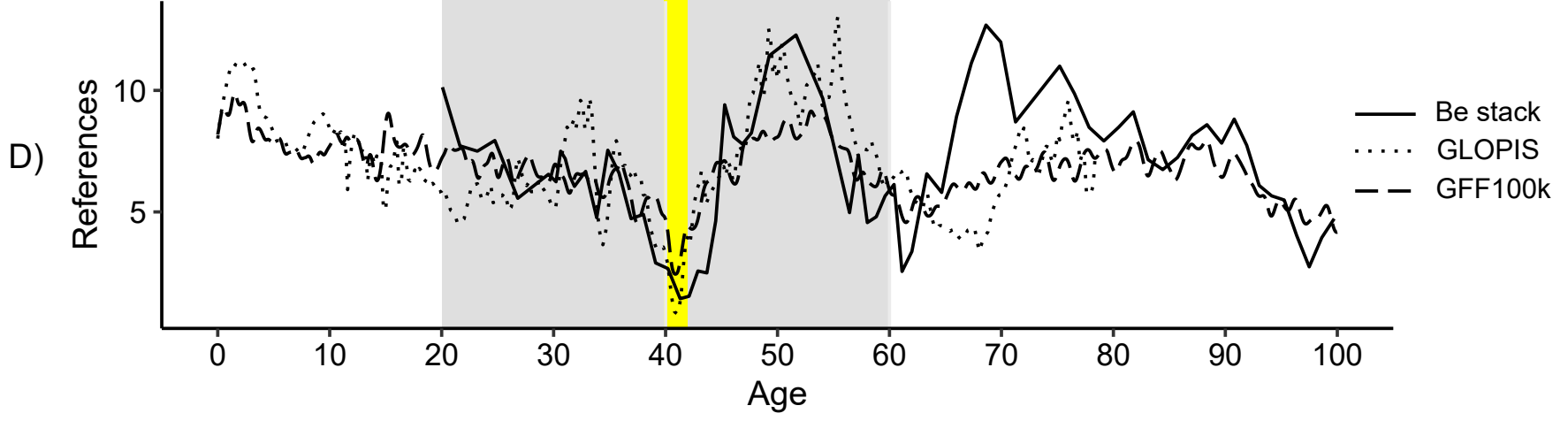




\section{Declaration of interests}

$\bigotimes$ The authors declare that they have no known competing financial interests or personal relationships that could have appeared to influence the work reported in this paper.

$\square$ The authors declare the following financial interests/personal relationships which may be considered as potential competing interests: 